LEVEL UP: DUAL ENROLLMENT IN AVID AND INTERNATIONAL

BACCALAUREATE DIPLOMA PROGRAMS

\author{
AS \\ 35 \\ 2016 \\ EDD \\ - R69 \\ A Dissertation submitted to the faculty of \\ San Francisco State University \\ In partial fulfillment of \\ the requirements for \\ the Degree \\ Doctor of Education \\ In \\ Educational Leadership
}

by

Holly Royaltey

San Francisco, California

May 2016 


\section{Copyright by}

\section{Holly Royaltey}

2016 


\section{CERTIFICATION OF APPROVAL}

I certify that I have read Level Up: Dual Enrollment in AVID and International Baccalaureate Diploma Programs by Holly Royaltey, and that in my opinion this work meets the criteria for approving a thesis submitted in partial fulfillment of the requirement for the degree Doctorate of Education in Educational Leadership at San Francisco State University.

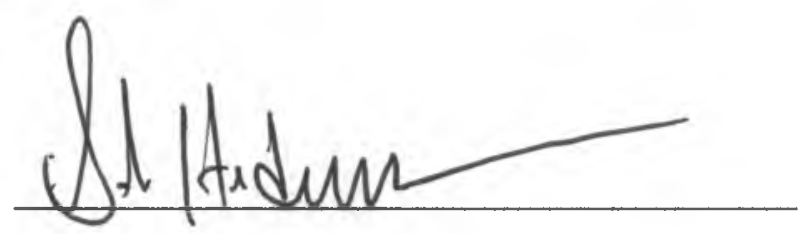

Barbara Henderson, Ph.D.

Professor of Education

Department of Elementary Education

Graduate College of Education

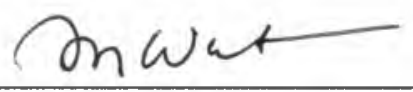

Maika Watanabe, Ph.D.

Professor and Chair

Department of Secondary Education

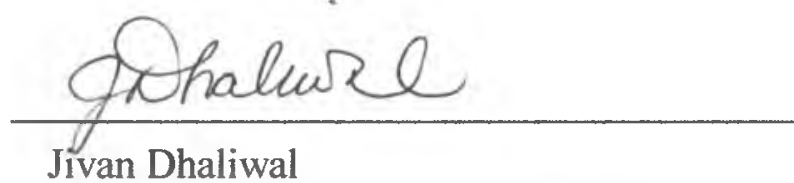

Director of Curriculum and Instruction

Campbell Union High School District 


\title{
LEVEL UP: DUAL ENROLLMENT IN AVID AND INTERNATIONAL BACCALAUREATE DIPLOMA PROGRAMS
}

\author{
Holly Royaltey \\ San Francisco, California \\ 2016
}

The AVID and IB programs are becoming popular reform initiatives for high schools seeking to close the achievement gap and better serve a growing number of underrepresented students. This study seeks to add to the literature on IB and AVID by examining the effect of combined enrollment in the two programs and analyzing students' perceptions of IB and AVID programs. Additionally, this study provides voice to a group of students, which in turn, may influence how other institutions seek to implement these programs as reform measures. The quantitative data provide insight into the level of college readiness of AVID and IB students, while the qualitative data explore what students identified as valuable as a result of dual enrollment. The qualitative and quantitative data were analyzed using theories of community cultural wealth (Yosso, 2005 ) and recent theories on college readiness (Conley, 2007). The study finds that dual enrollment in AVID and IB leads to an increased level of college knowledge for underrepresented students, smooth transitions to college, and increased levels of confidence with regard to academic and social self-perceptions.

I certify that the Abstract is a correct representation of the content of this dissertation.

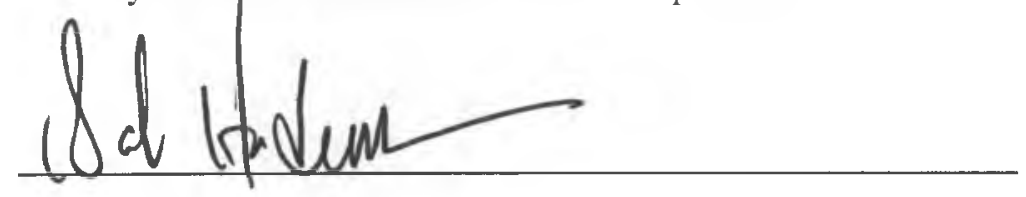

Chair, Dissertation Committee

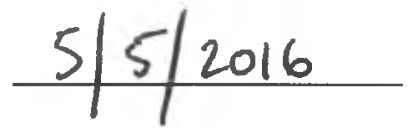

Date 


\section{ACKNOWLEDGEMENTS}

To my wife, Valerie, this has been a wild ride, and, I want to thank you for your constant support with school, work, and home, and for the countless number of times you helped me set and keep deadlines. Thank you also for your own perseverance, your work ethic, risk-taking ability, and your unwavering faith that we can do anything, has always inspired me. To Sage, thank you for your eternal patience with your mom and I as we have completed this journey. You are an inspiration to me every day with your flexibility, humor, and empathy. To Mom and Dad, thank you for your constant encouragement. And Hope, thanks for reminding me that sometimes you just have to keep writing, and that it will pay off in the end. To Grandpa, you are an inspiration.

To my advisor, Barbara Henderson, thank you for the constant readings and conversations to help me stay focused. And thank you more than anything for your constant encouragement. To my committee members, Jivan Dhaliwal and Maika Watanabe, thank you for your support and encouragement, and for readings the rather lengthy drafts.

Thank you also to my friends who have been patient and loving as I disappeared for a while.

Lastly, thank you to my students, who are a constant reminder of why this work is important. They are the reason this dissertation exists. 


\section{TABLE OF CONTENTS}

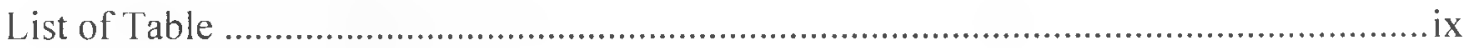

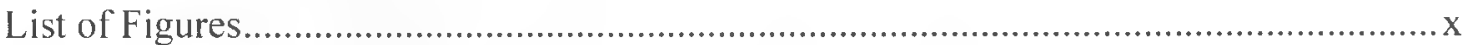

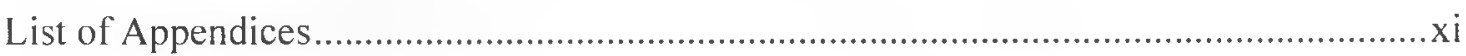

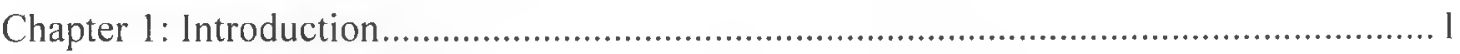

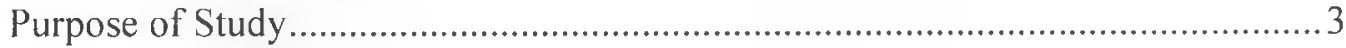

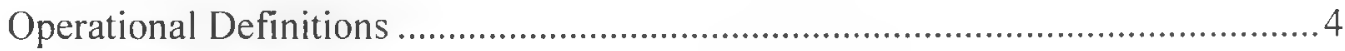

Conceptual Framework .....................................................................................

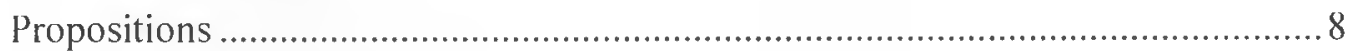

Research Design ..............................................................................................

Significance of Study .......................................................................................... 10

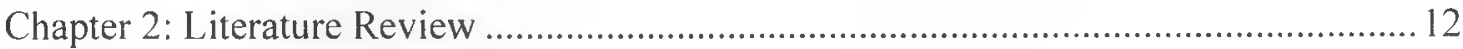

Methodology of the Review ............................................................................. 15

The Successes and Challenges of the IB Program in Public Schools ................... 16

IB and school culture and climate ....................................................... 17

Implementing the IB with fidelity: A model for reform ........................... 17

Effects of the IB on student performance ..................................................2 20

Challenges of the IB Diploma Program .....................................................

Tracking and Student Perceptions ……………………………..........................23

IB for all: An experiment in detracking ................................................26

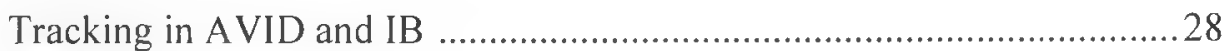

The Successes and Challenges of the AVID Program ..........................................29

AVID and post-secondary success ............................................................ 
AVID and student perception ............................................................... 31

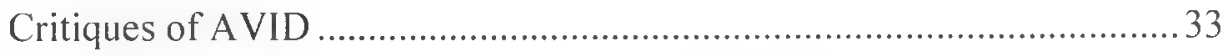

Current Discussions on the Combination of AVID and IB ..................................34

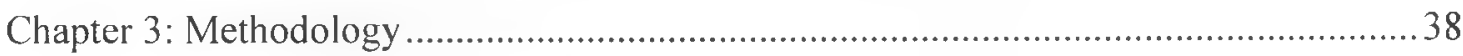

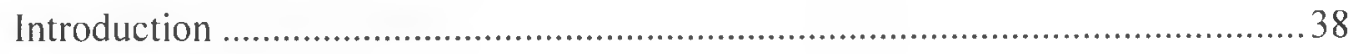

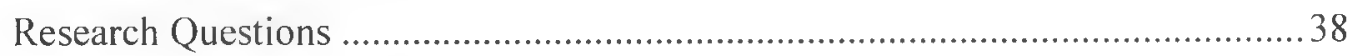

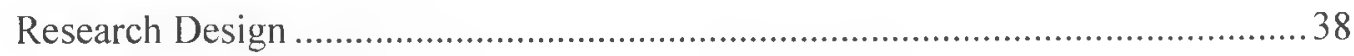

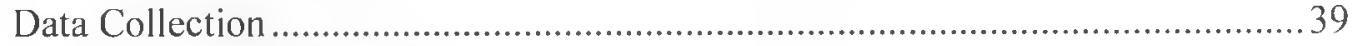

Role of the Researcher......................................................................................... 40

Population and Sample .................................................................................. 41

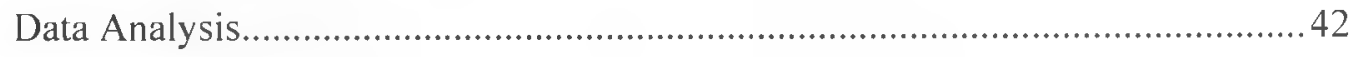

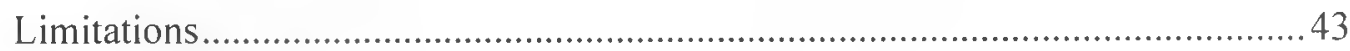

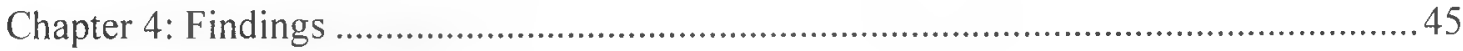

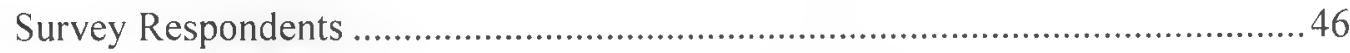

Portrait of Participants ................................................................................... 48

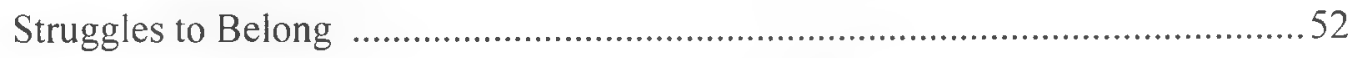

Know: The Double Effect of Dual Enrollment in AVID and IB ........................62

Go: Learning and Going to College ……………………................................. 72

Think and Act Like a College Student ………...................................................... 81

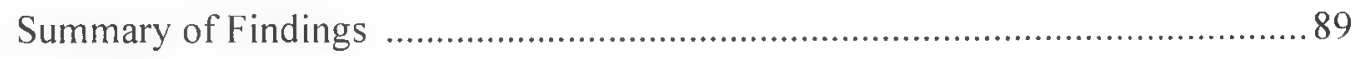

Chapter 5: Conclusions............................................................................................... 91

Interpretation of Findings ………………..................................................... 92

Adjusted Conceptual Framework ...........................................................................93

vii 


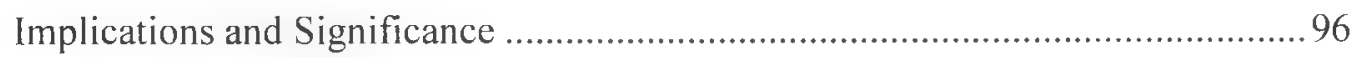

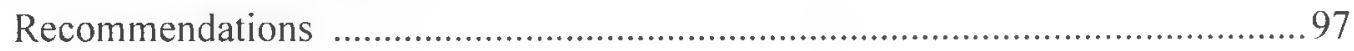

Recommendations for Further Study ...................................................... 108

Reflections on the Research Process ...................................................... 110

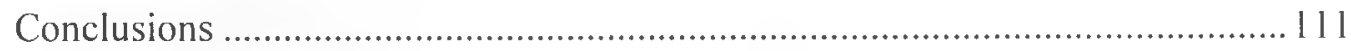

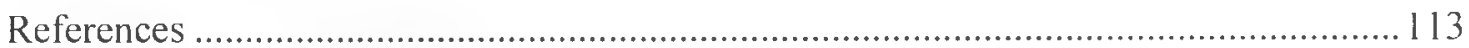

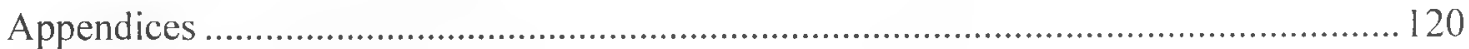




\section{LIST OF TABLES}

Table

Page

1. Demographics of interview participants .................................................49

2. Response to inclusion of cultural heritage in the IB Program......................53

3. Response to inclusion of cultural heritage in the AVID Program.................53

4. Perceptions of the value of linguistic wealth in the IB program...................59

5. Confidence level navigating the financial aid system................................76

6. Confidence level navigating college portals.............................................76

7. College navigation knowledge by program ...........................................77

8. Level of preparedness - note taking strategies....................................85

9. Level of preparedness - organizational strategies.....................................86 


\section{LIST OF FIGURES}

Figures

Page

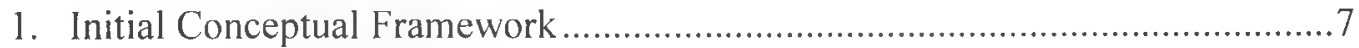

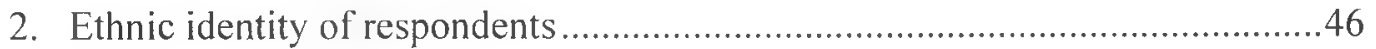

3. Yearly income of respondent household .................................................. 47

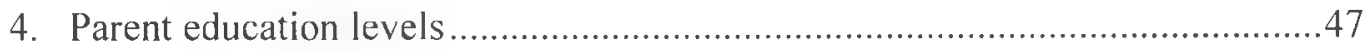

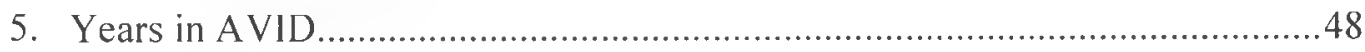

6. Adjusted Conceptual Framework.....................................................94 


\section{LIST OF APPENDICES}

$\begin{array}{lll}\text { Appendix } & \text { Page }\end{array}$

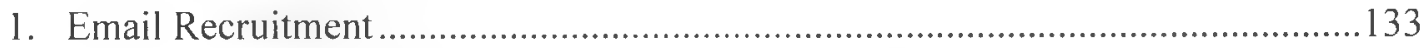

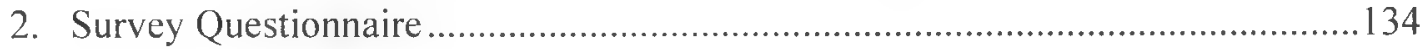

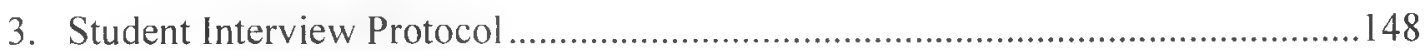

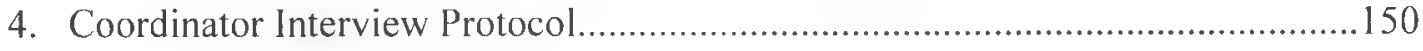




\section{Chapter 1: Purpose of the Study}

California currently faces an education crisis with the potential to become an economic crisis. Currently, only a small minority of underrepresented students attends and graduates from colleges and universities. Because the United States is in the midst of revolution akin to the Industrial revolution of the early 1900 s, the educational and opportunity gaps are significant. Almost $70 \%$ of the country's jobs now rely on specialized skills and knowledge as compared to only five percent of the jobs at the turn of the twentieth century. The exponential growth and change in the job market is exemplified by the fact that the top ten careers in 2010 , for example smartphone app designers or social media managers or content providers, did not exist in 2004 (Darling-Hammond, 2010). Additionally, the income resulting from a bachelors' degree is nearly double that of a high school diploma, according to the Federal 2010 US census. There is a lifetime earning difference of over one million dollars for those with a bachelor's degree compared to those with a high school diploma, and the difference is nearly two million dollars for doctoral degrees compared to individuals earning high school diplomas (Federal Census Bureau, 2010). More importantly, 59\% of employed Americans needed postsecondary education in 2007, a percentage expected to increase to $66 \%$ by 2018 (American Association of Community Colleges, 2012)

There is also an increasing gap between in-demand jobs and the available trained workforce. There are an estimated 15-20 million jobs that will need workers as the baby boomer generation retires, yet millions of people are at risk of being locked into permanent low-wage jobs that do not support their families unless the issue of college completion is addressed (American Association of Community Colleges, 2012). The US hires more foreign workers for high-skill jobs because the nation cannot produce the workers required by these jobs from its 
own labor force (Darling-Hammond, The Flat World and Education: How America's Committment to Equity Will Determine our Future, 2010). If the university gap remains, the US economy may become less competitive internationally (McKinsey and Company, 2009).

One major problem in California is that too few underrepresented students enter and complete post-secondary education, which exacerbates the opportunity gap and further erodes California's economic stability. Latinos, for example, will soon make up the vast majority of workers in California. Since 1990, the Latino working-age population in California has grown from $7 \%$ to $34 \%$, and is projected to be $50 \%$ of the working population by 2040 (Moore, Offstein, \& Shulock, 2011), yet, only 10\% of Latinos (and African Americans) complete degrees and certificates (Moore, Offstein, \& Shulock, 2011). This is due, in part, because many students do not graduate high school with the college readiness skills necessary to make the academic and social transition to higher education institutions. For example, in California, in 2010, the majority of students enrolled in the California State University system also needed remedial courses (National Center for Public Policy and Higher Education and Southern Regional Education Board, 2010). Presently, only eight percent of the bachelor's' degrees awarded by public institutions in California go to underrepresented students (Geiser \& Atkinson, 2010), and only $11 \%$ of the United States' socioeconomically disadvantaged students are expected to graduate with a Bachelor's degree (Steinberg \& Almeida, 2008).

Two organizations, the International Baccalaureate Program (IB) and Advancement via Individual Determination (AVID) have become popular reform programs aimed at increasing college acceptance, and indirectly, degree attainment. The IB program, created in 1968, was primarily for students of American military and diplomats. The program seeks to develop lifelong learners, and ultimately develop students with an intercultural mindset, who give back to 
their community, and engage in rigorous courses of study. The program begins as early as kindergarten, with the culmination of the IB Diploma in grades 11-12. The student who earns an IB Diploma can potentially graduate from high school with 30 post-secondary semester units in the University of California system across all content areas (IBO, 2014). Nearly $80 \%$ of IB Diploma Program students graduate from with their post-secondary degree within four years, with only slight variations for student who received the international diploma and those who do not (Bergeron, 2015)

Mary Catherine Swanson developed the AVID program in 1980 with the purpose of providing additional support and explicit instruction reading, writing, collaboration, and inquiry to socioeconomically disadvantaged students, as well as students who would be the first in their families to attend college (Swanson, 1989). The target group of students were those historically underrepresented on university campuses, either in terms of generational status, socioeconomic status, ethnicity, or language, and had between a 2.0 and 3.0 grade point average. The AVID curriculum is rich in reading, writing, inquiry, collaboration, and organization.

\section{Purpose of the Study}

The purpose of the study is to analyze the impact of the IB and AVID programs on first generation college students, as well as provide insight into how much the level of integration between the two programs matters in terms of student outcomes. Additionally, this study can provide voice to a group of students that may influence how other institutions seek to implement these programs as reform measures.

This study will explore the following questions:

- How do underrepresented students perceive the effects of combined/dual enrollment in the AVID and IB programs on their college readiness and academic and social transitions 
to college? What do students identify, if any, as valuable aspects of each program in their post-secondary success?

- How do underrepresented students perceive the impact of the AVID program on student experience in the IB program?

\section{Operation Definitions:}

For the purpose of this study, the following terms are operationally defined as follows: AVID is a 4-year college preparatory program designed for students who will be the first in their families to attend college, and who are classified as "underrepresented minorities" and are academically between a 2.0-3.5 GPA.

International Baccalaureate Diploma Program is a college preparatory program seeks to develop life-long learners, and ultimately develop students with an intercultural mindset, who give back to their community, and engage in rigorous courses of study. The student who earns an IB Diploma can potentially graduates from high school with 30 post-secondary semester units in the University of California system across all content areas (IBO, 2014).

College Readiness as defined, by David Conley, consists of knowledge in four key areas: Key cognitive strategies, key content knowledge, academic behaviors (self-management), and contextual skills and awareness (college knowledge). College readiness will be measured using four components derived from a study conducted by Conley regarding college readiness practices at 38 high schools across the nation (Conley, McGaughy, \& Kirtner, 2010).

1. GPAs gathered for both high school and college coursework

2. Number of IB classes taken

3. Scores on SAT

4. Scores on IB exams 
Underrepresented Students refers to students from a variety of backgrounds who historically have struggled to receive an equitable secondary education, and who are historically underrepresented in postsecondary education. For the purpose of this study the term encompasses students of color, those from socioeconomically disadvantaged backgrounds, English language learners, and undocumented students.

\section{Conceptual Framework}

The theory of social or cultural capital asserts that underrepresented students need to acquire the social capital of the dominant culture in order to achieve success or challenges social reproduction (Bourdieu, 1986). The theory of cultural capital essentially argues that marginalized students need to learn, adapt, and integrate into the dominant culture, which has the effect of denying the strengths and skills that they bring to school from their home cultures. Yosso provides an alternative analysis to the belief that students need to educate and integrate themselves into the dominant culture. Rather than looking at students through a deficit lens of them lacking cultural capital (Bourdieu, 1986), Yosso's (2005) model maintains a focus on knowledge and experience that exist within communities of color, and that can apply to language and socioeconomic groups. She emphasizes cultural, familial, linguistic, and historical strengths that educational institutions (teachers, curriculum, instruction) should consider in the education of their students in an effort to be more inclusive and empowering. In addition, Yosso (2005) defines community cultural wealth as knowledge, skills, abilities and social contacts used within the community to combat racism and other forms of oppression, and theorizes that wealth is comprised of six forms of capital: linguistic, familial, aspirational, social, navigational and resistant (Yosso, 2005). 
David Conley's (2007) theory for college readiness includes four domains that he short hands as think, know, act, and go. These are: key cognitive strategies ("think"), key content knowledge ("know"), key learning skills and techniques ("act"), and key transition knowledge and skills ("go"). Key cognitive strategies emphasize the thinking and performing elements of the students, including precision, accuracy, and synthesis. Key content knowledge primarily contains the academic capital of students, such as the knowledge frameworks associated with the disciplines. Learning skills and techniques, along with key transitional knowledge, are much harder to measure including such concepts as agency, self-advocacy, and persistence, along with tangible elements, like understanding and using financial aid systems.

The figure below represents my initial conceptual framework for examining the experiences of IB and AVID students and the relationship between cultural wealth and the four domains of college readiness. These theories are then mapped onto the constructs of the AVID and IB programs. The skills considered "key cognitive strategies" are the skills prized by higher education and are indicative of the types of tasks students will encounter in college. Understanding and applying these skills is a form of social capital because it provides access to understanding the culture and demands of higher education. Because the think domain also includes interpretation and communication, linguistic capital also fits because multilingual students have additional translation and interpretation skills beyond their monolingual counterparts. Although the IB program encouraged development and practice of the academic skills, and thus social capital, associated with this domain, I was surprised to discover that linguistic capital and the strengths of bilingualism were emphasized in the AVID program. 


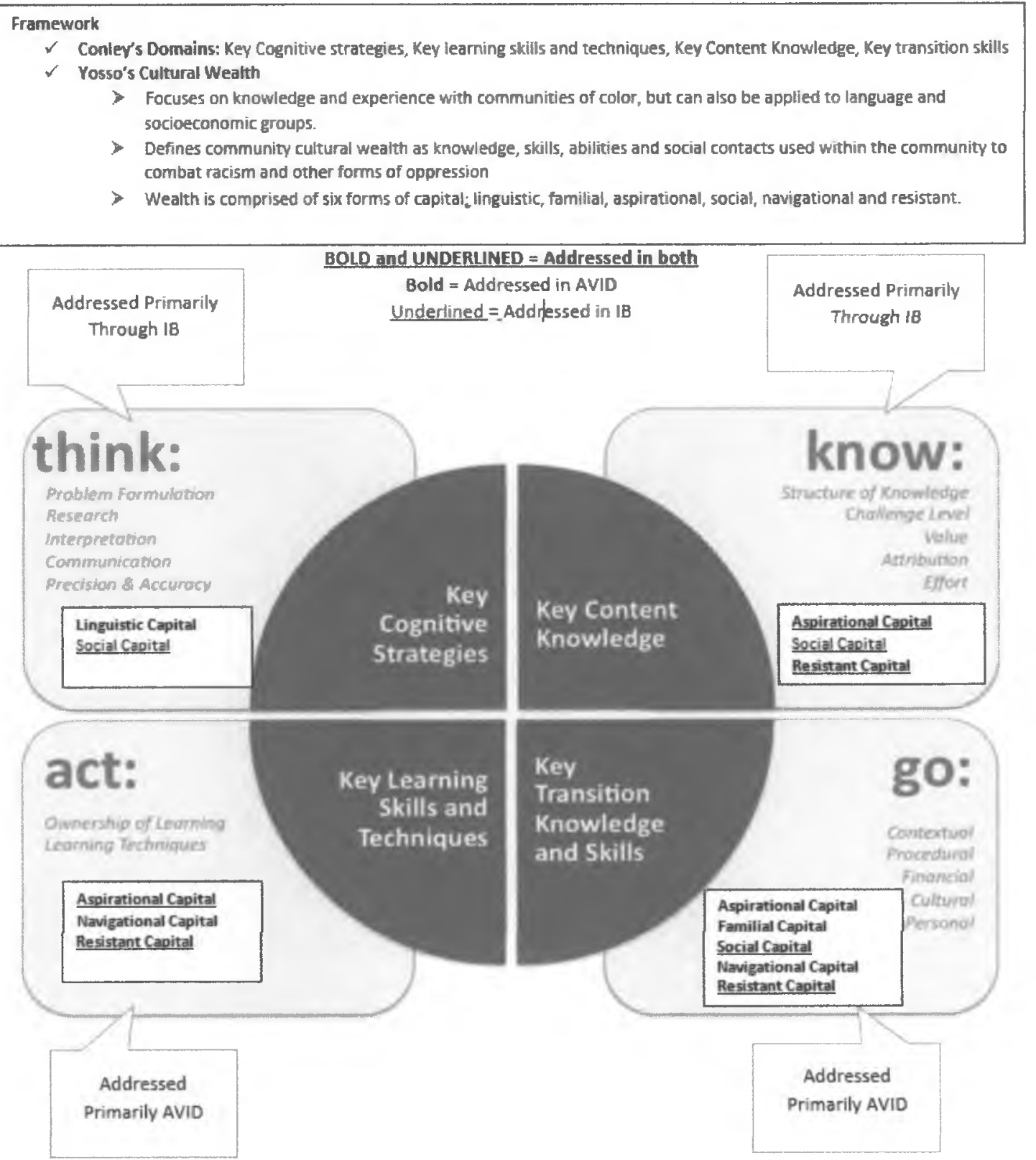

Figure 1: Initial Conceptual Framework

The key content knowledge and strategies domains are addressed primarily in the IB program but in two different ways, through its content and its workload. First, the content of the IB program builds and extends the social capital of students. The IB program does this through the Theory of Knowledge course which is essentially a course on the structure of knowledge, but also through the emphasis on skills and concepts of each discipline which is assessed through investigation, experimentation, and writing. The challenge level and efforts it takes to meet the 
course requirements, though overwhelming for students, also builds, and extends the aspirational capital, desire to achieve, and resistant capital, desire to persevere, of students.

The AVID program heavily addressed the last two domains, key learning skills and transitional knowledge, and aided students in further development of their aspirational, navigational, and resistant capital. Key learning skills, defined as "ownership of learning and learning techniques" is evident in the AVID curriculum, specifically the portions related to study skills, organization, and time management. As students developed what one participant will call "behind the scenes" skills, there was an increase in resistant and aspirational capital, best described as students accomplishing things they did not originally deem possible for themselves. AVID's emphasis on college instruction, specifically regarding application and admissions, as well as financial aid, increased the navigational capital of students with regard to college transition. Students learned, in AVID, how to apply for financial aid and scholarships, how to navigate the various portals, and also how to navigate the etiquette of university culture. There is significant overlap with the two theories when applied to underrepresented high school students and their experiences in higher-level courses and transitions to postsecondary education. However, neither theory provides a practical pathway to ensure the validation of community wealth, nor the development of college readiness.

\section{Propositions:}

Because both the IB and AVID programs have data to support college readiness and degree attainment, the combination of AVID and IB dual enrollment may lead to higher percentages of UC and CSU acceptance rates, degree attainment, as compared to the state means. Dual enrollment in the AVID and IB programs will develop the college readiness and support the transition into university for first generation students. AVID and IB specifically target 
elements of college readiness and cultural wealth, but neither one targets both completely, and are unable to develop all elements. Together, the combination gives first generation students a greater number of, and more sophisticated, tools to transition (academic, social, familial, etc) to four-year universities. Based on the present research, as well as my own experience as both an AVID and IB diploma teacher, it is my hypothesis that explicitly integrated AVID and IB programs will result in higher retention and higher GPAs for historically underrepresented students. Anticipated values of the AVID program initially included the cohort model of the classes as a support structure, the tutorial portion of the elective course, and the explicit instruction in reading and writing.

\section{Research Design}

A multimethod approach was employed, following the pattern of a convergent parallel design, though for sampling purposes, the quantitative data will be gathered first (Creswell \& Plano Clark, 2011). Quantitative data were used to triangulate with the findings of the qualitative data gathered from interviews with students and IB and AVID coordinators at the targeted schools (Creswell \& Plano Clark, 2011). Although understanding the student experience is the center of the study, knowledge, and insight, from AVID and IB coordinators will provide contextual background for the level of integration between the programs, as well as the relative strength of each program.

Although the AVID and IB programs have existed in separate spheres for the past three decades, a growing number of schools are currently working to integrate the programs in order to achieve greater success for their first generation, and underrepresented minority students. The new effort to blend AVID and IB may be due in part to the struggle schools have had enrolling and retaining underrepresented students in the IB Diploma Program (May \& Perna, 2011; Perna, 
May, Yee, \& al., 2013). Because the IB has become a significant reform program for schools with large populations of underrepresented, and socioeconomically disadvantaged students (May \& Perna, 2011), there is growing interest in the integration of these two programs.

\section{Significance of the Study}

AVID and IB have recently begun a series of online articles dedicated to facilitating a stronger relationship between the two programs. A large part of a successful integration is dependent on the scheduling and access to courses for the AVID students, as well as the abilities of the teachers and leadership on the school campus to address issues of instruction and expectations, as well as policies regarding open access to IB classes and master schedule (Tate, 2014). At a recent conference hosted by California Association of World Schools (CAWS), both the directors of AVID and the International Baccalaureate, Rob Gira and Bob Poole respectively, discussed a need for further research into schools that integrated the IB and AVID programs. Additionally, both reiterated a need for further research into the effects of the IB and AVID programs on the post-secondary success of students, specifically students who are enrolled in the AVID elective class.

Because both programs have data to support college readiness, in the case of AVID and IB, and degree attainment for IB, dual enrollment in AVID and IB may lead to higher degrees of college acceptance and unit completion rates, and second year enrollment than the state CSU and UC averages. The comparative data will be accessed using the CSU analytic data website, the institutional research reports and statistics found on the campus websites.

The conversation about AVID and IB is complicated. Marginalized students seem to struggle most with self-perception and access resulting from tracking, low expectations, and lack rich curriculum and instruction (Darling-Hammond, 2010; Perna, et al., 2013; Valenzuela, 
1999). The IB program would benefit from a close relationship with the AVID program. Additionally, the skills emphasized in the AVID program can potentially act as an accelerant to students looking to enroll in the IB program, but who may lack the experience and resources of other students. Bob Poole commented that the IB should not be considered elitist, and the two programs should not be viewed as competing programs within a school, but rather complementary (Gira \& Poole, 2013). Based on the research so far, the missions and goals appear to be symbiotic; however, it is the goal of this study to determine if there is improved performance, and whether the student-identified benefits carry forward into post-secondary educational experiences.

My interest in the relationship between the AVID and IB programs is not simply academic, but personal, and of critical importance to my practice and current site. I have been an AVID educator for eight years, and an AVID coordinator for five. In addition, my school site has recently been authorized as an IB World School offering the Diploma Program where I will be teaching the History of Americas and Theory of Knowledge courses. I am an advocate of both the AVID and IB programs, with my primary interest being the experience of the students I serve. This study is for practitioners, it is for teachers, coordinators, and sites who are working to better integrate the programs. As my colleagues and I prepare to inaugurate our first class of IB diploma candidates, over half of whom are also AVID students, it is the goal of this investigation to discover what students identify as facilitators and barriers to their success. In addition to the scholarly literature, and anecdotal experiences of sites and teachers, student voice and perspectives will better enable my colleagues and I to replicate what is working for students, as well as to avoid policies and practices that students identify as barriers to their success. 


\section{Chapter 2: Literature Review}

The educational system in the US was built to reproduce class structures and to maintain racial hierarchies (Anyon, 1980; Bourdieu, 1986; Bowles \& Gintis, 1976; Ladson-Billings, 2006). Several studies have illustrated the severity of social reproduction in the classroom (Anyon, 1980; Bowles \& Gintis, 1976; Finn, 1999; Solarzano \& Ornelas, 2004). Bourdieu (1986) argued that structures, educational institutions being a primary example, exist within a society to maintain social hierarchies of privilege. Ladson-Billings (2006), within the context of Critical Race Theory, expands the concept of social reproduction to encompass race and ethnicity, arguing that African-Americans particularly, now have educational debt created by generations of inequitable schooling. Valenzuela (1999) complicated the discussion on the relationship between expectations, pedagogy, and socioeconomic status by adding the additional layers of language ability, and immigrant status. Valenzuela (1999) found that teachers often do not expect as much from children from socioeconomically disadvantaged or minority, backgrounds, as they do from other, more privileged learners, and termed this phenomenon, subtractive schooling. Subtractive schooling is a deficit model of education that subtracts resources from marginalized youth in two major ways: first by dismissing their definitions of education, and second through assimilationist policies and practices that minimize their cultures and languages (Valenzuela, 1999).

Deficit model thinking, specifically regarding socio-economic, ethnic, linguistic, and immigrant status, demonstrably affected the relationships between teacher expectations, instructional practices, curriculum choices, as well as student definitions of knowledge and work (Anyon, 1980; Bowles \& Gintis, 1976; Burris, Wiley, Welner, \& Murphy, 2008; Kohn, 2011; Yonezawa \& Jones, 2006; Yonezawa, Wells, \& Serna, 2002). Lower tracks are often 
accompanied by lowered expectations, which then result in a teacher centered pedagogy focused on rote memorization, obedience, and minimal skills development (Darling-Hammond, 2010; Finn, 1999; Valenzuela, 1999).

Efforts to address the contrasting and inequitable educational experiences of students in the US are vast, ranging from federal solutions like No Child Left Behind, to district solutions dissolving or shifting tracking policies. For the purpose of this study, the decisions on the part of districts and sites to implement AVID and IB programs are the most significant. Since its inception, the IB program now spans the globe, and in the US, has become a new reform option for many schools. The IB has grown in Title I schools between 1995 and 2009, due in part to private funding from the Gates Millennium Foundation and federal grants (Corcoran \& Gerry, 2010; May \& Perna, 2011), and it is often part of larger measures to improve a school's reputation in the community (Mayer, 2010). The AVID program has also grown from its roots in one woman's classroom in one high school to an international program spanning nearly 5000 schools, including international schools and institutions of higher education (AVID Center, 2014).

Although the AVID and IB programs have traditionally served different populations, due primarily to the context and conditions under which they were created, an examination of their mission statements, indicates that their coexistence at a school site would not only be congruent, but ultimately, symbiotic. The IB Diploma Program philosophy is built upon educating the whole student through the development of traits like critical thinking, inquiry, empathy, international mindedness, and academic skills (IBO, 2014). The AVID program has a similar mission to the IB, however, the goal of AVID is more targeted, namely to achieve college acceptance and success in a global society for historically underrepresented students (AVID, 
2014). In most cases, AVID and IB are "loosely coupled" (Elmore, 2008), essentially co-existing as separate programs, sometimes overlapping with particular students, but rarely utilizing the capacities and strengths of the other (Duarte, 2012 ; Gira \& Poole, 2013; Mayer, Factors influencing the implementation of an International Baccalaureate program in a diverse urban high school, 2010; Tate, 2014; Welch, 2010). Recently, as sites have begun exploring explicit integration of the two programs, there is a growing interest in examining practices of sites, but also perceptions of students who are enrolled in both programs (Gira \& Poole, 2013; Misra, 2016; Tate, 2014; Welch, 2010)

I am primarily interested in the successes and challenges of the IB and AVID programs, with specific regard to underrepresented students in the United States. The purpose of my study is twofold, the first being to explore whether combined enrollment in AVID and IB has an effect on student performance and matriculation in post-secondary education. Therefore, in order to provide background on the status, successes, and challenges of the AVID and IB programs, this review encompasses three distinct bodies of literature: successes and challenges of the International Baccalaureate program, the policies of tracking and its effect on student perceptions, and successes and challenges of the AVID program. The chapter begins with an examination of studies on the International Baccalaureate Diploma program because it is a comprehensive reform program. I provide a survey of the literature regarding the successes, challenges, and critiques of the International Baccalaureate Diploma Program as a reform model. The examination will explore the successes in terms of student performance and matriculation, as well as the effect of IB enrollment on self-perception. Additionally, I present challenges of the IB Program, particularly for these underrepresented student population. The next section will address tracking policies, specifically focusing on open enrollment as a solution to tracking and 
the effects of tracking on student self-perception. The purpose of this section is to explore what the literature demonstrates as a major barrier to underrepresented student success in the IB program. Lastly, because it is both a support (both academic and social) program for underrepresented students and a counter-measure addressing tracking, I will discuss the success and challenges of the AVID program.

\section{Methodology for the Review}

I began with an exploration of articles about the IB and AVID, and found there is no scholarly literature on the explicit combination of the programs. However, among practitioners, as noted on both the IB and AVID websites, the discussion of explicit combinations is prominent (see Tate, 2014; Welch, 2010). The search terms used for this review were AVID and IB, IB and underrepresented students, IB and postsecondary success, AVID and post-secondary success, AVID and student perceptions, IB and student perception. The searches and resulting articles indicated that tracking practices, social reproduction, and support systems were barriers to the success of the IB program amongst underrepresented students. I pursued articles that discussed tracking, specifically, as it relates to teacher attitude and student perceptions, as well as the AVID and IB programs.

For the purpose of this literature review, articles on the topic of tracking and detracking are those articles specific to schools implementing the IB program, as well as those related to the effects of tracking on student self-perception, as that is of primary interest for the study. Articles on tracking and detracking in academic environments were selected because academic preparation is such a key part of success in the IB program, and because tracking has been a barrier to student success in schools with high populations of underrepresented students. Works that did not address underrepresented populations were excluded, as they would eliminate 
students who fit the AVID profile. Exception to this rule to focus on underrepresented students include reports from the IB Organization and larger comprehensive statistical samples, where sample populations were not delineated. These reports included reports on IB data reports on post-secondary retention, and academic performance (Bergeron, 2015; Conley, McGaughy, \& Davis-Molin, 2014; Halic, 2013).

\section{The Successes and Challenges of the IB Program in Public Schools}

Recently, several schools serving primarily socioeconomically disadvantaged and underrepresented minority students have adopted the IB Diploma Program as a reform effort to increase the level of rigor for all students and increase the numbers of students who meet college eligibility and complete college (Bergeron, 2015; Burris, Welner, Wiley, \& Murphy, 2007; Coca, Johnson, Kelley-Kemple, \& et al, 2013; Halic, 2013). Within this section, I examine the literature on the role of the IB in changing school climate, the persistence rates of diploma program candidates who fit these demographics, and the effects of enrollment in the IB Diploma Program on students of color, first generation, and socioeconomically disadvantaged students.

Given the increase in popularity of the program, I expected to find several sources that confirmed IB resulted in positive changes for students' academic self-perception and academic success. Although there are several sources that demonstrate the academic success of IB students, as well as the positive effects the IB program has on school culture and climate, very few articles addressed student self-perception, or even contained student voice (Bergeron, 2015; Burris, Welner, Wiley, \& Murphy, 2007; Conley, McGaughy, \& Davis-Molin, 2014; Mayer, 2010; O'Conner, 2011). What follows is a discussion on the successes of IB with regard to school climate and culture, and academic performance. 


\section{IB and School Culture and Climate}

The effects of the International Baccalaureate on school climate and culture, has not been widely researched until recently (Duarte, 2012 ; Mayer, 2006; Mayer, 2010). There is now a growing body of research on the facilitators and barriers to successful implementation, as well as the positive and negative outcomes on school culture (Burris, Welner, Wiley, \& Murphy, 2007; Coca, Johnson, Kelley-Kemple, et al, 2013; Mayer, 2006; O'Conner, 2011). Although limited in scope, much of the research on IB's effect on school climate is positive. The research indicates that IB can have positive effects on building student self-confidence and a college going culture, if the program is implemented with fidelity and teachers are provided with ongoing professional development (Burris, Welner, Wiley, \& Murphy, 2007; Mayer, 2010). Additionally, several studies demonstrated that teachers believed students could achieve the rigorous standards of the IB, that the IB model was a positive influence on their curriculum and instruction, and that networking with other IB teachers had a profound effect on their own practice (Corbett Burris, Welner, Wiley, \& Murphy, 2007; Corcoran \& Gerry, 2010; Perna, et al., 2013).

\section{Implementing the IB with fidelity - A model for reform.}

For the purpose of this section it is important to note that the IB can be implemented using a variety of models. Some schools, mainly charter and magnet schools like Chicago Public Schools, have an "IB for all" policy essentially stating that all students will enroll in the IB program as juniors and seniors, and some have policies that all students will take IB English and math classes, and then have choice (Burris, Welner, Wiley, \& Murphy, 2007; Roderick, Nagaoka, \& Coca, 2009). However, many schools contain tracks for IB as follows. A student must choose whether to be a "full diploma," "certificate," or "regular" students. A "regular student" does not take any IB classes; a "certificate" student takes a one or more IB courses, and 
sits for the exams, similar to an AP student. The "full diploma" student takes seven IB classes, including Theory of Knowledge, writes a 4000 word extended essay, and completes a Creativity, Action, and Service (CAS) Project (Duarte, 2012 ; IBO, 2014; May \& Perna, 2011; O'Conner, 2011; Perna, et al., 2013).

The IB program when implemented in a variety of school settings was able to achieve positive results in the face of the uncontrolled obstacles facing schools including issues of social reproduction resulting from perceptions of students and teachers, and poor preparation at the lower grades (Burris, Wiley, Welner, \& Murphy, 2007; Conley, McGaughy, \& Davis-Molin, 2014; Duarte, 2012 ; Mayer, 2006). Mayer's (2010) findings noted that the IB may be a particularly good options for urban schools because of its strict authorization guidelines and curricular focus on interdisciplinary academic skills, international and cultural awareness, and depth of knowledge versus breadth of knowledge (IBO, 2014; Walter, Jane Lo, \& Jude Yeo, 2013). Unlike Advanced Placement courses, which can be added to any school schedule, and do not require teacher training, becoming an IB school is a complex multi-year process (Mayer, 2010). The implementation of the IB program includes: school-wide assessment of organizational structures, plans for supporting students' mother tongues, and required shifts in curriculum, instruction, and assessment policies and practices throughout the school (IBO, 2014; Mayer, 2010). Schools cannot offer IB classes until they have met the requirements of the IB authorization committee and have sent teachers to IB curriculum workshops (IBO, 2014; Mayer, $2010)$

In addition to the rigorous process to become an IB Diploma Program school, the curricular and cultural elements, the program has the potential to have profound effects on school culture and climate (Burris, Welner, Wiley, \& Murphy, 2007; Conley, McGaughy, \& 
Davis-Molin, 2014; Mayer, 2006; O'Conner, 2011). Evidence suggests that the IB experience positively impacts minority students' perceptions of their education and academic abilities, such as increased confidence and perseverance (Bergeron, 2015; Coca, Johnson, Kelley-Kemple, \& et al, 2013; Conley, McGaughy, \& Davis-Molin, 2014). Evidence suggests that the combination of high expectations, rigorous curriculum, and supportive instruction demonstrated by the IB Diploma Program can increase academic motivation and create a positive self-image, as opposed to the negative assumptions that accompany deficit model thinking (Coca, Johnson, KelleyKemple, \& et al, 2013; Conley, McGaughy, \& Davis-Molin, 2014; Kyburg Dickenson, 2007; Mayer, 2006; O'Conner, 2011).

O'Conner (2011) and Duarte (2012) explored the impact of the IB program on school climate and culture in similar case-study designs. O'Conner (2011) examined the goals and effects of the IB program within an upper-middle class high school in the Midwest, using primarily qualitative data based on interviews with administrators and teachers. O'Conner (2011) points out that the original intention of the school was to have only Diploma candidates, but the school has not met that goal. However, the number of diploma candidates has risen steadily, as has participation in the certificate program (O'Conner, 2011). Duarte (2012) came to a similar finding, namely that the IB Diploma Program extended and drew in members of the school community beyond the students and teachers in the IB classes. For example, in describing the IB component or Creativity Action and Service (CAS), Duarte explained, "IB Diploma Program requirements have a strong reach on each campus" (p. 84). This is because clubs and activities required for CAS also involve teachers and students who are not affiliated with IB program. 
Though limited in terms of their generalizability, representing only three schools, both Duarte (2012) and O'Conner (2011) included findings that the IB Diploma program positively affected the culture of the school, and individual students, both participants and non-participants in the IB program. Specifically, all three sites were infused with sense of overall pride, student involvement, IB requirements, and the school's vision (Duarte, 2012 ; O'Conner, 2011). The students and teachers across both studies acknowledge that the IB program was a source of pride, and noted that student performance and teacher instruction had improved as a result of the program. Additionally, the effects of the program were not limited by the socioeconomic status of the neighborhoods indicating that diverse school types could benefit from the IB model.

\section{The effects of the IB on student performance.}

The most recent report on persistence and performance data of IB Diploma candidates also supports positive academic success. Bergeron (2015) examined the eligibility enrollment, destinations, retention, graduation rates and majors of over 15,000 diploma program candidates and those who successfully earned the IB diploma. Using a combination of National Clearinghouse Data and the International Baccalaureate data system, or IBIS, students who were IB diploma graduates and candidates have a much higher retention rate in their first and second years of post-secondary education, when compared with the total number of first and second year college students. However, Bergeron's (2015) data is not disaggregated according to generational, ethnic, or socioeconomic status, and therefore, does not necessarily reflect the issues related to recruiting and maintaining enrollment of students from historically underrepresented backgrounds. 


\section{Challenges of the IB Diploma Program.}

Clearly, the IB has the potential to be a transformative reform program because of the focus on internationalism, cultural relevancy, and demonstrated successes of IB Diploma candidates in post-secondary education (Bergeron, 2015; Burris, Welner, Wiley, \& Murphy, 2007; Conley, McGaughy, \& Davis-Molin, 2014; Halic, 2013; O'Conner, 2011). However, the IB has struggled to enroll and maintain participation of underrepresented students, due to teacher attitudes and beliefs, tracking practices, and systemic challenges like scheduling and district support (Burris, Wiley, Welner, \& Murphy, 2008; Corcoran \& Gerry, 2010; May \& Perna, 2011; Mayer, 2010). Additionally, there has been very little research from the student perspective on the lack of participation in the IB. The studies that explore IB participation are either whole district studies or longitudinal studies that lack qualitative explanations for the results.

As more public schools, serving high percentages of underrepresented students implement the IB program, studies reveal major difficulties retaining underrepresented students (May \& Perna, 2011; Mayer, 2008; Perna, et al., 2013). The data on IB students demonstrates that retention and success in college is a strength for IB diploma candidates. However, the literature on IB indicates that despite access to the IB program, students from socioeconomically disadvantaged backgrounds are not necessarily enrolling, or succeeding, in those courses primarily due to deficit model thinking on the part of teachers and coordinators, and institutional factors like tracking processes, the fidelity of implementation, and lack of support structures for students. (Burris, Wiley, Welner, \& Murphy, 2008; Coca, Johnson, Kelley-Kemple, \& et al, 2013; Perna, et al., 2013). In recent years, several studies have explored the magnitude of the challenges to the IB Diploma Program, as well as possible explanations, for the lack of participation by underrepresented students. 
Corcoran and Gerry's (2010) qualitative study was a program evaluation of the "IB Access" program started by Gates Millennium Foundation in 2009. The study examined eight high schools across three districts in the eastern United States. The IB program was evaluated in two categories: Climate and instruction, as well as teacher attitudes, beliefs, and practices. Findings noted that although teachers believed that students could achieve the rigorous standards of the IB, the IB model was a positive influence on their curriculum and instruction, and networking with other IB teachers had a profound effect on their own practice, the challenges section revealed patterns of social reproduction. When asked about student success and retention rates, teachers often exhibited deficit model thinking, stating that they believed that students (particularly those of low socioeconomic status and of African American or Latino heritage) did not possess the behaviors, skills, or responsibility to be successful (Corcoran \& Gerry, 2010). The findings in the 2010 study provide explanations for why IB programs have trouble recruiting and retaining students, and may explain the findings found in a series of recent studies in Florida.

Florida has seen a rapid expansion of the IB Diploma Program (Bergeron, 2015; May \& Perna, 2011; Perna, et al., 2013) to such an extent that nearly $55 \%$ of all socioeconomically disadvantaged students, as well as Latino and African American students have increased access, through open enrollment and magnet schools to the program (Perna, et al., 2013). However, findings demonstrate that these students are not participating in the IB program. The discussion offers several potential explanations for this: lack of counselors, tracking in early years, as well as a phenomenon called "opportunity hogging," whereby more resourced students take the spaces in IB courses and programs, leaving other students locked out. Mayer (2010) offers a broader explanation for the failure of IB programs to retain underrepresented students, 
noting that in order for IB to succeed there needs to be consistent leadership from retaining principals trained in IB and on-going support from the district (Mayer, 2010).

May, Perna, and Yee (2013) conducted an in depth analysis of data from the IB database, National Center for Education Statistics (NCES), and data from Florida state's IB programs with the purpose of examining the growth, success and challenges to accessing the IB program. The data set encompassed 400,000 records collected between 1995-2009 making it one of the most comprehensive quantitative studies on participation of underrepresented minority, and socioeconomically disadvantaged students in the IBDP in the United States (Perna, May, Yee, \& et al, 2013). This most recent study found that despite the growth of Latino participants in the program, attracting and retaining minority and economically disadvantaged students remains a major hurdle for the IB in American schools (Perna, et al., 2013).

\section{Tracking and Student Perceptions}

As noted in the prior section, tracking, teacher attitudes and corresponding instructional practices all serve as barriers to underrepresented student success in the IB program. School structures and programs have the potential to enhance or remove barriers to student success. Advanced courses like Advanced Placement and International Baccalaureate classes are major gateways to admission into four-year universities, and data shows that students who take AP or

IB courses are more likely to enroll and matriculate through post-secondary education (Bailey \& Mechur Karp, 2003; Bergeron, 2015; Halic, 2013; Koch, Slate, \& Moore, 2013; Mattern, Shaw, \& Xiong, 2009). AP and IB courses are rigorous college prep courses that require critical reading, critical thinking, and writing skills (Conley, McGaughy, \& Davis-Molin, 2014; IBO, 2014; Koch, Slate, \& Moore, 2013; Mattern, Shaw, \& Xiong, 2009; Solarzano \& Ornelas, 2004). For example, students who score 3 on the AP exam or a 4 on an IB exam, often earn college 
credit thus decreasing the financial burden of college by earning dual credit in high school courses. However, embedded patterns of institutional racism and classism continue to prevent all students from accessing advanced coursework in secondary education (Koch, Slate, \& Moore, 2013; Solarzano \& Ornelas, 2004). The purpose of this section is to illustrate how tracking policies, specifically open enrollment, negatively affects student academic self-perceptions. Lastly, this section will evaluate one detracking effort, specifically related to the IB program in an effort to illustrate how one district is working to sustain the underrepresented student involvement in the IB program.

Historically, underrepresented students do not enroll in large numbers in advanced classes, and when they do, they often lack access to the infrastructure and support to succeed (Koch, Slate, \& Moore, 2013; Kyburg Dickenson, 2007; May \& Perna, 2011; Solarzano \& Ornelas, 2004). This phenomenon is caused by a web of issues including language, ethnic and cultural pressures, socioeconomic status, and teacher attitudes often result in policies of tracking (Conchas, 2001; Corcoran \& Gerry, 2010; Darling-Hammond, 2010; Mayer, 2006; Solarzano \& Ornelas, 2004). Tracking can be overt, as when different pathways are predesignated for students according to performance and test scores, or covert as with open enrollment, where all students are given access to courses, but not guaranteed support (Burris, Wiley, Welner, \& Murphy, 2008; Darling-Hammond, 2010). Tracking can occur within a public school or when students apply for entrance into public charter or magnet school, as with many IB students in Chicago and across a range of Florida's public schools (Coca, Johnson, Kelley-Kemple, \& et al, 2013; Corcoran \& Gerry, 2010; Perna, et al., 2013).

Regardless of the construct of the policy, tracking practices often place students in a situation of conflict between their peer culture and academic aspirations, and are detrimental to 
student self-perception. Conchas' (2001) case study of Latino students in a heavily tracked school system exemplifies the issues facing underrepresented students in advanced courses. The study revealed that students in the higher tracked courses, especially AP, essentially had to choose academic rigor over peer relationships. Students in the study felt disconnected from both their Latino peers not enrolled in AP, as well as their predominately White and Asian peers in the advanced courses.

Yonezawa (2002) expands on the work of Conchas (2001) by examining open enrollment. Yonezawa's (2002) qualitative study examined the concept of choice, or open enrollment, as a method of detracking high schools. The evidence suggested that leaving the low track was not an easy decision for many underrepresented students. The findings indicate that the concept of choice is much more complex for students due to institutional and social factors, and supports the findings in Conchas (2001) where many students struggled to reconcile their academic aspirations with the threat of alienation from their peers. In a follow up to the 2002 study, Yonezawa (2006) also examined student perspectives on detracking in relation to the process of tracking, the effects of tracking, and detracking though focus group interviews, representing 500 students from 12 high schools across three urban school districts in California (Yonezawa \& Jones, 2006). With regard to practice, most students believed that the process was often arbitrary and done for the benefit of scheduling rather than students. Additionally, students noted that the tracks were inaccurate, with many students misplaced in both low and high tracks. Students across the spectrum, according to the findings, explained that the "gap between AP and regular classes" should not exist and that "all kids deserved a good education" (Yonezawa \& Jones, 2006, p. 19). 
In recent years, school districts have voluntarily adopted policies of open enrollment, which eliminate prerequisites for advanced courses (e.g., honors, Advanced Placement, International Baccalaureate). In systems of open enrollment, students select their courses, often as early as the seventh grade, and typically by the ninth grade. Yet open enrollment, or student choice, is not an effective remedy for tracking (Yonezawa, Wells, \& Serna, 2002). Choice is much more complex for students due to institutional and social factors. Many students struggled with the "need for respect" and connection from their peers versus their "aspirations" (Cammarota, 2004; Conchas, 2001; Yonezawa, Wells, \& Serna, 2002). Often low and middleincome students struggle with their aspirations for higher track classes, but receive mixed messages from teachers, counselors and want classes where they can be successful (Yonezawa, Wells, \& Serna, 2002). Open enrollment places students in the position of having to decide whether they are an "honors" student in a given subject area (Watanabe, 2008; Yonezawa, Wells, \& Serna, 2002). Three of the four articles, conclude that open enrollment, or student initiated course selection, effectively places a burden of choice on the student. Schools that offer several levels of a particular course, such as English 3, English 3 Honors, IB English, may harm student self-perception as students choose courses that define them academically and socially (Yonezawa \& Jones, 2006; Yonezawa, Wells, \& Serna, 2002).

\section{IB for all: An experiment in detracking.}

The literature on student performance suggests that participation in the IB Diploma program, as a diploma candidate has a positive impact on student performance in secondary as well as post-secondary academic success. Many of the studies examining the effect of the IB on students of color, or from socioeconomically disadvantaged backgrounds, are conducted at magnet or charter schools. Thus, the admissions process serves as a version of ability tracking 
because students need to meet minimum testing requirements and apply for admission (Coca, Johnson, Kelley-Kemple, \& et al, 2013; May \& Perna, 2011; Perna, May, Yee, \& et al, 2013). The charter model contrasts with comprehensive public high school model of the sites whose students participated in this study. In an effort to demonstrate a successful detracking effort involving the IB diploma program, I have included Carol Burris' (2008) study and subsequent of detracking in a non-magnet public school with an IB Diploma Program school. While African American, Latino students, and socioeconomically disadvantaged students were a minority of the student body, they were still enrolled in a regular public high school making the site a closer match to the sites I have targeted for this study.

Carol Burris, a high school principal in the Rockeville School District in New York, has written extensively on the effects of detracking on student achievement based on an experimental design of a district wide detracking model implemented between 1993 and 2000 (Burris, Wiley, Welner, \& Murphy, 2008). Although the district did not eliminate all tracks, the school eliminated what Burris termed the "third track," or non-honors diploma. The following steps were taken to increase the number of Regents Diplomas and increase participation in the IB program.

First, all students took the same English and Math classes in their 9th and 10th grade years, and then were told in their junior year that they could choose to be IB Diploma candidates, or work to attain the New York Regent's Diploma; there was not an option for a "non-honors" diploma. Participation in the IB program grew and $97 \%$ of Hispanic and $88 \%$ of A frican Americans earned regents diplomas, rates well above the state average for White and Asian students (Burris, Wiley, Welner, \& Murphy, 2008). Prior to the detracking initiative, only 13\% of African American and Latino students were IB diploma candidates. Two years later that 
number had nearly tripled, with $38 \%$ of A frican Americans and Latinos enrolling as IB diploma candidates. Additionally, 70\% of A frican-American and Latino students enrolled in advanced IB English and IB math (Burris, Wiley, Welner, \& Murphy, 2008).

The factors of success in the detracking movement included an explicit focus on instruction, and systemic changes such as introductions to the IB curriculum in IB preparatory courses in the $9^{\text {"n }}$ and $10^{\text {m }}$ grades, student support periods built into the school day (Corbett Burris, Welner, Wiley, \& Murphy, 2007; Burris, Wiley, Welner, \& Murphy, 2008). Although this study provides evidence that detracking can have a significant positive effect on student performance outcomes, it does not discuss students' perceptions. We do not know how students or teachers felt about the process, only that student academic performance increased. Although the findings of Burris (Burris, Wiley, Welner, \& Murphy, 2008) may not be generalizable to larger populations, this model of detracking provides an example of how schools and districts could approach the issue of tracked classes.

\section{Tracking in AVID and IB.}

Both the AVID and International Baccalaureate Programs are opt-in programs, meaning students choose, through open enrollment, their level of participation. In the case of public charters or magnet schools that emphasize IB, students must self-select and apply for admission. Students decide their level of participation in their junior year, and may have self-selected into IB honors courses in the $9^{\text {tn }}$ and $10^{n}$ grades. Additionally, AVID students need to apply and be selected for the AVID program in secondary schools. AVID does takes steps to disrupt the systems of social reproduction, primarily, by requiring students to take advanced courses in the $11^{\text {th }}$ and $12^{\text {th }}$ grades (AVID). Although AVID removes one layer of choice in an open enrollment system, though not quite as effectively as Burris' high school (Corbett Burris, Welner, Wiley, \& 
Murphy, 2007). The policy in Burris'school was to dictate that all students take IB English and IB math, thereby further eliminating choice. However, as an AVID instructor, I have watched students agonize over their choices, usually trying to talk themselves into taking challenging courses. Removing one layer of choice may help students to some extent, but it does not alone diminish the anxiety students have about their abilities or sense of belonging in advanced courses.

\section{Successes and Challenges of the AVID Program}

As underrepresented students work to gain access and academic achievement in advanced high school courses, they are often facing issues of tracking while trying to survive the rigorous coursework (Bernhardt, 2013; Burris, Wiley, Welner, \& Murphy, 2008; Coca, Johnson, Kelley-Kemple, \& et al, 2013; Solarzano \& Ornelas, 2004). AVID has the potential to bridge the gap between success in IB classes and the effects of tracking and lack of support for underrepresented students because of its mission and model, a focus on academic skills, organization, and community (Bernhardt, 2013; Espinosa, 2012; Kouba, 2011; Swanson, 1989; Watt, Johnston, Huerta, \& al., 2008). The purpose of this section is to examine the success that AVID has had in each of those areas, and also to determine where AVID struggles as well as critiques of the program.

Because AVID has grown rapidly in the US and internationally, I anticipated finding several comprehensive studies, as well as studies reviewing AVID from a critical standpoint. Instead, I found that much of the research on AVID success is based on students who have met the requirements for participation in the AVID program. Additionally, the samples for many of the AVID studies included only those students who had matriculated through the program all four years. This makes the research on AVID take on a certain circular logic in that the success 
of AVID is based on successful AVID students, who maintained their position in the program. There is very little research on students who were exited from the program because of due to behavior or grades, or who chose to exit the program. Although qualitative data overwhelmingly supports the notion that AVID successfully promotes college readiness in historically underrepresented and underserved students, the quantitative data is limited and inconclusive (McCready, 2014)

The literature on AVID demonstrates that the program positively contributes to the system access to process, procedures, and curriculum necessary to enter college, to be college prepared. The program specifically targets the practice of tracking by requiring students historically underrepresented in advanced course to take at least one course at the highest level in high school, often an AP or IB class, as well as providing guidance to the college process (Advancement Via Individual Determination, 2014; Bernhardt, 2013; Espinosa, 2012; Watt, Johnston, Huerta, \& al., 2008). AVID is designed as a cohort model in an attempt to combat the feelings of alienation that underrepresented students may experience in advanced courses and tracks (Bernhardt, 2013; Kouba, 2011; Watt, Johnston, Huerta, \& al., 2008). However, AVID programs struggle with attrition from the program, primarily between the freshman and sophomore year, and very little quantitative research beyond graduation, college application, and college acceptance rates, exists on the success of the program (Huerta, Watt, \& Reyes, 2013; McCready, 2014; Watt, Johnston, Huerta, \& al., 2008). Additionally, the data on graduation and college application and acceptance is based on the students completing the program as seniors, which does not address the students who were dropped, or chose to leave for one of the reasons mentioned above. 


\section{AVID and Post-Secondary success.}

The success of the program with relation to college acceptance, is already evident in the senior data collection of 2013. Students who stay in AVID complete college entrance benchmarks at a much higher rate than non-AVID students in the same subgroup (AVID Center, 2014; Kouba, 2011). For example, of the 34,000 A VID seniors who graduated in 2013, over $90 \%$ of students met college entrance requirement, and $76 \%$ were accepted into university (Advancement Via Individual Determination, 2014). Jeffrey Huerta, Karen Watt and Cynthia Reyes associated with the University of Texas Pan American, where much of the research on A VID has been conducted, added to the body of literature regarding AVID postsecondary performance and retention. Huerta, Watt, and Reyes' (2013) participants included 85 students from 12 Texas high schools who met at least one of the following criteria: AVID participation in high school for at least two years, maintained a 2.0 grade point average, and identified as part of an underrepresented minority group. In the study, $94 \%$ of the students were progressing towards college goals, however, only $31 \%$ of students met all three criteria for selection (Huerta, Watt, \& Reyes, 2013). The survey results indicated that for students the AVID elective, AVID teacher, AVID tutorial model, and organizational strategies were identified as factors in success. These findings were echoed by Espinosa's (2012) study of two southern California high schools as students identified help on the SAT, note taking, organization, and study groups as beneficial.

\section{AVID and student perceptions.}

Several studies include findings that suggest that AVID demonstrates long-term success in fostering transformative thinking and self-efficacy as well as success in helping students, primarily first generation and underrepresented minority students, resist elements of social reproduction that serve as barriers to success. Dissertations make up the primary portion of this 
section indicating that there is a growing interest in filling a student voice void.

Overwhelmingly, the dissertations present AVID as a positive program, however, all of the dissertations suffer from a lack of perspective, only reflecting the views of students who matriculated through the program.

Evidence suggests that when students are made aware of the benefits of AVID early on, attend a school with a structure that supports their enrollment in AVID and AP, and experience the "family like atmosphere" of AVID, that students tend to stay in the program (Bernhardt, 2013; Espinosa, 2012; Kouba, 2011). For example, Kouba's (2011) qualitative case study on the impact of AVID program on students' perceptions of college readiness draws readily from the work of Bourdieu (1986) and Conley (2007). Conley’s (2007) key components of college readiness are the primary framework, while Bourdieu (1986) lays the groundwork for the notion of "hidden curriculum," a phenomenon also observed and analyzed in Anyon (1980).

One critique of Kouba (2011), for example, is that the sample were all students who prior to, and including their involvement in AVID, maintained a 2.8 to $3.5 \mathrm{GPA}$. This is a slight contrast from the AVID profile, which defines a target AVID student as earning a GPA between 2.0 and 3.0. Therefore, the students in Kouba's study would be considered the top performers not only in AVID, but within the larger school community. Though limited, the sample yielded clear evidence that AVID increased access and student self-efficacy. The theme of access consists of four component: access to the "hidden curriculum," knowledge of academic skills, access to preAP and AP classes, and access to college knowledge (Kouba, 2011). The data included interviews with current college students who overwhelmingly credited AVID with their access to the processes and procedures of applying to college, including completing applications and financial aid forms. Kouba's (2011) conceptual model for self-efficacy included components of 
transformative thinking: maturity, strong self-perceptions, an ability to shift or be flexible as a learner, and perseverance. The community element of AVID, termed collective efficacy, also had a strong impact on transformative thinking (Kouba, 2011).

Kouba's (2011) findings were echoed in Bernhardt's (2013) field report on the how the AVID program seeks to increase the cultural capital of the program's target population, namely low-income students who will be the first in their families to attend college. Bernhardt (2013) and Espinosa (2012) investigated the concept of cultural capital within AVID, and the context for which the AVID program was created and why it remains a necessary program. The findings of both studies argue that AVID is both a means of disrupting social reproduction as well as a transmitter of social capital. AVID fosters academically minded peer communities, and helps shape student identity (Bernhardt, 2013). The AVID emphasis on meaningful relationships with families, mentors, and peers taps into a support system that already exists for many children, which contributes to the larger effort to build a supportive network of relationships (Bernhardt, 2013). Additionally, AVID teachers are categorized as "institutional change agents" (Espinosa, 2012 , p. 81 ) helping students build social capital in the form of academic behaviors, as well as navigational capital in terms of knowledge of requirements and processes necessary to enter college.

\section{Critiques of AVID.}

McCready (2014) illustrates weaknesses in the overall body of AVID literature. The qualitative data on AVID has established clear positive patterns, however, quantitative data on the success of AVID students compared to their non-AVID peers has demonstrated ambiguous results (2014). McCready establishes a need for more quantitative research. Additionally, only two studies have examined why students exited the AVID program (McCready, 2014; Watt, 
Johnston, Huerta, \& al., 2008). Although approached differently, McCready (2014) and Watt, Johnson, and Huerta (2008) both found that scheduling, dedication, and awareness seem to be the primary reasons students drop from the program, according to the interviews of students and teachers. However, in most cases, student attrition was placed under the category of "lacking determination" which was a broad category identified by the authors during data analysis (Watt, Johnston, Huerta, \& al., 2008, p. 35).

Although Watt, Johnston, Huerta, et al. (2008) identified the key factors that influence attrition, the findings did not necessarily explain how particular school environments controlled or managed those factors. McCready (2014) offered a more complicated analysis of student exits from the AVID program. McCready's (2014) categorized student exits into four categories: experiencing doubt, seeking alternatives, community inclusion/exclusion, and turning points. However, the authors determined the most concrete finding was that the majority of AVID exits occur after the first and second semester in the program, usually at the end of the first year (McCready, 2014). McCready's (2014) findings supported those of Watt, Huerta, and Johnson (2008) because in most cases, AVID students need to take an extra class in the sophomore year, which forces them to choose AVID over other electives.

\section{Current Discussions on the Combination of AVID and IB}

For the purpose of this study, one major gap in the literature exists with regard to schools that have integrated AVID and IB programs. Duarte's (2012) study of the impact of IB at two California high schools exemplifies this gap. In the discussion section titled, "School within a School," Duarte (2012) noted, "(LHS principal) attributed much...academic growth to the AVID program, science and technology magnet academy, and intervention programs (p. 90). Later he discusses that the both of his sites had "strong AVID programs" (p. 96), but there is no 
discussion as to how or why AVID worked in conjunction with the IB. In the implications and recommendations sections, Duarte mentions that perhaps scholars should investigate the effects of AVID on school culture, and while there are a fair number of studies exploring AVID and school culture, there are no scholarly studies on the combined effects of AVID and IB. And, practitioners are increasingly turning to blogs and site to site support for ideas and recommendations to better integrate the programs.

Adria Tate, a professional developer for AVID and employee of Denver Public Schools, has recently written a series of blogs that investigated the facilitators and barriers to effective combinations of AVID and IB Programs (Tate, 2014). The blogs, which include anecdotal evidence of district and school practices, echoed the need for scholarly literature. Another gap in the literature is insufficient research on the relationship between the AVID and IB programs from the student perspective, as noted by the heads of AVID and IB California at a recent conference in Sacramento (Gira \& Poole, 2013).

Thus far, Jeb Stuart High School in Fairfax County, Virginia offers one example of the blended relationship between AVID and IB programs, as well as surfacing some of the challenges. The school started with IB and brought in AVID as a support program. Welch's (2010) article about his own district, published in AVID's Access Magazine, illustrates one major shortfall of the blended programs, namely that AVID students do not have access to the full IB diploma due to scheduling conflicts. Ultimately, the blended approach of the school has increased the numbers of both AVID and IB students, however, this was made possible, at least in this case, by the collaboration of teachers, coordinators, and administrators (Welch, 2010).

In a report for AVID, Tate (2014) explored how various sites sought to implement the AVID and IB programs, identified patterns, and provided recommendations for promising 
practices, based on schools with identified successful integration. The recommendations include having the AVID and IB coordinator drive the master scheduling process, and extensive professional learning for all staff on both the AVID and IB mission and model (Tate, 2014). The definition of success, it should be noted, has not been validated by independent research, and is anecdotal based on the certification studies conducted by the AVID program and interviews conducted by Tate. However, the blog have sparked an interest in research. The International Baccalaureate Organization has recently developed an initiative called the E2: Excellence in Equity. The E2 initiative is currently in the middle of study examining schools that have demonstrated a commitment to the recruitment and inclusion of historically underrepresented students in the IB program (Misra, 2016).

Overall, the literature on AVID and IB suggests that programs, when implemented with fidelity and with high levels of support, have profound positive effects on student self-perception and academic performance, both in secondary and postsecondary settings (Bailey \& Mechur Karp, 2003; Burris, Wiley, Welner, \& Murphy, 2008; Coca, Johnson, Kelley-Kemple, \& et al, 2013; Conley, McGaughy, \& Davis-Molin, 2014; Espinosa, 2012; Kouba, 2011). However, the literature also indicates that teacher attitudes, coupled with detrimental structural practices, like tracking and master schedule challenges, are major impediments to the success of underrepresented students in advanced courses and college (Burris, Wiley, Welner, \& Murphy, 2008; Conchas, 2001; Koch, Slate, \& Moore, 2013; May \& Perna, 2011 ; Perna, May, Yee, \& al., 2013; Solarzano \& Ornelas, 2004; Yonezawa \& Jones, 2006). Another major finding from the body of literature on the IB is that students often exit the program with a feeling of accomplishment (Coca, Johnson, Kelley-Kemple, \& et al, 2013; Kyburg Dickenson, 2007). And 
lastly, AVID aids is a strong support for students in advanced courses, who also use the AVID strategies in their post-secondary education (Huerta, Watt, \& Reyes, 2013; Kouba, 2011). 


\section{Chapter 3: Methodology}

\section{Introduction}

This study explored how the combined enrollment in AVID and IB programs impact student academic self perceptions of their high school experience and their acceptance and transition to university. This study aimed to insert a unique student voice into the literature on the AVID and IB programs, and to discover what students found challenging and valuable about the experience. This chapter outlines the methodology of the student, beginning with the research questions and design.

\section{Research Questions}

This study aimed to answer the following questions:

- How do underrepresented students perceive the effects of combined/dual enrollment in the AVID and IB programs on their college readiness and academic and social transitions to college? What do students identify, if any, as valuable aspects of each program in their post-secondary success?

- How do underrepresented students perceive the impact of the A VID program on student experience in the IB program?

\section{Research Design}

In order to address the questions, a multi-method approach was employed, following the pattern of a convergent parallel design, though for sampling purposes, the quantitative data was gathered first (Creswell \& Plano Clark, 2011). The study began with a survey sent to graduates of two schools with IB and AVID programs. Following the survey, I conducted individual semistructured interviews with voluntary participants in order to paint a clearer picture of the experiences of the students. The data was integrated concurrently with the quantitative data used 
to triangulate with the findings of the qualitative data gathered from interviews with students, as well as IB and AVID coordinators, at the targeted schools (Creswell \& Plano Clark, 2011).

\section{Data Collection}

Quantitative questions include demographic information, including ethnicity, gender, the number of years enrolled in each program, and the IB courses and tests taken in high school. Data collected from AVID center was also used as part of constructing the context for the school sites. The instrument included questions regarding college matriculation and grade point average, the role of both AVID and IB. The survey used Likert scale questions designed to determine the level of preparation for the four domains of college readiness, as well as elements of Yosso's (2005) community cultural wealth. College readiness was measured using four components derived from a study conducted by Conley regarding college readiness practices at 38 high schools across the nation (Conley, McGaughy, \& Kirtner, 2010). The questions regarding community culture wealth were embedded in the college readiness domains as indicated in the conceptual framework. The quantitative questions aided in determining larger trends in student perception since the interview participants was a relatively small number.

The qualitative analysis will seek to explain, from the students' perspective, what the values and limitations were of the IB and AVID programs. Although understanding the student experience is the center of the study, knowledge, and insight, from AVID, and IB coordinators provided contextual background for the level of integration between the programs, as well as the relative strength of each program. One proposition is that was that schools with highly integrated AVID and IB programs will result in higher retention and higher GPAs for first generation, socioeconomically disadvantaged students. Anticipated values of the AVID program include the 
cohort model of the classes as a support structure, the tutorial portion of the elective course, and the explicit instruction in reading and writing (Huerta, Watt, \& Reyes, 2013).

\section{Role of the Researcher}

Throughout the course of this study, I taught AP US History and AVID, and served as the AVID coordinator, in a suburban high school with a predominantly Latino and socioeconomically disadvantaged population. I had previously worked at a predominantly White and affluent institution teaching the IB History of the Americas course. During the three years of this research project, my school site adopted the IB Diploma program, in which I am slated to teach the History of the Americas and Theory of Knowledge courses. The decision to "go IB" at my site originated as a reform effort from the school community, and the questions and findings discussed herein organically arose out of IB journey at my school site. Because of these developments, this project became a matter of great personal and professional importance, as the findings will guide my professional practice.

Prior to this study, I was, and continue to be, a proponent of the AVID and IB programs, and had initially hoped to study the population at my site. Because our program would not be ready, I decided to explore the experiences of students from schools currently offering both the AVID and IB programs. Although an outsider to the specific site targeted for the study, my experience with AVID and IB allowed me to gain access and trust with both coordinators and participants. The coordinators of each program were invaluable participants providing the contexts of their programs, and helping me gain access to graduates and students who would fit the selection demographics. 


\section{Population and Sample}

Because of the limited availability of students, the sample is one of convenience. The ideal participants were first and second year college students who were concurrently enrolled in AVID and IB in high school, and must fit the "AVID Profile." AVID students are, generally: first in their families to attend college, underrepresented (e.g. ethnic minorities, and socioeconomically disadvantaged populations) in institutions of higher education, and need to have started the AVID program with a GPA of 2.0-3.0. In some circumstances, there are students enroll in AVID because of unique circumstances, despite the fact that they may not meet the usual selection criteria. The students will have graduated from one of two California high Schools that offer both the AVID and IB programs. The coordinators of AVID and IB was from the same schools and may or may not have known the students.

The following steps were taken to obtain the participants. The first step was to contact the coordinators of AVID and IB at California schools, because they have access to the high school performance data for students, as well as names and contact information of senior AVID teachers, and ultimately students for potential interviews. Potential respondents will receive a survey that also includes a question as to whether they would be willing to participate in individual interviews. Using convenience sampling, respondents were selected from those who volunteered on the survey.

The intended sample of students consists of 30-50 survey respondents who are first and second year college students, and who graduated from high schools that had both AVID and IB Diploma Programs. The actual number of respondents was 25. From the participants, seven were selected for interviews, in addition to two or three IB and AVID coordinators at the same schools. 


\section{Data Analysis}

Phase one of the study included introductory survey with questions relevant to Yosso's theory of cultural wealth and Conley's theory of the four domains of college readiness. The purpose of the survey was for students to self-identify individual levels of preparation in the four domains of college readiness, and to discern if their preparation came more from IB, AVID, or both. Additionally, the instrument provided the basic framework for the interviews by creating a quantitative expression of success and perceived values of each program. The goal of the survey was to explore the following:

1. Did the students matriculating through college attribute portions of their success to one program or another?

2. Did the students perceive that IB or AVID emphasized the elements of community cultural wealth?

The survey examined the perceptions of students regarding support for their aspirational, linguistic, familial, and navigational capital. The concepts of preparedness, resistance, and social capital were further investigated during the interview research and analysis, and in conjunction with the concepts included in the survey. Basic descriptive statistical analysis such as frequency, percent, and cross tabs, were used first to determine if there are relationships between particular AVID experiences and IB success, and to determine whether one element of AVID or IB is prevalent across the sample size. In a modified explanatory manner, interviews were used to interpret the survey data, and also to delve into topics that were not covered thoroughly in the survey. Additional comments to the open-ended questions were analyzed using first and second cycle coding. 
The survey yielded 25 respondents, 8 of whom agreed to be interviewed. In total, seven participants were selected for semi-structured interviews in phase two of the study. All interviews were recorded, and a gloss of each interview was written and analyzed for emerging themes as a whole before the more in-depth analysis of the full transcription. Upon complete transcription, the qualitative data, primarily data memos and verbatim interview transcripts, underwent a first cycle coding consisting of four methods of coding: descriptive, evaluative, affective, and in vivo in order to induce patterns and themes from the data (Miles, Huberman, \& Saldana, 2014). After the initial coding phase, I employed a variety of second cycle coding methods to arrive at categories and emerging themes. The data was grouped first by program, and then, according to theories of both Conley and Yosso. Throughout the process, I used pivot table to explore and conduct basic quantitative analysis of the qualitative data. The survey responses triangulate the qualitative data by cross-referencing with the interview data in order to determine whether the themes emerging from the interviews were consistent with the larger sample (Creswell \& Plano Clark, 2011).

\section{Limitations}

Much of the research on AVID success is based on students have met the requirements for participation in the AVID program (completion of A-G requirements, 2.0 or above grade point average, and participation in advanced coursework). One major limitation to the research on AVID is that is does not take into account the experiences, academic performance, and matriculation of students who have been exited from the program due to behavior or grades. This study continues in this theme as all interview respondents and survey responses graduated from the AVID program. 
Another limitation is the sample size with 25 responses out of the 80 students who received the survey. This led to a small pool of potential interviews, and I interviewed all but one student who volunteered. In addition, while there were several students who did not identify as Latino, all of the interview participants identified as Latino except one. So while this study may provide insight into the experience of Latino student, it does not adequately represent the population of survey respondents. Additionally, all of the students interviewed attend the same high school, though they graduated in different years.

A third limitation is potential researcher bias as I am a practitioner and advocate of both programs. I added the open-ended questions as part of the survey to provide opportunities to participants to express their opinions on a particular set of questions if they felt that the survey was limited. I also added "other" as an option on several questions so that participants could add responses they felt were missing in the data. In terms of the interviews, I asked the same questions about each program, in the hopes of gaining multiple perspectives on each program. I asked each student to assess the values and limits of each program in order to gain a greater perspective on their experience. 


\section{Chapter 4: Findings}

The primary goal of this study is to contribute to the literature on both AVID and IB by adding student voice to the literature on AVID and IB. The other focal point of the study is to explore the issues students identified as barriers to success in the IB program and their university experiences. It is a goal of this study to identify practices that students find valuable from their combined enrollment in AVID and IB with the hope of increasing historically underrepresented student participation in the IB program, as well as acceptance, retention, and graduation in postsecondary education.

The findings of this study shed light on the experience of underrepresented students who enrolled in both the AVID and the International Baccalaureate Diploma Program in high school. The findings address primarily what students identify as values and limits of each program with respect to aspirations, academic and social self-perception, academic performance, and their path to university. The stories of students humanize the AVID and IB programs, and provide necessary insight into promising practices that can be employed by AVID and IB coordinators in increasing participation and bettering the experiences of the students in the programs. This chapter begins with a summary of the survey participants and portraits of the interview subjects. The rest of the chapter is organized by the four themes that emerged from the data: Struggle to Belong, the Double Effect, Covert and Overt College Knowledge, and College Confidence.

\section{Survey Respondents}


The survey yielded 25 participants, $44 \%$ of whom graduated in 2013 . Respondents identifying as Hispanic / Latino were the dominant ethnic group with 56\%, with the next largest group, 20\% identifying as White with European heritage (Figure 2). There was a fairly even distribution of family income with $56 \%$ percent of students growing up in homes with household incomes under $\$ 60,000$ (Figure 3), well under the median incomes of $\$ 78,000$ per year for San Francisco County, and the $\$ 91,000$ and $\$ 93,000$ per year median incomes of San Mateo and Santa Clara counties respectively (US Census Bureau, 2015).

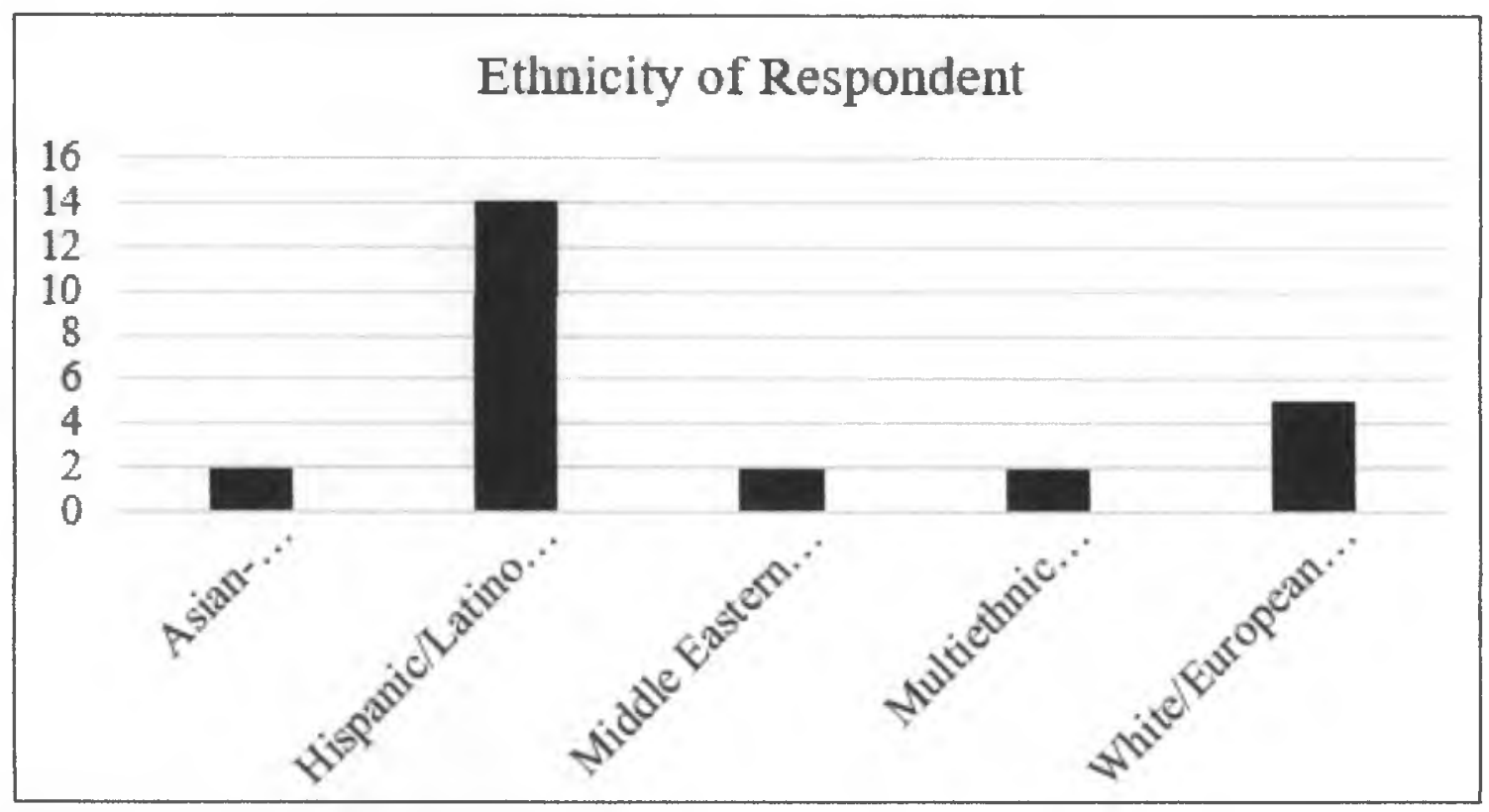

Figure 2: Ethnicity of respondents 


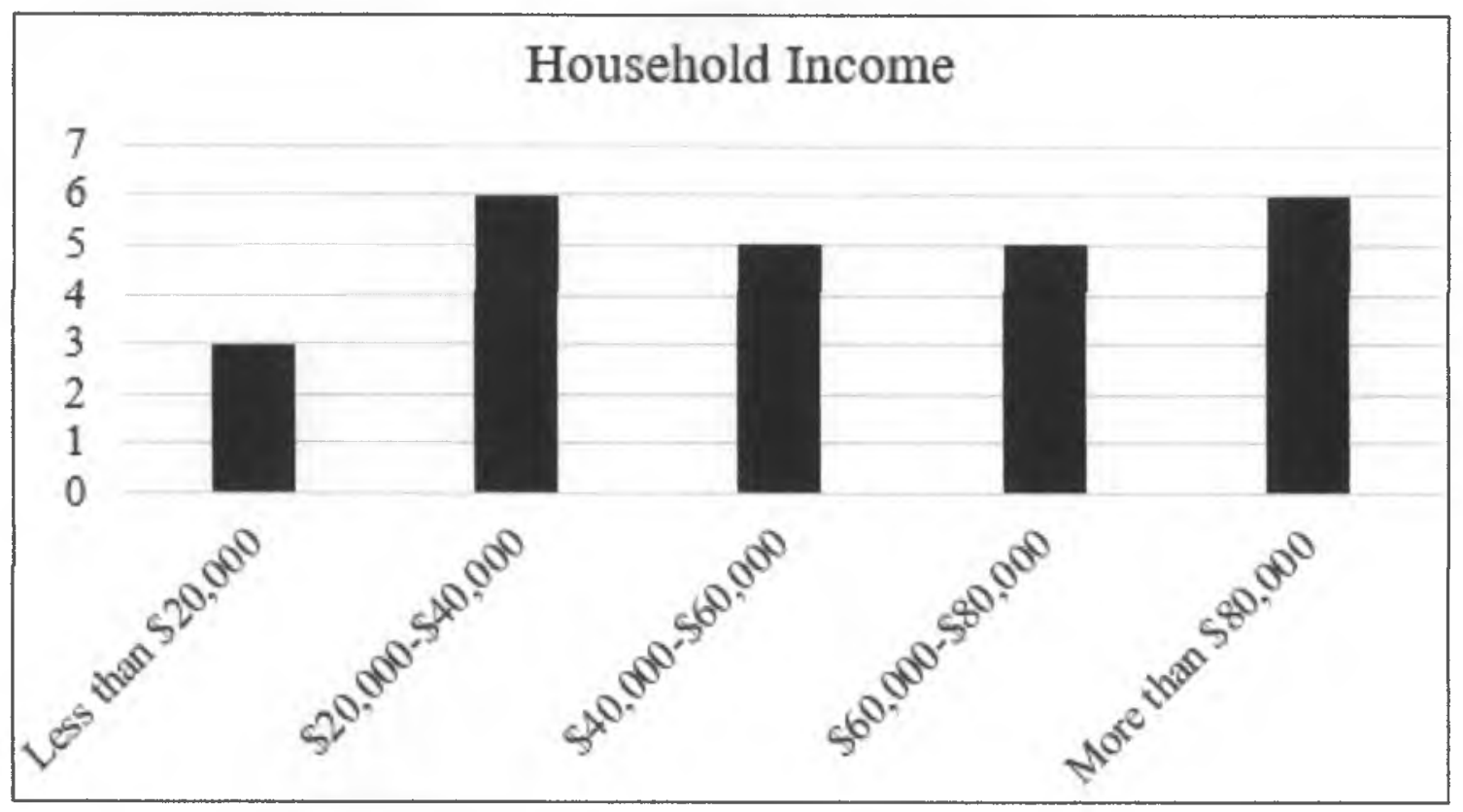

Over $70 \%$ of respondents were first generation college students, including $32 \%$ whose parents did not graduate from high school.

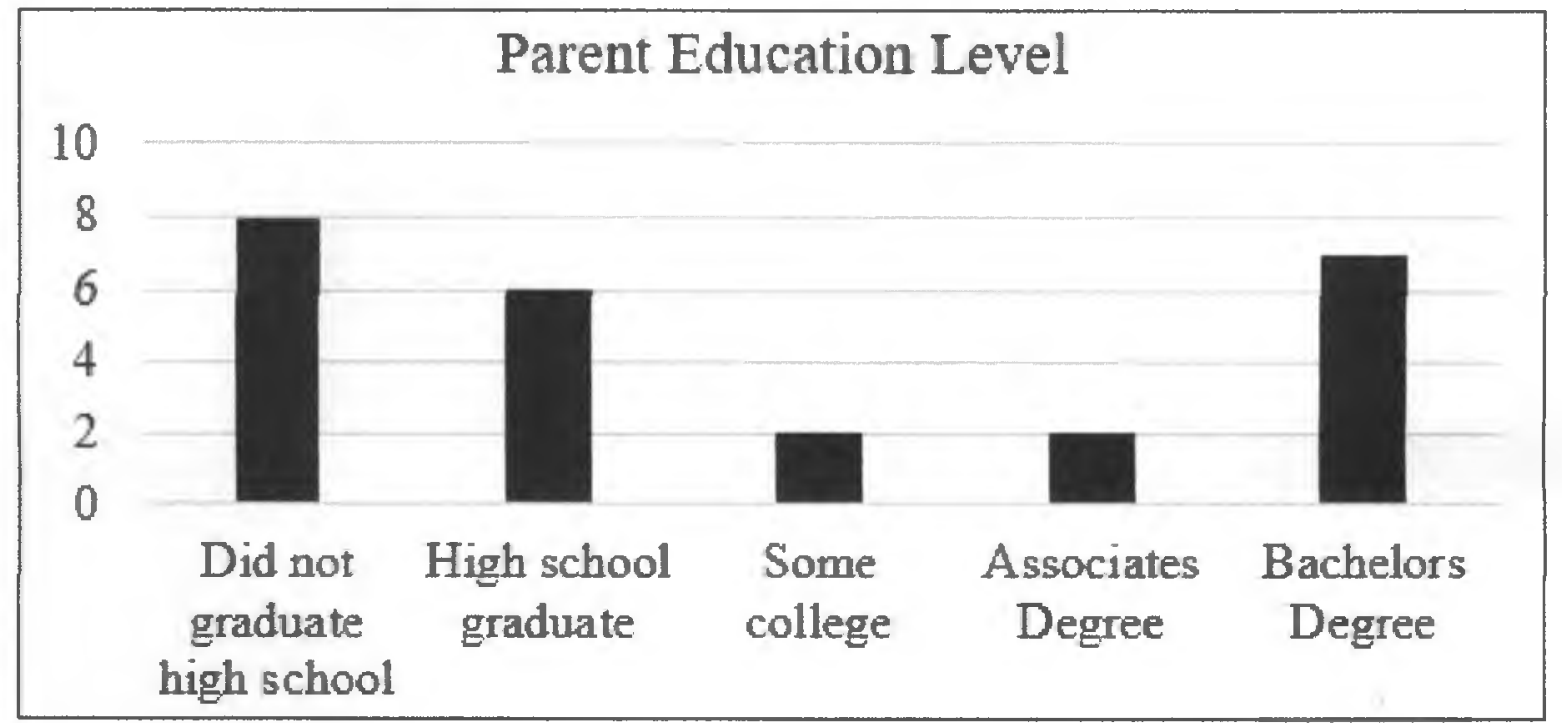

Figure 4: Parent education levels 
Overall, the students in the survey fit the AVID profile as underrepresented due to socioeconomic, ethnic, or generational status. Additionally, all students graduated high school with a 2.5 or above, and all, except one, were enrolled in AVID all four years of high school.

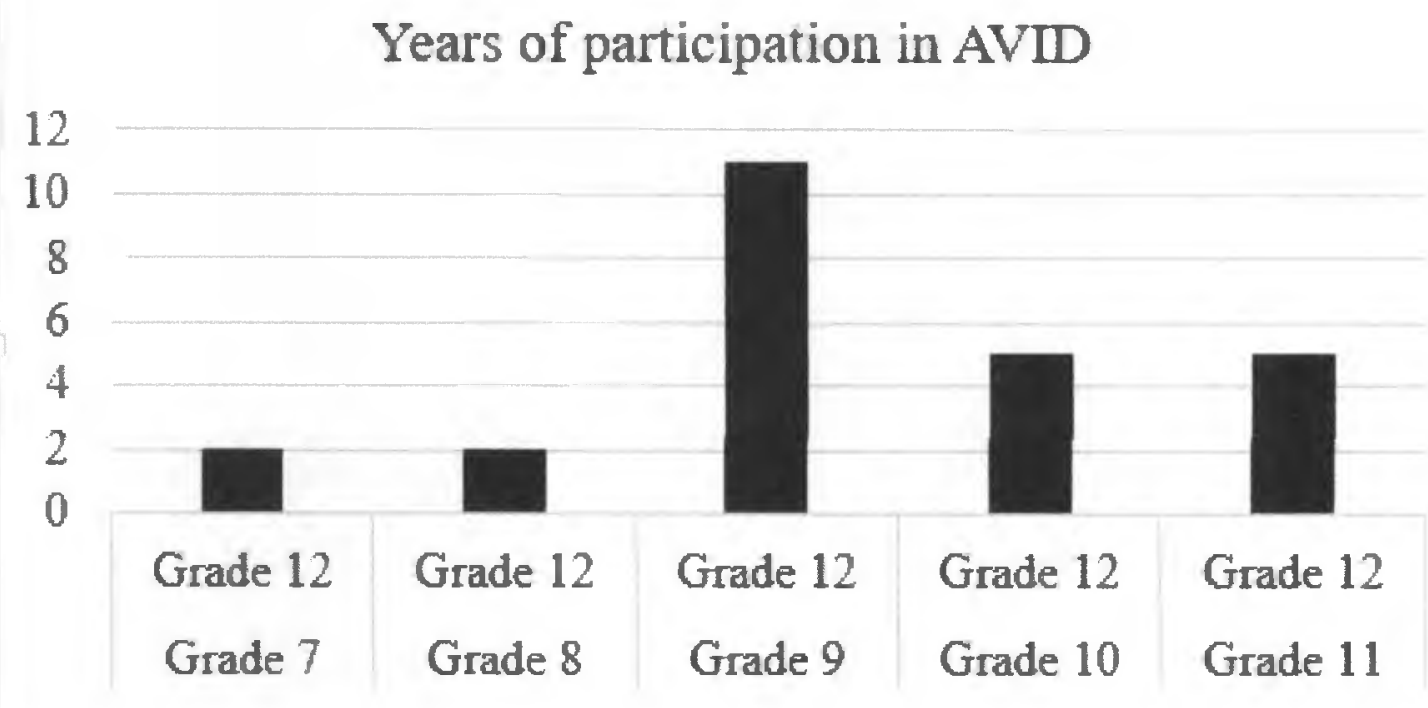

Figure 5: Years in AVID

\section{Portraits of the Participants:}

The following is an introduction to the interview subjects, although for the purpose of confidentiality, I have reconfigured the various identifying factors of each participant into a series of student portraits. In some cases, specific locations or group have been changed or generalized for the protection of student identity. Additionally, student who volunteered to be interviewed were identified in the survey by email address, thus the identifier of "Survey Respondent" is any student who completed the survey but did not wish to be interviewed. 


\begin{tabular}{|c|c|c|c|c|c|c|c|c|}
\hline Firticipant & Salf-ledentifying Quates & $\begin{array}{l}\text { Parent } \\
\text { Ethestim } \\
\text { Lerel: }\end{array}$ & $\begin{array}{l}\text { Fantly } \\
\text { Incocuse } \\
\text { Lerel }\end{array}$ & Pthmicity & Gadix & $\begin{array}{l}\text { Yeas a } \\
\text { AVID }\end{array}$ & IB Partikipaticm & $\begin{array}{l}\text { Thye of } \\
\text { Callege }\end{array}$ \\
\hline Alex & 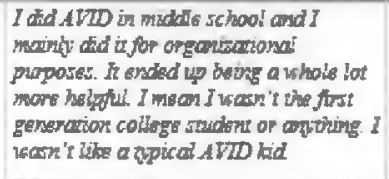 & $\begin{array}{l}\text { Bachelor's } \\
\text { Degree }\end{array}$ & $\begin{array}{c}\text { Mare } \\
\text { thom } \\
580,000\end{array}$ & $\begin{array}{l}\text { Asian- } \\
\text { American } \\
\text { Asian } \\
\text { Heritage }\end{array}$ & Fensile & 4 & Certificate & $\begin{array}{l}\text { Private } \\
\text { college }\end{array}$ \\
\hline Hailey: & 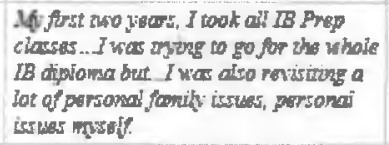 & $\begin{array}{c}\text { Bachelor's } \\
\text { Degree }\end{array}$ & $\begin{array}{l}160,000 \\
\$ 80,000\end{array}$ & $\begin{array}{l}\text { Hispanicl } \\
\text { Lnino } \\
\text { Hertige }\end{array}$ & Fenale & 4 & Cerificare & $\begin{array}{l}\text { Private } \\
\text { college }\end{array}$ \\
\hline Jerus & 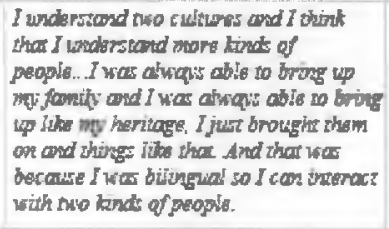 & Same college & $\begin{array}{l}\$ 20,000- \\
\$ 40,000\end{array}$ & $\begin{array}{l}\text { Hispavicl } \\
\text { Letino } \\
\text { Hertitge }\end{array}$ & Male & 4 & Certificale & $\begin{array}{l}\text { Califormia } \\
\text { State } \\
\text { University }\end{array}$ \\
\hline Jolio & 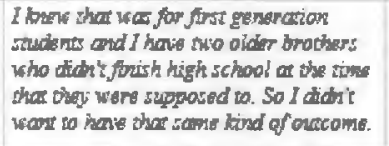 & $\begin{array}{l}\text { Did not } \\
\text { graduate high } \\
\text { school }\end{array}$ & $\begin{array}{l}\$ 20,000- \\
\$ 40,000\end{array}$ & $\begin{array}{l}\text { Hispanic } \\
\text { Latino } \\
\text { Heritzge }\end{array}$ & Male & 4 & $\begin{array}{l}\text { Foll Diploma } \\
\text { Strudent }\end{array}$ & $\begin{array}{l}\text { California } \\
\text { State } \\
\text { Luivergity }\end{array}$ \\
\hline Lizbeth & 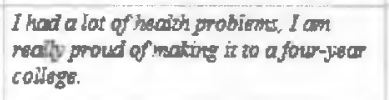 & $\begin{array}{c}\text { Bachelor's } \\
\text { Degree }\end{array}$ & $\begin{array}{l}\$ 50,000- \\
\$ 80,000\end{array}$ & $\begin{array}{l}\text { Mfatiethnic } \\
\text { Heritage }\end{array}$ & Fensle & 3 & Centificare & $\begin{array}{l}\text { Cinversity of } \\
\text { Califomia }\end{array}$ \\
\hline Nick & 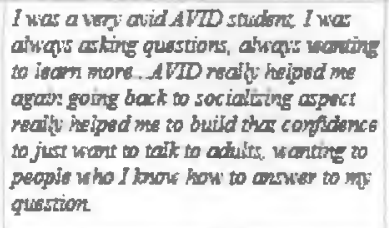 & $\begin{array}{l}\text { Did not } \\
\text { granuate bigh } \\
\text { school }\end{array}$ & $\begin{array}{l}\$ 40,000 \\
360,000\end{array}$ & $\begin{array}{l}\text { Hispanicl } \\
\text { Lationo } \\
\text { Herituge }\end{array}$ & Male & 4 & Foll Dyplama & $\begin{array}{l}\text { Prixate } \\
\text { College }\end{array}$ \\
\hline Sim & 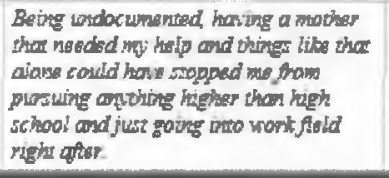 & $\begin{array}{l}\text { Did not } \\
\text { gratuate high } \\
\text { school }\end{array}$ & $\begin{array}{l}\text { Less than } \\
\$ 20,000\end{array}$ & $\begin{array}{l}\text { Hispanic } \\
\text { Latino } \\
\text { Heritgege }\end{array}$ & Fensle & 4 & Cerrificate & $\begin{array}{l}\text { Liniresity of } \\
\text { Califomia }\end{array}$ \\
\hline
\end{tabular}

Table 1: Demographics of interview participants

Alex is a second year university student, with college-educated parents, majoring in communications, and attending a private liberal arts college. She did not identify as a "typical" AVID kid because her parents graduated from college, and yet explained that she entered the program for help with organization, time management, and getting to college. She spoke extensively of how AVID opened her eyes to the experience of Latino students, as well as the segregation and struggles that students faced on the campus. Over $84 \%$ of Alex's interview was coded as positively, and she credits the IB program with easing her academic transition to 
college, and AVID for her success in the IB program, a common theme across the interviews and survey data.

Nick graduated with a full IB diploma, and is currently majoring in humanities. He attends a private liberal arts college, though he has spent a portion of his college years studying abroad. He identifies as Latino and an "avid AVID student." Nick's data show a 58\% positive commentary, indicating a predominantly a predominantly positive experience in the AVID and IB program. Nick spoke openly during his interview about wrestling with maintaining his academic identity and a sense of social and personal confidence. He offered a very telling summary of his experience essentially stating that even though he achieved everything he wanted to academically, he never felt successful or that he belonged in the IB program. However, he said that the IB prepared him for college and that AVID served as an adequate support system for his decisions about college.

Julio, a Latino and first generation student, also graduated with full IB diploma, though he noted that if he could go back to high school, he would not have completed the diploma. For Julio, the workload to gain the IB Diploma was not worth the gain. He stated that he could have earned just as many college credits without completing the Theory of Knowledge course, community service, and extended essay requirements. Julio's story indicates that he was always highly motivated, he mentions talking to a counselor as a ninth grader because he believed he was placed inaccurately in his high school classes. Though he struggled in his IB journey, he credits IB as the source of his academic preparation, and characterizes AVID as the place where he learned to socialize and communicate academically. Just over $56 \%$ of his comments coded positively, and while he struggled in the IB program, he maintained above a 3.5 GPA in high school. He is the first in his family to attend college, and currently attends a CSU, majoring in 
communications. His family's background was a primary motivator for his choices in high school and college, and he hopes to have a career helping underrepresented youth gain access to higher education.

Sierra, a Latina and first generation student, is a student in the UC system currently majoring in humanities and communications, with plans to attend graduate school after she earns her bachelor's degree. She, like Julio, has the goal of helping underrepresented youth succeed in higher education, perhaps working in the University of California system. She is very close to her family, and her family's journey to the US and their struggles serve as her motivation. She credited the IB program with her ability to succeed academically in college, but credits AVID with her ability to get to college and succeed in the IB program. Over $66 \%$ of her comments identified AVID and IB as positive influences on her academic and social identities, as well as her decisions to attend university.

Jesus identifies as Latino and first generation, and is currently enrolled in the CSU system and majoring in the arts. His motivation was derived from watching both of his brothers drop out of high school. He expressed pride in his bilingualism noting that he can understand two cultures and he can engage with multiple types of people. His commentary was overwhelmingly positive, with $86 \%$ positive responses about his experience in both programs. He primarily credited his positive high school experience to his AVID class, and his teacher, though he credits the IB with his academic skills.

Hailey is a Latina, first generation college student, who attends a small private college in California currently majoring in information technology. Like many of the interview participants, Hailey credits IB with her academic preparation for college. However, she is the 
only participant with a predominantly negative AVID experience. Hailey had $23 \%$ positively coded comments, and $58 \%$ negatively coded. Hailey expressed that AVID did not supply her with the necessary support, and so she chose to search for support outside of AVID and the school.

Lizbeth currently attends a UC campus, majoring in communications. Lizbeth was an IB certificate student who took four IB classes. She credits AVID with her academic preparation, primarily in the area of public speaking, and with keeping her "on the right track." She credited the IB program with her writing ability. She also said she has received praise for her public speaking and wiring skills from her university professors, which has become of source of confidence. Lizbeth was one of the few students who felt that her IB and AVID programs were connected and complimentary. Lizbeth is also one of the few students who took the survey who is not a first generation college student. The other unique perspective provided by Lizbeth is that she voluntarily exited the AVID program in the $10^{\text {th }}$ grade, and then reapplied and was granted readmission in her junior year.

\section{Struggle to Belong}

The first theme to emerge from the data was the struggle of belonging that AVID students experienced in the IB program. This section will highlight the three major categories that emerged from the data beginning with the student perception that the IB program is for white, affluent, students with college-educated parents and that the AVID program is for Latino students from socioeconomically disadvantaged backgrounds. One of the more surprising developments regarding the inclusion and value of the participants' linguistic capital will follow this section. Lastly, I will discuss the struggles of the students to negotiate the workload of the IB program. 


\section{Struggle to Belong: Separate Programs:" IB is white and AVID is Latino"}

Overwhelmingly, the AVID and IB programs were viewed as separate entities by the interviewees and survey respondents. The students repeatedly expressed sentiments that the programs were separated by a diversity gap.

Table 2: Response to inclusion of cultural heritage in the IB Program

\begin{tabular}{|l|l|l|l|}
\hline Ethnicity of Respondent & Not included or valued IB & Included IB & Included/valued IB \\
\hline $\begin{array}{l}\text { A.sian-Aimerican } \\
\text { Asian Heritage }(N=2)\end{array}$ & $50.00 \%$ & $0.00 \%$ & $50.00 \%$ \\
\hline Hispanic/Latino Heritage $(N=14)$ & $50.00 \%$ & $7.14 \%$ & $42.86 \%$ \\
\hline Middle Eastern Heritage $(N=2)$ & $100.00 \%$ & $0.00 \%$ & $0.00 \%$ \\
\hline Multiethnic Heritage $(N=2)$ & $0.00 \%$ & $0.00 \%$ & $100.00 \%$ \\
\hline White/European Heritage $(N=5)$ & $60.00 \%$ & $20.00 \%$ & $20.00 \%$ \\
\hline
\end{tabular}

Table 3: Response to inclusion of cultural heritage in the AVID Program

\begin{tabular}{|l|l|l|l|}
\hline Ethnicity & Not included or valued AVID & inciuded AVID & Included/valued AVID \\
\hline $\begin{array}{l}\text { Asian-Aimerican/ } \\
\text { Asian Heritage }(N=2)\end{array}$ & $0.00 \%$ & $50.00 \%$ & $50.00 \%$ \\
\hline Hispanic/Latino Heritage $(N=14)$ & $7.14 \%$ & $14.29 \%$ & $78.57 \%$ \\
\hline Middle Eastern Heritage $(N=2)$ & $0.00 \%$ & $50.00 \%$ & $50.00 \%$ \\
\hline Multiethnic Heritage $(N=2)$ & $0.00 \%$ & $0.00 \%$ & $100.00 \%$ \\
\hline White/European Heritage $(N=5)$ & $20.00 \%$ & $60.00 \%$ & $20.00 \%$ \\
\hline
\end{tabular}

The survey data revealed that while various ethnic groups felt that their ethnic identity was included in both programs, there was a significant difference for Latino participants. Half of Latino participants did not consider their culture included or valued in their IB experience (Table 2) compared to $78 \%$ who experienced that their culture was included and valued in AVID (Table 3). Although this could be dependent on the IB classes taken by these students, it does 
demonstrate incongruence between the IB mission to create communities of diverse and internationally minded learners and the experience of historically underrepresented students in the program. These data, including the students who were interviewed and additional survey data from students who did not opt in for interviews, share a common language regarding the diversity gap and illustrate a perspective shared across the majority of participants that the IB program is for Whites while AVID is for Latinos.

Nick: Okay, so I feel like there is a disconnect between AVID and IB primarily because added tended to have only Latinos in that program and then we had IB where it primarily white with like a few Latinos.

Survey Respondent: Also, AVID is highly more valuable in my opinion than IB. There is a huge diversity gap between AVID and IB where IB tends to be largely white and unprepared to meet the needs of more students of color.

Hailey: They (IB and AVID) were very different because just to give you an example like the socio-economic of it, a lot of the students in AVID were Pacific Islander or something else. There weren't any white kids in there and then IB was very dominant and white people.

Every student interviewed either alluded to, or directly commented on the ethnic and socioeconomic divide between the AVID and IB programs. The excerpts above describe the IB program as "White" and ill equipped to meet the needs of students of color.

In both the survey and the interviews, students consistently reported that IB was for white affluent students with college educated parents, while the AVID program, though special, was for first generation students of color. Notably, all of the students interviewed and surveyed 
attended schools with majority Latino populations. However, the demographics of the school were not reflected in the IB classes, a struggle that IB programs throughout the state and country are attempting to remedy (Corcoran \& Gerry, 2010; May \& Perna, 2011; Misra, 2016).

Several categories emerged as all seven interviewees described feeling alienated, invisible, and underprepared upon their entry into the IB Diploma program as high school juniors. The following excerpts offer examples of how and why students felt excluded. Jesus and Sierra both infer that their "families" and "background" were not normal.

Sierra: I felt out of place being there, one, because being stereotypical I didn't fit the whole 'great family' type of thing where that's how I felt most of the classes whereas if you were in IB you had like to right kind of background fitting for it. Lisbeth: IB, in a way, probably decreased [my confidence]. In AVID, I was seen as like the top star, like the best student in the class. In IB, there were like these diploma students that were like 4.0 and above, and I thought like I was good, I was smart, but then compared to them, my work was kind of just average. And I kind of felt discouraged by that in my IB class.

The claim by Sierra that her family did not have the "right kind of background" indicates an awareness that she was venturing into classes not designed for her, specifically in terms of generation, ethnic, linguistic, and socioeconomic identity. In a similar fashion, Jesus explained how he and his AVID classmates did not feel strong enough to be in IB courses because of their "families."

Jesus: That goes a long way but I think that we felt that because of who we were and who our families were, that we compare ourselves to a lot of the majority 
students in our IB classes so we didn't feel like we were good enough or strong enough as them.

All seven students discussed how they could not relate to the students in their classes. Nick for example, said he would usually enter the classroom and look for another student of color to sit next to in order to relate to someone. He said, "I felt silenced in my IB classes." Nick, who earned an IB diploma and now attends a prestigious liberal arts university, could not admit success because how well he had done in high school; he never learned to speak up in class. He noted, "Well I definitely I guess the other - the academic, the arty side, I feel like I did kind of fulfill what IB wanted us to be and like creative thinkers and mindful thinkers for the future and everything." Nick's academic achievements did not equate to success in the IB program. In response to whether he considered himself a successful IB student, he stated, "I mean academic wise yeah sure but like I feel like just the speaking part, I felt like I failed to do that and like I failed to speak up." He grappled constantly between his academic and social identities, as evidenced by his statement at the end of the interview when he said, "I never felt like that connection to [IB students] and that's one of the reasons why I never felt comfortable speaking up and speaking to them [in class]... I felt like [my opinion] wasn't valued." Ultimately, the experiences describe above support the literature that already exists on the challenges of students in advanced courses. Underrepresented students often struggle in secondary education to achieve their aspirational goals while battling structural and social barriers to their success (Bernhardt, 2013; Burris, Wiley, Welner, \& Murphy, 2008; Conchas, 2001; Solarzano \& Ornelas, 2004; 2006). 


\section{Struggle to Belong: Linguistic Capital: "Spanish is good for passing the test"}

In addition to more generalized feelings of "not belonging" or "not fitting-in," was the unexpected finding, six out of the seven students interviewed did not identify being bilingual or bicultural as a value supported by the IB program. The IB mission is to develop students with strong academic and cultural skills who can succeed in the $21^{\text {st }}$ century, and the IB application requires the acknowledgement and celebration of primary and secondary languages of students (IBO, 2014).

Of the bilingual students who completed the survey, 50\% did not perceived bilingualism as a valued portion of the IB curriculum (Table 4). Three of the five bilingual students interviewed provided insight into this trend, and viewed their linguistic wealth as a means to an end, a skill necessary for passing the Language B test.

Julio: In IB, the only reason you needed to know in other language was to pass the exam.

Nick: I mean I didn't really see [bilingualism] as something I used in my IB English class or history... I wouldn't see it as like a full on strength and skill that you would use in those classes, only in Spanish.

Nick and Julio are explicitly state that Spanish was not useful in other classes, and while some students believed that their cultural knowledge benefitted them in other classes, they did not feel that their IB peers or teachers recognized linguistic capital as a value or skill.

The evidence indicates that in spite of the structural framing of the IB Diploma Program and the programmatic emphasis on using two languages, the important element of the value of bilingualism was lost. The following excerpt exemplifies the increased feelings of alienation that 
resulted from cursory attempts to connect to students' cultural heritage. In this case, the student had to present a topic for the IB extended essay, a 4000 word research paper that is completed by all of the diploma candidates. The student acknowledges the attempt by the teacher to encourage investigation into his heritage, while clearly resenting the fact that she ignored his interests and ultimately had no understanding of his culture. The following excerpt illustrates how careful teachers need to be when discussing issues of heritage and ethnicity with students. In this excerpt, Nick recounts an encounter with his Theory of Knowledge (TOK) teacher. The Theory of Knowledge course is considered an IB Core Course that is taken by all IB Diploma candidates. The course is essentially epistemology, focusing on the question, how do we "know" what we know.

Nick: Okay. One of my TOK teacher, I presented my extended essay piece to this German White lady. I presented to her my project and everything, my ideas and I was going to write about...the Hetch Hetchy water, you know, the Hetch Hetchy reservoir and everything. The startup and like creation of it and everything. Then she looked at me and said, "Don't you want to write something about Latinos." I looked at her and I was like, "No, I want to write something about environmentalism." Then she obviously looked very disappointed in me. She obviously didn't like my idea and wanted me to really reach out. She was like "think more about your culture"...as if she knew what my culture was. It was talked about but in the way that I didn't really wanted it to be.

In this case, the student had to present a topic for the IB extended essay, a 4000 word research paper that is completed by all of the diploma candidates. The student acknowledges the attempt by the teacher to encourage investigation into his heritage, while clearly resenting the 
fact that she ignored his interests and ultimately had no understanding of his culture. For the student, the teacher's attempt to "honor culture" appeared restrictive and superficial, and the student, as evidenced by the last two lines, felt increased alienation rather than inclusion.

Initially, I believed that support for multiple languages would be a highlight of the IB program because of its emphasis on multilingualism and educating students in the "mother tongue" (IBO, 2014). As a result, it was surprising that while $80 \%$ of the respondents identified as bilingual, only $16 \%$ of respondents stated that their linguistic background was equally valued in both programs, and not one student linked the value of bilingualism to the IB program (Table 4).

Table 4: Perceptions of the value of linguistic wealth in the IB program

\begin{tabular}{|l|l|l|l|l|}
\hline Ethnicity & $\begin{array}{l}\text { Not included or valued } \\
I B\end{array}$ & $\begin{array}{l}\text { Included in } \\
\text { IB }\end{array}$ & $\begin{array}{l}\text { Inciudedivaiued } \\
\text { IB }\end{array}$ & $\begin{array}{l}\text { Not an English } \\
\text { learner }\end{array}$ \\
\hline $\begin{array}{l}\text { A.sian-American/ } \\
\text { Asian Heritage }(N=2)\end{array}$ & $100.00 \%$ & $0.00 \%$ & $0.00 \%$ & $0.00 \%$ \\
\hline $\begin{array}{l}\text { Hispanic/Latino Heritage } \\
(N=14)\end{array}$ & $50.00 \%$ & $14.29 \%$ & $28.57 \%$ & $7.14 \%$ \\
\hline $\begin{array}{l}\text { Middle Eastern Heritage } \\
(N=2)\end{array}$ & $100.00 \%$ & $0.00 \%$ & $0.00 \%$ & $0.00 \%$ \\
\hline Multiethnic Heritage $(N=2)$ & $50.00 \%$ & $0.00 \%$ & $0.00 \%$ & $50.00 \%$ \\
\hline $\begin{array}{l}\text { White/European Heritage } \\
(N=5)\end{array}$ & $20.00 \%$ & $20.00 \%$ & $0.00 \%$ & $60.00 \%$ \\
\hline
\end{tabular}

This trend represents a missed opportunity on the part of teachers who did not capitalize on this area of linguistic wealth. For the teachers that actively sought to incorporate linguistic wealth, whether consciously or unconsciously, the effects on students were notable. For example, Hailey said, "there was only one teacher... who would always address this issue [of self imposed separation in the IB classroom]... she ended up switching all our seats. [She would say] 
'I want you guys to switch it up and rearrange and get with other people.' She was the only teacher ever to address cultural issues and was culturally sensitive, [maybe] because she was half Mexican and half Polish." Yosso (2005) defines linguistic capital as the knowledge, skills, and confidence gained by growing up bilingual, and the IB program has the capacity to capitalize on that area of cultural wealth. This section, more than the others, exemplifies the detachment between the IB mission and the reality of the classroom.

\section{Struggle to Belong: Workload}

The students' perceptions of a choice between social alienation and academic success, versus a less academically challenging schedule but a sense of belonging discussed in Conchas' (2001) study of high performing Latino students is evident in this study as well. Students mentioned that despite the discomfort, they enrolled in IB classes because they wanted to be challenged and prepared for college, and did not want to enroll in the "regular" or "normal" classes.

Nick: I mean primarily because I wanted to one challenge myself but two because I wanted to just to look like I wasn't taking on just regular mainstream classes. I didn't want to have this English 1 or English 3 on my transcript.

In addition to issues of identity and belonging, many students expressed that they were underprepared, academically, for their entry into the IB program, whether they had been enrolled in the IB preparation courses or not. One student who earned the full diploma, and so essentially started his first year at university with sophomore status reflected that if he had the option to go back, he would not have completed the full diploma, noting that he felt much of the IB Diploma was about completing requirements and not about learning and growing. He felt that the Theory 
of Knowledge class was a waste of time, and he still could have earned plenty of college units passing a series of IB exams rather than taking on the full Diploma course of study. This sentiment was echoed by a survey respondent who noted that the "[IB] does not adequately prepare you to be independent of everyone else nor does it give an honest reflection of what professors will expect." Additionally, Hailey also argued that the workload in IB was not at all similar to college because most students at university are only taking three or four classes instead of seven. She also said the workload and time management were at the heart of why she dropped out as a diploma candidate.

Although the majority of students expressed some sense of frustration with the volume of work in their IB classes, the excerpts below are also telling because they represent the various methods that students use to overcome the obstacles. Alex, the full diploma student above, did not feel positively about how he dealt with his workload, he noted that he just stayed quiet and kept his frustration to himself. The selections below illustrate the sheer sense of overwhelm that students experienced in their transition to the IB program.

Jesus: [I was] overwhelmed in IB mostly because the workload...but I would just stay up until 3 and do my work.

Nick: But in IB I always felt that constant I had so much homework and stressed out, I have a paper due and like 60 pages to read. I did feel overwhelmed all the time. I think I confronted and dealt with that in a bad way.

While Jesus acknowledges he would just stay up until three in the morning and Nick was not proud of the way he handled the stress, both students completed their work. Both students passed all of their IB classes and earned the college credit for the exam. Jesus mentioned that he 
would often discuss these frustrations with his peers in the AVID class, while Nick simply felt like he shut down emotionally. The experiences of Nick and Jesus are common, and I have observed AVID students in my classes work through the same sense of belonging and an overwhelming workload. In my experience, as an AVID teacher for the last eight years, the lack of confidence and workload causes a sense of paralysis in students, and often times they simply stop working. It is as though they need a break from the stress resulting from the academic and social pressures of advanced courses.

\section{Know: The "Double Effect" of Dual Enrollment in AVID and IB Programs}

Although students struggled with workload, and feeling like they were valued and belonged in the IB program, the second emerging theme was that students ended their experience with a sense of accomplishment, as explained in the excerpt below.

Sierra: In IB I felt kind of like one out of a couple. I just felt out of place. I think at first it lowered my self-esteem about myself and about being open about my background or my ethnicity or things like that. But then after a while when I got comfortable, maybe too comfortable, it actually boosts myself to being one in I guess not in a million but in that respect being one in 30 . I was very confident that, wow, I actually made it to this class or things like that. So, it boosts my confidence after I got over it. So it was like a double effect.

The double effect that Sierra describes was common across all but one of the interviews and a theme in the survey responses as well. The following section explores how the IB program influenced student confidence and then follows with a discussion on sources of student support. 
The first section discusses the role of teachers as motivators and mentors, while the second explores the value of peer relationships, found specifically in the AVID elective class.

\section{Increased academic and social self confidence}

Despite experiencing decreased confidence upon entering the IB program, the three excerpts below from Sierra, Alex, and the survey respondent reflect the experience of the majority of students interviewed and surveyed. Several students discussed their discomfort with IB, but the majority of students reflected that in the end they felt more confident about their abilities.

Survey Respondent: Although IB was challenging, all the work was worth it because it made me realize how capable I was of taking on challenges and working hard. I would say that both AVID and IB were the two biggest reasons why I went to college.

Alex: IB, I guess confidence is increased just in the sense that I could say I was in accelerated courses. Does that make sense? You know like talking about it...like you're a little more proud of what you're doing.

Lisbeth: Both programs are designed to get you prepared for college, even if it's hard at first. You know, I thought IB was super hard and I hated it. I wanted to get out of it in second year, but you can't. They don't let you. But then in the end, after seeing the IB scores and finding out that I don't even have to take my English requirement, it makes me so grateful that I took IB.

The excerpts above illustrate examples of resistant capital defined as the ability to engage in social justice actions that result in securing equality or freedom. In this case, student resistance 
took the form of conquering self-doubt, workload, and rigor of the IB program. Solarzano and Delgado-Bernal (2001) explored various actions of resistance ranging from self-defeating to transformational, whereby student act in a manner designed to "prove wrong" the individuals and systems that are obstacles to their success. The excerpts above, by using words and phrases like "pride," "capable," "boosts my confidence," demonstrate that the IB experience can result in transformational resistance. It also appears that the dual enrollment in AVID, where students experienced additional teacher and peer supports significantly influenced the appearance of the "double effect."

Julio: IB really enforced all of the beliefs AVID brought in because it allowed me to see within an actual experience it seeking in class that I could be exactly at a higher level with my peers

Nick: IB helped me with the more academic and writing component and that aspect. No, the first one was IB. The second one AVID helped me with the more socializing aspect and like the idea of speaking to professors. I kind of have like they both have helped me but in different ways.

Sierra and Jesus offer primary examples of the "double effect" of the IB program. Both students openly discussed feelings of frustration that ultimately ended with a feeling of accomplishment and confidence. The excerpts below tell Sierra's journey, and provide insight into how she learned to manage her workload.

Sierra: When I just got sent into IB, the first semester was rough because at it I wasn't accustomed to the workload. Because I also had a part-time job and everything so I thought I had to fair it out but once that extra workload came in I 
was like, oh, I need to prioritize more for studying or things like that... So in preparation I think it helped me a lot kind of almost a little lesson for almost the type of course I take in college more or less especially my freshman year.

At several points in the interview, Sierra had commented on how much she learned about communication from AVID, noting that at one point, "AVID became like her spokesperson." Her growth from a self-described "shy girl" struggling with the IB workload, to a confident student who credits the IB experience as part of her university success is evidence above. Jesus told a similar story, noting that he struggled to complete the work in high school, but then realizing that his experience with that struggle made him feel "stronger" and increased his confidence. Jesus also credited AVID as a place where he could voice his concerns and frustrations.

Jesus: I thought college was going to be super hard, which I'm not saying it isn't but there's a lot more time to do things. So even though the workload in IB felt bigger, stronger, I think it felt stronger because there was not as much time to do everything...

Ultimately, despite an initial dip in self-confidence, six of the seven participants exited high school -- and the AVID and IB programs -- with increased confidence about their college choices, academic preparation, and confidence in their ability to transition to college. This trend was supported by survey data as well. The findings in this study and recent studies exploring perceptions of underrepresented students in advanced courses indicate that participation in the AVID or IB programs leads to increased accomplishment and strong feelings of pride and 
confidence by the end of the experience (Coca, Johnson, Kelley-Kemple, \& et al, 2013; Kyburg Dickenson, 2007).

\section{Culture of Support: Teacher Encouragement}

For many students such a transformational experience was aided by their relationships with teachers. Every student interviewed mentioned an AVID or IB teacher who had a positive influence on their AVID and IB experience, a pattern that also emerged in the survey data. Teacher support primarily falls into two categories: cultural support and academic encouragement.

Teachers, especially AVID teachers, emerged as a primary source of linguistic and cultural validation. Although the value of Spanish language fluency did not transfer from the IB mission statement to the IB classroom for these students, several remarked that that they felt that their linguistic wealth was valued in their AVID class, and especially by their AVID teacher.

Julio: Well for AVID, it was very valued to know English and Spanish as both of the population that was served in my school that was first generation were people who knew Spanish of that primary language. So celebrated, it was very celebrated socially and culturally (in AVID).

For Julio, who struggled with a sense of belonging in IB, the AVID teacher "celebrating" his linguistic capital was a source of pride. The notion of pride was also explicit in other samples, often with students equating bilingualism with increased opportunities, as was the case with Nick and Sierra.

Nick: I remember because my AVID teacher was also bilingual and she was also bilingual in Spanish and English. So [she talked about] opportunity that you would 
have with knowing two languages. I kind of thought that was a good thing in AVID. Yeah, my AVID teacher did kind of presented to us and said oh because you're bilingual more people are going to like you, more career. You're going to have more career options with you. I kind of liked that.

Sierra: Because of that extra skill, I guess you could call it a skill, I think I got more of opportunities from my AVID teacher instead of other people being just one language.

All of the positive quotes about bilingualism related explicitly to the AVID classes indicating again that AVID was the place to celebrate culture. The issue of language and culture provides one specific example of how the relationship between AVID and IB can be symbiotic. However, the findings also indicate that the level of cultural and linguistic inclusion was dependent on what the dominant culture was in the classroom. For example, while Latinos felt that AVID provided a strong sense of cultural support, their Asian and Middle Eastern peers did not feel that IB or AVID included or valued their linguistic wealth. This indicates that while AVID valued the dominant culture in the AVID class, there is still room for growth, and a need to create inclusive environments for all participants.

Although AVID validated cultural and linguistic elements of the students, teachers, both in the IB and AVID program were credited as sources of academic support and encouragement.

Julio: What really shaped me was AVID that instructor for that program specifically that you can have all the hopes and dreams that you want but none of that is going to become a reality just by believing that you can do it. 
Alex: AVID was able to motivate kids, because IB was an option that a lot of these guys never even have considered... the teacher was great about, like, pushing kids to try and do more and achieve more.

Both Julio and Alex use the words indicative of aspirational wealth (Yosso, 2005) such as "motivate, hopes, and dreams" with reference to their teachers. Alex's remark is interesting because she sets herself apart from the group, but recognizes the impact the AVID teacher has on others. Alex did not identify as a "typical AVID student" primarily because her parents had bachelor's degrees, and she was the only participant who did not identify as being overwhelmed in the IB program. The phrase, "an option these guys had never considered" offers almost an outsider perspective of the AVID environment, despite her participation in the class. The language in the quote is one of an observer, and her observations about others in her class supports the experiences of students like Julio, who was "typical AVID student" who felt completely overwhelmed by IB and credited the AVID teacher with academic encouragement.

Survey Respondent: I had a hard time accepting whenever I didn't understand something or even acknowledging that I needed help during high school, especially in my IB classes. My relationship with my AVID teacher helped open my eyes to this (learning to ask for help).

Jesus: "Okay. So, junior year, I had [an IB]teacher...I admire that woman so much. I feel everything we've learned in class stuck with me and just the little, even the little things she would say about reading the world around us and things like that, that got me thinking a lot. So after class, I would spend like the rest of the day just 
pondering on what I learned and how I can view the world differently and think about if I'm really trying as hard as I can or if there's more I could do and just things like that. It made me, helps me learn to evaluate myself more. And I still do that. And that was something that I didn't do before her class and now I do. So I think it made a difference in who I am as a person but also as a student."

For Jesus, the IB teacher elicited reflection upon how the content connected to the world, but also, as noted later in the excerpt, challenged Jesus to evaluate and reflect on his actions. The act of reflection described by Jesus is also an element of the IB learner profile, which is a core component of the IB Diploma program (IBO, 2014). It is an also an element of Conley's (2007) "act" and "go" domains which consist of key learning skills and techniques as well as transitional knowledge. Reflection is part of goal setting and self-awareness, as well as identity and agency. Jesus clearly addresses self-awareness, goal setting, and agency as he discusses "pondering" his own effort and thinking about what he is learning and how he can apply it.

While Jesus and the survey respondent both had specific moments or skills that they attributed to specific teachers, Sierra captures the encompassing importance of the teachers. The following excerpt demonstrates how teachers both positively and negatively influenced Sierra, as well as how her teachers' attention was ultimately a catalyst for the confidence she felt at the end of the program.

Sierra: It all boiled down to the teachers for me... My AVID teacher worked pretty much hand in hand with my IB teachers checking in and kind of seeing where I needed help or where I was doing good, things like that... In IB, I think when my teachers started acknowledging me more and them themselves they are 
more comfortable with my opinion, so they started asking me questions directly and that helped me see that I was valuable student and my opinion mattered. So things like that, small things but it counts in the long run.

Sierra did not discuss any of the content that she learned in her classes. Instead, the primary focus of the majority of her comments were her relationships; she discussed her relationships with her peers, her teacher, and her family. As demonstrated above, for many of the students the relationships with the teachers was a crucial part of the transition from a self-perception that they did not belong in the IB program to a new perception that they not only belonged there, but could succeed as well. Students that experienced cross over with teachers in their AVID and IB class tended to identify more positively with both programs than students who felt that the programs were isolated.

\section{Culture of Support - Peers}

Julio: "This is gonna sound weird but I would have to say that we all felt challenged in kind of being taught to believe in myself"

Julio's sentiments illustrate the importance of peer relationships and an academic community for historically underrepresented students engaging in the rigorous IB program. Students consistently identified their AVID class as a safe community for both academic and social support. Additionally, students credited AVID with their success in their IB classes primarily because of the sense of belonging associated with the class. The two excerpts below illustrate the importance of family that is a key finding in much of the literature on AVID (Bernhardt, 2013; McCready, 2014; Watt, Johnston, Huerta, \& al., 2008). 
Survey Respondent: I lacked that motivation from my family and from home because my parents never even made it to middle school, so it wasn't as important for them and they didn't really push it on me.

Alex: AVID honestly helped... if I ever felt overwhelmed in IB classes, I would have AVID to fall back on. If I get notes, I'm having a classmate who could help me out with notes. I really have a good group of people that was there to have a background and that sort of stuff.

Survey Respondent: I feel that AVID as a community encouraged me to go to college.

Yosso (2005) defines familial capital as knowledge created, and nurtured, through culture, community, and history. She explains that in terms of cultural wealth, "family" may transcend traditional boundaries, and AVID appears to provide a surrogate sense of family for first generation students venturing into territory where their traditional family has no history. Multiple studies have acknowledged the value of AVID as a path to gaining cultural capital, or the knowledge of the dominant culture (Bernhardt, 2013; Espinosa, 2012; Kouba, 2011). However, the experiences of students in this study illustrate that while students may gain cultural capital through AVID, they are also creating their own sense of familial capital with their AVID peers.

Jesus: And also being able to see your average peers in your IB classes, it encourages you to try harder because you know that you guys are in the same boat and so you don't have to feel scared or you don't have to be intimidated by the other students. 
Sierra: And AVID, I think it helped a lot in that I felt other people from the other end of the spectrum that helped a lot seeing other people in the same shoes as me and all of us kind of striving for the same thing.

The excerpts above demonstrate the importance of peer connection and visibility in the IB program. For Jesus and Sierra, already struggling to fit into the IB world, the notion of being with students in the "same boat" or "same shoes" was a comfort, and an indication that they did belong in the program. For Jesus, having students in the "same boat" led to encouragement and alleviated some of his fear. For Sierra, having students in the "same shoes" was a source of motivation, and sense of community, and that they were part of a team.

In the end, the students dually enrolled in AVID and IB exhibited many of college readiness qualities in Conley's (2007) "Know" domain. The key content knowledge in that domain consists of understanding the construction of knowledge, the values of effort and challenge. The participants overwhelmingly felt accomplished due to their effort, they understood how to struggle in difficult academic circumstances and for many, the experience in IB cemented their confidence they would go to college.

\section{Go: Learning and Going to College}

Nick: Yeah definitely. I mean yeah in AVID I did it [learned about college] but like in IB I mean I feel like the fact that I was surrounded by these sets of people that had the motivation and had already this kind of sense of wanting to go to college...Primarily, because a lot of the families went to college and their siblings. I think because of that like I was surrounded by these people. I was able to move forward and like actually want to go to college myself. 
Nick's description of his college knowledge accurately reflects the experience of many of the participants. His description of learning about college in AVID has a "matter of fact" tone whereas his description of being surrounded by students who were expected to go to college had a positive effect on his aspirations. Nick's academic success (earning the IB Diploma) and decision to attend a private liberal arts college support AVID's policy of requiring enrollment in courses of rigor. However, his experience demonstrates another important, and indirect, secondary benefit, namely the peer knowledge that he gained through his interactions with his IB classmates.

The following section begins with an explanation of the "covert" college knowledge gained by AVID student in an IB environment, followed with a short discussion on barriers to college that resulted from the data. Lastly, this section ends with a discussion on the "overt" college knowledge resulting from the AVID program, and the role of teachers in students' postsecondary decisions.

\section{Covert Social Capital - College Knowledge (Go)}

Yosso (2005) argues that students of color continue to have high expectations, "hopes, and dreams" despite encountering institutional barriers, and that their networks of peer relationships and networks are important elements of community cultural wealth. Several students commented that there was an expectation of attending college in the IB classes, and that being around IB students with this attitude indirectly had a positive impact on their selfperception, and aspirations.

Julio: So, IB really pushed students to go at UC, push them to go to try Ivy Leagues. 
Alex: Most of the [IB] students were very prepared and knew exactly what colleges are we going apply to or how to apply the college and what kind of preparations that you needed.

Nick: IB was valuable because I was surrounded by people who wanted to go to college. In my junior year, people starting asking "where will you apply to colleges" and started talking about colleges I didn't know.

The student experiences in the IB classes increase student social capital, which then positively affected their aspirations. For many in this study, IB was a covert system of college knowledge, in that underrepresented students gained access to knowledge they deemed privileged. In Burris' detracking study (2008) there was a dramatic increase in the number of students of color participating and graduating from the IB program. This data offers one possible explanation, namely, that the removal of tracked English and math classes gave more students opportunities to engage with peers who, by the nature of socioeconomic status or the education levels of their parents, operated under a different set of expectations.

\section{Barriers to College Transition}

Although aspirational wealth is an important starting point, Nick's comment about IB students discussing college he did not know illustrates a core struggle for underrepresented students in their college journeys. As Julio stated, "it is not enough to want something; you have to put reality into action." Although $90 \%$ of high school seniors plan to attend college, a lack of information on financial aid or the procrastination of students and parents, results in a failure to complete the Federal Application for Student Aid (FAFSA) means far fewer numbers will attend college (Ross, White, Wright, \& Knapp, 2013). Ross, White, Wright, and Knapp (2013) also 
made the argument that acknowledged that first generation students, or those from socioeconomically disadvantaged backgrounds, often avoid applying for financial because the form is too complex, the timing is complicated, and intricate (Ross, White, Wright, \& Knapp, 2013). Sierra expressed the same sentiments when she said, "Right now we're living in a situation where a lot of people don't go to college because especially for financial aid reasons." She also expressed the sentiment that first generation students get overwhelmed with the whole process of applications and navigation of the college admissions process.

\section{Overt Social and Navigation Capital - College Knowledge (Go)}

Sierra: "I felt overwhelmed because I didn't know how to narrow it down and this is what I would have done differently, started to research on what colleges I wanted to go to."

Despite experiences like Sierra's, a majority of survey respondents, felt adequately or very prepared for navigating college portals and the financial aid system. The data below exemplify the benefit of overt instruction in "college knowledge." Because generational status is a key component for navigating the college applications, admission, and financial aid processes, the tables below reflect the level of preparation of students organized by the education level of their parents (Ross, White, Wright, \& Knapp, 2013). 
Table 5: Confidence level navigating the financial aid system

\begin{tabular}{|l|l|l|l|}
\hline Generational Status & $\begin{array}{l}\text { Very prepared - } \\
\text { Navigating } \\
\text { Financial Aid }\end{array}$ & $\begin{array}{l}\text { Adequately prepared - } \\
\text { Navigating Financial } \\
\text { Aid }\end{array}$ & $\begin{array}{l}\text { Somewhat prepared - } \\
\text { Navigating Financial } \\
\text { Aid }\end{array}$ \\
\hline Bachelor's Degree (N=6) & $14.29 \%$ & $57.14 \%$ & $28.57 \%$ \\
\hline $\begin{array}{l}\text { Associate's Degree } \\
(\text { N=2) }\end{array}$ & $50.00 \%$ & $0.00 \%$ & $50.00 \%$ \\
\hline Some college (N=2) & $50.00 \%$ & $50.00 \%$ & $0.00 \%$ \\
\hline $\begin{array}{l}\text { High school graduate } \\
(\text { N=6) }\end{array}$ & $50.00 \%$ & $50.00 \%$ & $0.00 \%$ \\
\hline $\begin{array}{l}\text { Did not graduate high school } \\
(\text { N=8) }\end{array}$ & $62.50 \%$ & $25.00 \%$ & $12.50 \%$ \\
\hline Grand Total & $44.00 \%$ & $40.00 \%$ & $16.00 \%$ \\
\hline
\end{tabular}

Table 6: Confidence level navigating college portals

\begin{tabular}{|l|l|l|l|}
\hline Generational Status & $\begin{array}{l}\text { Very prepared - - Navigating } \\
\text { Portals }\end{array}$ & $\begin{array}{l}\text { Adequately prepared - } \\
\text { Navigating Portals }\end{array}$ & $\begin{array}{l}\text { Somewhat prepared - } \\
\text { Navigating Portals }\end{array}$ \\
\hline $\begin{array}{l}\text { Bachelor's Degree } \\
(\text { N=6) }\end{array}$ & $42.86 \%$ & $28.57 \%$ & $28.57 \%$ \\
\hline $\begin{array}{l}\text { Associate's Degree } \\
(\text { N=2) }\end{array}$ & $50.00 \%$ & $0.00 \%$ & $50.00 \%$ \\
\hline Some college (N=2) & $50.00 \%$ & $50.00 \%$ & $0.00 \%$ \\
\hline $\begin{array}{l}\text { High school graduate } \\
(\text { N=6) }\end{array}$ & $50.00 \%$ & $33.33 \%$ & $16.67 \%$ \\
\hline $\begin{array}{l}\text { Did not graduate high } \\
\text { school } \\
\text { (N=8) }\end{array}$ & $50.00 \%$ & $37.50 \%$ & $12.50 \%$ \\
\hline \begin{tabular}{l} 
Grand Total \\
\hline
\end{tabular} & $48.00 \%$ & $32.00 \%$ & $20.00 \%$ \\
\hline
\end{tabular}

Tables 5 and 6 demonstrate the level of preparation students identified in the areas of navigating college portals and financial aid systems. Over $85 \%$ of first generation college students felt adequately prepared to navigate the college portal and financial aid systems. 
Table 7: College navigation knowledge by program

\begin{tabular}{|l|l|l|l|}
\hline $\begin{array}{l}\text { Generational Status } \\
\begin{array}{l}\text { Bachelor's Degree } \\
(\mathbf{N}=6)\end{array}\end{array}$ & Addressed in both programs & Addressed in AVID & Addressed in IB \\
\hline $\begin{array}{l}\text { Associate's Degree } \\
(\mathbf{N}=2)\end{array}$ & $0.00 \%$ & $100.00 \%$ & $0.00 \%$ \\
\hline Some college (N=2) & $0.00 \%$ & $100.00 \%$ & $0.00 \%$ \\
\hline $\begin{array}{l}\text { High school graduate } \\
(\mathbf{N = 6})\end{array}$ & $16.67 \%$ & $83.33 \%$ & $0.00 \%$ \\
\hline $\begin{array}{l}\text { Did not graduate high } \\
\text { school } \\
(\mathbf{N}=\mathbf{8})\end{array}$ & $12.50 \%$ & $75.00 \%$ & $0.00 \%$ \\
\hline Grand Total & $\mathbf{8 . 0 0 \%}$ & $\mathbf{8 8 . 0 0 \%}$ & $12.50 \%$ \\
\hline
\end{tabular}

Of the students identifying as adequately and very prepared for navigating college portals and financial aid, $76 \%$ said their preparation came from AVID, and $88 \%$ indicated that AVID was responsible for their knowledge of the financial aid system. Ironically, the students with collegeeducated parents felt the least confident with regard to financial aid and navigating college infrastructures, such a school portals. Because all of these students had been in AVID during grades 11 and 12, they had access to the AVID curriculum on these topics, however, these data create a question about where students who are not in AVID receive support for these questions. The interview data supports the survey data as students credited AVID as their primary source of college knowledge, ranging from field trips to completing applications and FAFSA. Whereas the students in the IB tended to influence students in a covert way, a sort of indirect access to college knowledge via increased social capital, AVID provided direct and overt access to college knowledge. 
Jesus: I learned about colleges was through AVID mostly because AVID provided us with college fairs that we could go and college field trips. And I think the biggest thing was the college field trips because you have to -- just like seeing campuses and being on them and then looking around students, listening to the tour guides, it motivates you to work hard because you want to be in a campus like that one day.

Survey Respondent: AVID taught me that I had the opportunity to and AVID showed me the path to get there. I was always well informed about college stuff, deadlines, and even financial aid. In fact, I was always helping my friends who weren't in AVID with college applications and FAFSA. I'm grateful for AVID!!

Survey Respondent: The support and push made it so much easier to get through the whole college application and selection process. My family knew very little about what needed to be done and I am a huge procrastinator so without AVID I probably would have struggled to get where I am today.

The excerpts above clearly illustrate was Conley (2007) identified in his "go" or "key transitional skills" category of college readiness. Each participant explicitly cites AVID as the place where students researched colleges, and met with their AVID teachers and families regarding decisions. The excerpts include both interview subjects and survey respondents, and the excerpts support the quantitative survey data that credits AVID with overt instruction in the navigating the college application and admission process.

Another category within this theme was the role of the teacher in increasing student navigation capital of the college application and admissions process. AVID teachers' 
relationships with students were a crucial component of this value, and most students credited, directly or indirectly, their teachers for the success of their college navigation system.

Survey Respondent: All of my IB teachers and the AVID teachers really supported each of us when we had questions about college and how it all worked.

In the excerpts below, Nick, Alex, Jesus, and Sierra all comment on how helpful it was to have a guide through the process. All four students appreciated the open dialogue that the teachers had with them and their parents.

Nick: But I think it's only because of the support that I have from teachers, the support that they gave me to leave California. I think without their support I wouldn't have gone because definitely my parents did not support me. They definitely did not like the idea of me going out of state. I guess that yeah, that was really useful.

Alex: Yeah, it definitely plays a huge role in me choosing to attend [private university]. I mean I met (about financial aid packages, and choice) with my teacher and my mom, which kind of put everything on the table, pros and cons, a few different times.

Jesus: Because I was conflicted about schools and I didn't know ultimately which one to choose...it wasn't until I had a meeting (including parents) with [AVID teacher] and [AVID Coordinator], it was a very small meeting, informal but still very helpful... 
Nick, Alex, and Jesus all mentioned the importance of having help navigating the college decision-making process. The AVID teacher served as a guide for them and their parents, helping to bridge the gap for families. For all three students, their experience going to college has also brought them closer with their families, a development that can be attributed to the family inclusion in the college process via AVID. Without AVID, as these student excerpts indicate, there would have been very little opportunity for their families to be part of the college process, thereby creating distance, especially with Nick, for example, who noted that his parents did not agree with his decision to attend schools out of state. However, when asked about his relationship with his family now that he attends school out of state, he said, "I feel like I has recently gone stronger as like a family...I mean I didn't really like feel excited and talking to my dad or my mom. But like whenever I'm college and I feel a phone -like on this call, I'm always like oh no, I have to call them back. I guess just like I feel more connected to them now that I'm over here and they're over there."

For Sierra, the role of the teacher was even more crucial. She discussed earlier that her mother's health had been her primary focus in high school, and she was worried that if she went to school to close to home, then her mother's health would take precedence over her academic success.

Sierra: "I realized how much my family situation which I had no control over was affecting me and my decisions. For example, I could have done the diploma or not have to work and get better grades in high school. So things like that that I saw in college although I didn't go that as far away because I still wanted to be close to my mom, I went to [college] that's like a two-hour drive [away]. So I'm close enough but far enough to get my space and grow individually without my family." 
In partnership with her AVID teacher, Sierra selected a school farther away than she originally planned, a choice that has improved her relationship with her family, and has increased her independence.

\section{Think and Act Like a College Student}

The combination of AVID and IB results in a smooth transition from high school to college. The data suggests that the IB program provides explicit instruction, and experiences, in the domains of key cognitive strategies, and key content knowledge, whereas the AVID program provides explicit instruction, support and experience in the domains of key learning skills and techniques and key transitional knowledge. Overall, three categories of increased transitional confidence emerged: academic confidence, academic behaviors, such as organization and the ability to adapt to a university workload, and navigating university culture.

\section{Think like a College Student - Academic Skills Confidence}

Nick: Definitely the most beneficial part I think is the writing component because in IB we're like always writing and like always turning in these papers, all these like nicely structured papers, from the extended essays to like every single class had like some form of writing component.

Students overwhelmingly felt that they were prepared for college level writing tasks and test, primarily due to the emphasis on writing in the IB classes.

Survey Respondent: Taking more IB classes outside of math may have been more beneficial to adapt to the reading/writing rigor of college GE classes. 
Hailey: I would say IB because it expanded my critical thinking skills and I definitely learned that on a good writer because it has helped me with working in [my internship].

Alex: Definitely the test style was very helpful just getting away from your classes like high school test and giving more (attention) towards like essay writing on demand and just being more prepared and more understanding of what's going to be expected either in college.

With regard to analyzing prompts, $96 \%$ of students indicated that they felt adequately prepared or very prepared with $44 \%$ of students identifying that their preparation occurred equally in both programs. Additionally, $92 \%$ of students indicated that they were adequately or very prepared in terms of synthesizing information. Nearly $50 \%$ of students said their development occurred equally in both programs, while an additional $38 \%$ credited IB as the program where they received the most preparation. Although the survey data supports the notion that both AVID and IB were equally responsible for the increased writing, the interview subjects overwhelmingly credited the IB program for improving their writing ability.

Lisbeth: IB, I think all the writing that we did for sure. IB English, it really helped with my writing skills. As a freshman, I think I was a terrible writer, even my mom said, like even now, she sees how my writing has progressed. Last semester from my Philosophy class, I tuned in a persuasive essay...and when my professor followed up with me about it, he actually said that it's the best essay he's ever gotten... 
Lisbeth's account demonstrates the effect that the focus on writing in the IB has on a student. She had earlier discussed in her interview how she was perceived as a star student in her AVID class, and average in her IB classes. Despite her perception, Lisbeth acknowledges her improvement, her pride highlighted by references to her mother and her professor. Her story personifies the survey data, but also, exemplifies the positive double effect of participation in the IB program, participation supported by her AVID teacher and peers.

\section{Act Like a College Student}

The vast majority of participants, $96 \%$ and $92 \%$ of survey respondents respectively, indicated that that students were aware of their strengths and weaknesses as learners and felt adequately or very prepared to manage any frustrations they might encounter. According to the survey, the preparation in these areas occurred primarily in AVID, or was addressed equally in both the AVID and IB programs. The interview data bolstered the survey data as students attributed their success in transitioning to a college workload to the rigor of IB classes, and the time management strategies that they learned in the AVID program.

Sierra: So for my IB courses, if I hadn't taken those, I think my transition to college wouldn't have been as smooth because I would have just been "face flat" into something new.

Jesus: IB definitely prepared me for college because I can handle big assignments that have very little instruction, things like that. So I think that if I wasn't in IB and I was given a college assignment, like the ones that are given out, I'd probably freak out and be like, "Okay. I don't know what to do." 
Jesus's perspective acknowledges the "double effect" of participation in the IB program extends beyond student self-perception and into academic perseverance, a perspective further supported by two survey respondents and Alex.

Survey Respondent: IB was helpful as well because the classes were extremely difficult to the point where I truly feel that I can take on some college classes here at the [college] I currently attend. The rigorous courses I took in high school prepared me for tough classes.

Survey Respondent: Being in AVID helped me learn how to organize what I should do and IB has taught how to deal with fast pace things. AVID has emphasized the use of planners which has benefited me a lot to this day!

Alex: I mean I could have totally seen myself I mean not like finding out IB classes but like I could have totally seen myself struggling a whole lot more just with time management and getting all my work and stuff. So AVID was hugely helpful with that.

While Alex, indicated that she never felt overwhelmed in the IB program, and self identifies as "not a typical AVID student" in terms of generational and linguistic status, as she was raised in an English-speaking household, and with college educated parents. She articulately illustrates, in the excerpts below, the mutually beneficial relationship that AVID and IB can create to aid students. 


\section{Behind the Scenes Support}

Jesus: But AVID was more behind the scenes things, I think, because it prepared us for like the tools necessary for college. I think it was more how to get involved in the campus, how to engage with other students when it comes to studying and things like that, different study methods.

AVID consisted of, what Jesus aptly described as, "behind the scenes" support, known to the AVID community as WICOR. WICOR forms the five pillars of the AVID elective: writing, inquiry, collaboration, organization, and reading. Multiple respondents and interview subjects echoed Jesus' description of AVID as "behind the scenes" support. For example, one survey respondent stated, "AVID helped me understand what was to be expected in my further studies and how I can alter my techniques to do better and succeed. I still use AVID note taking and studying skills in my college classes and I couldn't have a clearer understanding of them."

Examining the survey data, $92 \%$ of students considered themselves adequately or very prepared in terms of note taking. Of the $68 \%$ percent of students who indicated they were very prepared, $64 \%$ indicated their preparation occurred primarily in AVID.

Table 8: Level of preparedness - note taking strategies

\begin{tabular}{|l|l|l|l|}
\hline Years in AVID & $\begin{array}{l}\text { Very prepared - } \\
\text { Note taking }\end{array}$ & $\begin{array}{l}\text { Adequately prepared - } \\
\text { Note taking }\end{array}$ & $\begin{array}{l}\text { Somewhat prepared - } \\
\text { Note taking }\end{array}$ \\
\hline $2(N=5)$ & $80.00 \%$ & $20.00 \%$ & $0.00 \%$ \\
\hline $3(N=5)$ & $80.00 \%$ & $20.00 \%$ & $0.00 \%$ \\
\hline $4(N=12)$ & $66.67 \%$ & $16.67 \%$ & $16.67 \%$ \\
\hline $5(N=1)$ & $0.00 \%$ & $100.00 \%$ & $0.00 \%$ \\
\hline $6(N=2)$ & $50.00 \%$ & $50.00 \%$ & $0.00 \%$ \\
\hline Grand Total & $68.00 \%$ & $24.00 \%$ & $8.00 \%$ \\
\hline
\end{tabular}


In addition, $92 \%$ of students also identified as adequately or very prepared with regard to organizational strategies. Similarly, to note taking, $60 \%$ of the very prepared cited AVID as the source of preparation.

Table 9: Level of preparedness in organization strategies

\begin{tabular}{|l|l|l|l|}
\hline Years in AVID & $\begin{array}{l}\text { Very prepared } \\
\text { Organization }\end{array}$ & Adequately prepared - Organization & Somewhat prepared - Organization \\
\hline $2(N=5)$ & $80.00 \%$ & $20.00 \%$ & $0.00 \%$ \\
\hline $3(N=5)$ & $40.00 \%$ & $40.00 \%$ & $20.00 \%$ \\
\hline $4(N=12)$ & $66.67 \%$ & $25.00 \%$ & $8.33 \%$ \\
\hline $5(N=1)$ & $0.00 \%$ & $100.00 \%$ & $0.00 \%$ \\
\hline $6(N=2)$ & $50.00 \%$ & $50.00 \%$ & $0.00 \%$ \\
\hline Grand Total & $60.00 \%$ & $32.00 \%$ & $8.00 \%$ \\
\hline
\end{tabular}

Many of the participants credited AVID with their study skills, and ownership over learning. The excerpts indicate that organization and note taking are the most useful instructional components of AVID, apart from the college knowledge and social support.

Nick: I mean the most useful thing that I've so far has used is just like my organization like organizing the way I'm organized here. It's sort of similar to what I did in high school.

Survey Respondent: AVID has helped me learn how to take effective notes. It emphasized the importance of organization, which is extremely important even here in college. I was aware of many things that college would have thanks to AVID. 
Although the findings on the academic components, writing and reading, are mixed, with many respondents saying these were emphasized in both programs, the interview subjects indicated that IB was the primary environment where they learned how to read and write effectively. However, there is a clear pattern that the time management, organizational and notetaking components of the AVID elective are the elements of the AVID experience that students use the most in college.

\section{Navigating College Culture}

Another prominent theme with regard to values of the AVID program support offered by AVID was the idea of learning to socialize, or navigate the etiquette of university, as a college student. Conley"s (2007) key transition knowledge and skills or "Go" domain includes many of the elements described by the participants including navigation of financial aid and college portals and post-secondary culture. The "Go" domain is similar to Yosso's (2005) "navigational" component of community cultural wealth. While the IB appears to have introduced students to the more covert elements of these concepts, such as the different types of colleges, as well as the more overtly beneficial instruction in research writing, and rigorous coursework and exams, the findings indicate that AVID's explicit instruction in postsecondary behavior was a source of confidence for students. Multiple interview subjects spoke of AVID as the locus of their knowledge about resources, and academic behaviors outside the classroom.

Nick: Because of AVID I was able to understand the idea of office hours, the idea of speaking to professors, note taking like all these skills, all this information. Because of AVID I was able to do that... 
Survey Respondent: I find myself more prepared after taking AVID classes 7th grade through 12th than many of my classmates who relied heavily on the IB program for preparation for college

In the following excerpts, Nick and Jesus both discuss the importance of postsecondary behavior, acknowledging that AVID provided access to the "hidden curriculum" or social capital of college transitions.

Jesus: And if I hadn't been in AVID, then I also wouldn't know where to go for resources. And AVID taught me about getting to know my resources so I know where to go now in college. In case I need help, I know where the learning centers are. I know where I can get a seat and things like that.

Nick: Like AVID really taught me and like showed me how to speak to professors, how to write to professors, how to ask them questions that [don't have] answers on the syllabus. But it's just like that socializing with adults. Socializing with professors and...I think that's - what they really helped me with and they helped like craft that just like that socializing aspect.

Although students struggled with the socializing aspect of "fitting into" the IB program, it appears that the combination of the AVID and IB enrollment leads to an understanding of how to "fit into" college. There does not seem to be the same struggle for students at the college level to feel like they belong, and I wonder if that is, in some way, a result from the struggle and conquering of the IB program. 


\section{Summary of Findings:}

The findings demonstrate that often, the underrepresented students at the core of this study felt that they did not belong in the IB program because of their ethnic, linguistic, or socioeconomic status. Students also felt that they did not belong in the program because they could not manage or were unprepared for the workload. Corcoran and Gerry (2010) and May and Perna (2013) longitudinal studies who noted that public schools with IB programs have trouble recruiting and maintaining enrollment of the underrepresented students in IB programs. Neither of those studies contained students' perceptions, but rather focused on the infrastructure and adult perceptions of the sites studied. The experiences of these students could explain the struggles in recruitment and retention found in recent studies, and highlight the importance of creating structures that academically, and socially, support underrepresented students.

However, the findings provide valuable insight into both the struggles of self-perception and confidence that underrepresented students face in advanced courses like IB, but also, the increased levels of confidence and skill they feel they gain by their involvement in the IB program. Additionally, the findings demonstrate how AVID provides social and academic support structures for students. Students, for example, predominantly identified a perceived ethnic barrier to their success in IB, with several students commenting, "IB is white and AVID is Latino." However, students also explained that their decision to take IB classes ultimately resulted in increased academic confidence due in part because of the support, both academically, "behind the scenes", and socially, as AVID provided a peer support in an environment where cultural, linguistic, and aspirational wealth were valued.

Another major finding was that expectations and attitudes of teachers have a great impact on student success, however, the interview and survey data suggests that the expectations of 
fellow students in a particular course can also have a great effect on aspirational wealth and gaining social capital through peer interactions. The "covert college knowledge," namely expectations or visualization of a "college reality" which occurred through peer interactions and supported by AVID's overt instruction demonstrated an overwhelmingly positive effect on students' college application process and decisions.

The impact of dual enrollment in the AVID and IB programs results in increased transitional confidence for the students. Overwhelmingly students identified that participation in the IB program with support from AVID in the form of peer relationships and teacher encouragement transition to the workload of college. In three cases, students indicated that college was easier than the IB program. Students identified their confidence and skills in writing primarily with the IB program, noting that the rigorous reading and writing requirements prepared them for their college workload. At the same time, students also indicated that AVID was primarily responsible for behind the scenes supports in the form of note-taking, organization and time management, as well as overt instruction in the "hidden curriculum" and social capital of college, such as etiquette with professors, and how to engage in academic conversations with peers and adults. 


\section{Chapter 5: Discussion and Conclusions}

The primary purpose of this study was to explore the secondary education and postsecondary transitional experiences of historically underrepresented students who participated in the AVID and IB programs in high school. The goals were to examine what students define as critical elements of each program, and to discern the combined effects of the program on students secondary achievement and transition to postsecondary education. The convergent multi-method design included quantitative survey data and longitudinal data from the AVID and IB organizations. The qualitative data consisted primarily of interview data, and open-ended survey responses. I interviewed seven students, all of whom fit the AVID profile with reference to grades, special circumstances, or underrepresented status. It is a goal of this study to add student voice and experiences to the literature on the AVID and IB programs.

The stories of the seven students provided a wealth of knowledge and perspective as to the student experiences, perceptions, and values associated with the two programs. For example, Sierra grew up below the poverty line, with undocumented parents who spoke only Spanish at home. She entered high school with the goal of becoming the first in her family to attend college, and with none of the social, financial, and academic supports that can be taken for granted by her affluent peers who come from generations of college graduates. Her story is a reflection of the others in this study, who on paper reflect the growing number of historically underrepresented students entering high school with aspirations for college and beyond. My current school site is roughly $70 \%$ Sierra, Jesus, Nick, Hailey, Lisbeth, Alex, and Julio and the voices of the students in this study created humanized portraits of the statistical data on recruitment, retention, and success data that exist within the current literature, but more importantly, they offer hope to those in their same shoes. Although several studies examine the failure of underrepresented 
students, there are too few that address the counter narrative and help to explain how and why underrepresented students succeed (Gonzales, 2013).

At the heart of the opportunity gap is the notion of "educational debt," defined as the sums of the political, social, economic, and educational deficits that have built up in American society (Ladsen-Billings, 2006). For example, historically underrepresented students do not enroll in large numbers in advanced classes, and when they do, they often lack access to the infrastructure and support to succeed. California schools have increased their focus on helping students meet A-G college entrance requirements, and have created open enrollment and other policies to foster student achievement, and a heightened emphasis on college acceptance.

However, being admitted to a post-secondary institution is only the start of the journey. Though high schools may promote postsecondary enrollment, they fail to ensure that students have the skills and knowledge necessary to succeed in a college environment as evidenced by the low rates of graduation, and high rates of remedial coursework (National Center for Public Policy and Higher Education and Southern Regional Education Board, 2010).

\section{Interpretation of Findings}

This study aimed to address the following questions: How do underrepresented students perceive the effects of combined/dual enrollment in the AVID and IB programs on their college readiness and academic and social transitions to college? What do students identify, if any, as valuable aspects of each program in their post-secondary success? How do underrepresented students perceive the impact of the AVID program on student experience in the IB program? This study has filled an important gap in the literature because while there is literature examining the experiences of AVID students and discussing the experience of IB students, there has not been an exploration of how the two programs interact to make a combined effect on student 
achievement, self-perception, and their transition to college. Instead, much of the literature focuses on each program in isolation. The programs often exist in separate spheres, due in part to school faculty and students" perceptions of "who belongs" in each program. As IB programs struggle to recruit and retain students, and to ensure their success, schools have added the AVID program in an attempt to provide support. Alternatively, other schools have had the AVID program on the campus, yet the two programs have had trouble establishing collaborative relationships.

\section{Adjusted Conceptual Framework}

In analyzing the experiences of this group of AVID/IB students who participated in this study, I created a conceptual model grounded in the domains of college readiness (Conley, 2007) and community cultural wealth (Yosso, 2005) that illustrates the goals and transitions of this group in high school and college. Although I initially viewed the theories as overlapping, addressed directly or indirectly in the AVID and IB programs, the stories of the students and the survey data illustrated a series of specific interactions and relationships between and amongst the college readiness domains, community cultural wealth, and which programs. 


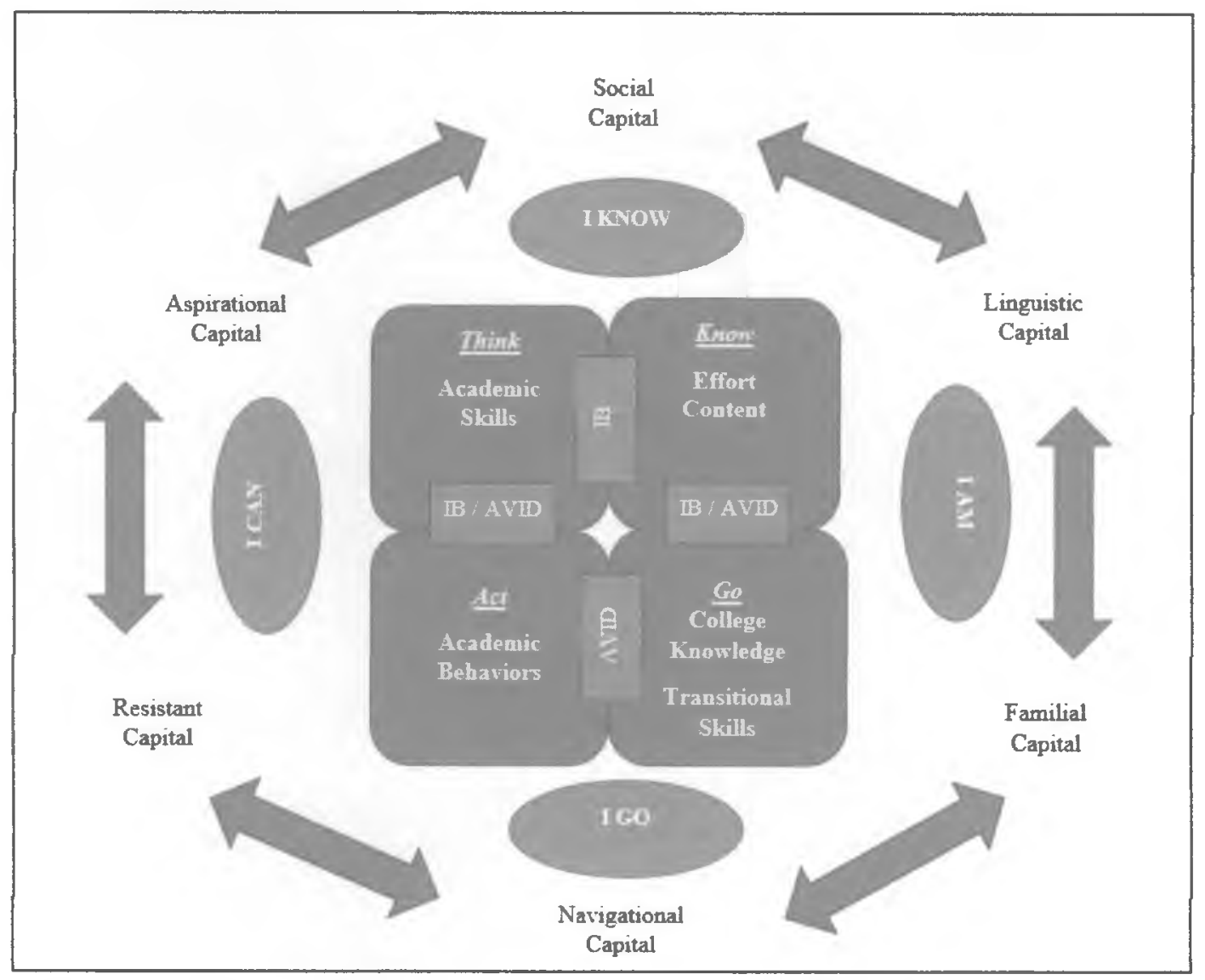

Figure 6: Adjusted Conceptual Framework

Figure 6 illustrates the more specific combination of skills, behaviors, and identity that combine to create a smooth transition from secondary to postsecondary education for historically underrepresented students. At the center of the model are Conley's (2007) domains of college readiness from the original framework and the intersection of each domain with the AVID and IB programs, based on where the elements of that domain were explicitly taught. The placement of the AVID and IB labels was derived from findings where students identified their levels of preparation in each domain, and identified which the program provided them with this preparation. The location of the boxes titled AVID and IB reflect which program students identified as their primary source of preparation. 
Just outside of the domain are the phrases "I can, I know, I am, and I go" which reflect the findings and outcomes of the students' various journeys. While the majority of students initially entered the IB program with a sense of "I can" do this work, stemming from their own resistant and aspirational capital, they struggled with believing in themselves and their abilities (I know) as well as an overall sense of belonging. AVID helped a majority of the students in this study develop a sense of pride and identity with regards to IB. Students identified AVID's strengths as promoting positive peer relationships with other AVID students, teacher inclusion, and family inclusion. These changes in identity and pride represented a shift from "I can" complete the IB tasks and work, to "I am" an IB students, and a similar transition occurred in their university experience. Students overwhelmingly moved through various cycles from "I can accomplish going to college," to fully identifying as a college student. Encircling the domains and students' journeys are elements of community cultural wealth (Yosso, 2005), which were crucial elements of each student's journey. The arrows between each aspect are two directional, and they are organized around the domains based on the findings.

The findings of this study demonstrate that combined enrollment in AVID and IB addresses many of the recommendations discussed in the recent report IB released on the success and persistence of socioeconomically disadvantaged students in IB. Additionally, schools and districts have started formally and informally gathering data on the facilitators and barriers to implementing AVID and IB, as discussed in a set of education blogs and district inquiries regarding IB and AVID schools. Overwhelmingly, the findings indicated that combined enrollment in AVID and IB leads to increased confidence with regard to college choices and transitions, as well as a high degree of college readiness, as defined by Conley (2007). Students identified the IB program as the source for their academic preparation and ability to meet the 
college workload requirements, and AVID as the source of their navigational capital with regard to information about college (applications and financial aid), social capital in terms college culture and socialization, and intangible benefits such as time management, organization, and study skills. Reading, writing, and research were the most valuable elements of the IB program, especially as part of the academic transition to university. Another benefit of the IB identified by students was the notion that the IB courses were dominated by students with familial expectations of going to college and were, in the words of several students, "serious about their education." Students claimed that they learned about colleges they had not heard of, and benefited from the expectation on behalf of the teachers and peers in the class that being in IB meant going to college. The IB program increased and promoted aspirational capital, while AVID supported those aspirations through direct instruction of how to navigate the college process. In terms of AVID, the benefits for students included preparation in elements of "hidden curriculum" such as organization, time management, and study skills, as well as social support.

\section{Implications and Significance}

The opportunity gap, exemplified by lower achievement scores, lower participation in advanced courses, and lower rates of acceptance, retention, and graduation from universities, is a key issue facing California. One group of historically underrepresented students, Latinos, for example, will soon make up the majority of residents in California. Since 1990, the Latino working-age population in California has grown from $7 \%$ to $34 \%$, and is projected to be $50 \%$ of the working population by 2040 (Moore, Offstein, \& Shulock, 2011), yet, only 10\% of Latinos (and African Americans) complete degrees and certificates (Moore, Offstein, \& Shulock, 2011). The barriers to academic success and matriculation are complex and varied; however, there are consistent themes. Tracking policies that result in lowered expectations and poor instruction, 
lack of systemic social and academic supports for underrepresented students in advanced courses, lack of specific and targeted instruction in the college research, application, enrollment, and financial aid processes, and the intangible barriers such as student self-perception, confidence all serve to perpetuate the opportunity gap.

While participation of underrepresented students in the IB program in the US has grown because of the numbers of schools adopting the IB as a reform measure, the IB has only just started to assess the facilitators and barriers to student success. A recent report, released in March 2016, reveals the successes, challenges and recommendations for schools serving large populations of socioeconomically disadvantaged students (Caspary, Woodworth, Keating, \& Sands, 2016). Essentially the report demonstrates that socioeconomically disadvantaged students enrolled in the IB program are accepted and graduate from colleges at a higher rate than their non-IB peers. However, there is a significant achievement, acceptance, and graduation gap between affluent IB students and their socioeconomically disadvantaged peers. Among the recommendation of this study, which was conducted at a small number of schools, are removing placement barriers to the IB program, incorporating inclusive models of teaching and learning, such as rethinking homework and incorporating academic behaviors such as note taking and time management. The report also suggests creating school wide support systems such as high expectations and peer supports, and lastly providing postsecondary college counseling (specifically regarding standardized testing and financial aid), and transitions services (Caspary, Woodworth, Keating, \& Sands, 2016).

\section{Recommendations - Policies and Practices}

The most important question following the findings of this study is what actions and steps should high schools take to address the challenges and gaps, and to build on the strengths 
of each program in order to serve, through both increased preparation and readiness, underrepresented students for college. While AVID incorporates many of the recommendations suggested in the Caspary and Woodward report (2016), the student voices in this study offer specific actions that teachers, coordinators, and school leaders can implement at sites and in districts.

The following recommendations, though student generated, reflect the broader findings of this study and of the literature on IB, AVID, tracking, and pedagogy, as a whole. The following actions aim to: a) increase the recruitment and retention of historically underrepresented students in IB programs; b) increase underrepresented student achievement in the IB program, including the number of students attempting and completing the IB diploma; c) increase the acceptance and retention of historically underrepresented students in higher education. Overall, these recommendations are designed to increase the social, academic, and transitional confidence of underrepresented students graduating from IB schools and entering institutions of higher education. This section will be organized according to the conceptual model, and recommendations will be associated with phases of the student journey: I can, I know, and I am.

I Can: Policies and practices to increase access to AVID and IB. Recommendation 1: Combine AVID 11-12 and Theory of Knowledge.

One potential barrier to student access and success in the IB and AVID programs results from constraint of the master schedule (Tate, 2014).

Jesus: I just wish that maybe there was a little bit more room in my schedule for some fun classes. So, I think because I was committed to advanced dance and 
AVID all four years, that took off my zero and seventh period. And then there's a limit that high school students can take. So I wasn't -- I always wanted to take art and I never did or photography or something like that. There was just never any room for that in my schedule.

Many schools have a six or seven period day, and some even have eight periods. For a student to participate in both IB and AVID, the student essentially needs to take seven courses beginning as a freshman and extending to eight courses if they decide to become an IB Diploma candidate. While students may take more advanced courses knowing that they would have AVID as a support, they are also signing on for a longer school day, which may deter students from participating in both programs, despite the potential financial gain of completing the IB Diploma. As schools seek to increase the number of underrepresented diploma candidates there are two scheduling recommendations to consider.

The first recommendation is to combine the AVID elective with the Theory of Knowledge course in grades 11 and 12. The Theory of Knowledge course is a core component of the IB Diploma with a primary goal of demonstrating the connectivity amongst the IB courses, as well as teaching students essentially epistemology, helping them to understand how knowledge is constructed, used, and the intersections of a variety of disciplines. Additionally, the TOK class is not supposed to be homework heavy, and is supposed to be student centered. The assessments for Theory of Knowledge include an essay and research presentation, both of which correspond to the requirements of the AVID 11-12 course. However, part of what made AVID a safe space was that it was a place to process and work with information from other classes without the stress of major assessments and IB credit. 
Although many of the AVID students in this study found that AVID provided a respite from the overwhelming workload of the IB program, a combination of the two courses would alleviate the need for an $8^{\text {th }}$ period, and would ensure that the students saw a link between their AVID and IB experiences. Along with the academic and scheduling need a combined AVID/TOK would fulfill, it would also ensure that the AVID teacher was knowledgeable in the IB program, and be able to provide additional supports and links between the two programs, an attribute that Alex found valuable in her experience. The combination of TOK and AVID would ensure that AVID students are exposed to Conley's second domain of college readiness, key content knowledge.

\section{Recommendation 2: Detracking $9^{\text {th }}$ and $10^{\text {th }}$ Grade English and History courses.}

Tracking policies, including open enrollment and opt in policies, are detrimental to the development of students' academic self-perception, and removing tracking policies has resulted in greater achievement of underrepresented students. The participants in this study all identified the writing in their English and History courses as sources of increased transitional confidence. Therefore, it is a recommendation to end open enrollment policies for IB prep classes in the $9^{\text {th }}$ and $10^{\text {th }}$ grade in favor of making the entirety $9^{\text {th }}$ and $10^{\text {th }}$ grade English, science, and History classes IB prep courses. There is evidence to support such shift from the Burris (2007) study. Prior to detracking, only $13 \%$ of Black and Latino students were IB diploma candidates. Two years later that number nearly tripled, increasing to $38 \%$ IB diploma candidates, and $70 \%$ of Black and Latino students enrolled in IB English AND IB math (Burris, Welner, Wiley, \& Murphy, 2007). Although the students in the aforementioned study were not necessarily socioeconomically disadvantaged, there is certainly enough evidence to suggest that detracking, 
especially with a tightly integrated AVID program for support, could increase recruitment, retention, and performance of underrepresented students in the IB Diploma program.

The detracking would have five advantages in terms of recruitment and retention of IB. The first advantage to detracking English, History, and science classes and making them all IB prep courses is that it removes the stigma of choice from the student. Under open enrollment, students are required to define their academic personhood as a freshman, a decision that can have a long lasting impact, and making it a difficult decision on the part of the student to leave the "low track" (Yonezawa \& Jones, 2006; Yonezawa, Wells, \& Serna, 2002). Students labeled as low track have difficulty choosing to exit that track through open enrollment, and many students are asked, through open enrollment, to choose their track as a freshman in high school. All students deserve access to an IB preparation, and then when they are juniors or seniors, they can choose to continue with IB courses, pursue the IB diploma, or take non-IB English classes.

The second set of advantages in moving to an IB for all model in $9^{\text {th }}$ and $10^{\text {th }}$ grade courses is that students will be exposed to the types of tasks and rigor associated with the IB program. Because students will have the chance to work on modified versions of IB assessments and writing components, they will be able to make much more informed choices in their junior and senior year about what IB courses they wish to take. Additionally, an IB for all model requires teachers to have high expectations for students, and when combined with scaffolding, allows students to access and gain social capital from their classmates in the $9^{\text {th }}$ and $10^{\text {th }}$ grade rather than waiting until the $11^{\text {th }}$ and $12^{\text {th }}$ grade. The participants in this study demonstrated the value of the college going culture of the IB classroom, and engaging with students who were serious about their learning and studying. 
Perhaps the biggest counterargument to this recommendation would be from stakeholders in the school systems who do not believe that all students can effectively access and participate in a rigorous environment, a philosophical perspective that perpetuates deficit model thinking. Much of this argument stems from teachers' experiences with students who do not understand the "hidden curriculum" of school, such as note taking, organization, critical reading, and agency. However, AVID provides structures and systems that can be used schoolwide to address these issues. AVID has a defined organization system, notes system, and critical reading system that teachers can access through their AVID coordinators, site team members, and elective teachers. In order to implement an IB for all model successfully, it would need to be in conjunction with an AVID for all model, where all teachers incorporated AVID methodologies and systems into their courses. Schools need to consider the IB program as providing the curricular and assessment focus, or the "what" that teachers teach, while AVID provides the "how" by creating academic and social support structures schoolwide, as well as incorporating promising instructional practices that facilitate student engagement and learning.

\section{Know: Easing the IB transition.}

At many schools AVID and IB operate as separate entities (Gira \& Poole, 2013), targeting different populations, thus reinforcing a perception that "AVID students" are separate from "IB students." The first set of recommendations of this study is that school with high populations of underrepresented students is to implement AVID and IB together as tightly woven programs. 


\section{Recommendation 3: Capitalize on teacher relationships.}

Sierra: My AVID teacher worked pretty much hand in hand with my IB teachers checking in and kind of seeing where I needed help or where I was doing good, things like that.

One of the main challenges of students in the AVID and IB programs resulted from a sense of disconnect and separation. Students felt that the IB teachers did not understand their needs, or experiences. The findings of this study support the findings of previous studies that teachers are a crucial component of student success, and that many historically underrepresented students in IB courses attribute their success to a "master adult" who provided support and encouragement emotionally, socially, and academically (Halic, 2013; Kyburg Dickenson, 2007). The students who were most positive about their experiences were also the students who had teachers that overlapped the AVID and IB environments. Alex, Sierra, Hailey, and Jesus all discussed teachers who were able to bridge the "diversity gap" between AVID and IB.

Because of the positive impact teaches have on student experiences, there should be purposeful and increased crossover between teachers in the IB program and AVID teachers. One approach to creating this cross over would be for sites to ensure that they have IB teachers on the AVID site team, and teaching the AVID elective course. Alex expressed the value of this recommendation in the excerpt below.

Alex: My AVID teacher is also my IB History teacher for year one. And, that was at least really helpful in getting through that class... she was also very knowledgeable about the IB program. So it made it fairly easy to just understand what the expectations were and what I needed to be doing to do well in every 
class because she would be meeting with our IB teachers, not only for AVID, but

also as an IB teacher. So, she had a little better understanding of all of that.

Alex asserts that a teacher in both programs can create a greater sense of continuity for students, especially students battling issues of confidence, language, or cultural barriers to success in the IB program.

Having interviewed the AVID and IB coordinators at Alex's school, it is clear that the two coordinators have worked to create a tight integration between the two programs. The IB coordinator conducts IB presentations in the AVID classes, and in the words of the IB coordinator, the question for students is not "Will I take an IB class," but instead, "Which IB classes will I take." Several AVID teachers at the school who teach IB courses and the interconnectedness between the programs may be partially responsible for the positive outcomes found in this study.

\section{Recommendation 4: Cohort Scheduling.}

One major barrier students face in the IB program, and potentially in college, is the struggle to belong, evidenced in this study by the notion that IB was for white affluent students, not for socioeconomically disadvantaged, or students of color. This belief led to students feeling silenced in their courses, and general feelings of alienation. Nick spoke about finding the one other student of color in the room to sit next to, while Hailey discussed how students of color were afraid to speak in the IB classes. However, being surrounded by motivated students who were expected to attend college was also a valuable part of their IB experience.

The second recommendation is to ensure that AVID students are scheduled in IB classes together in small cohorts of at least five to seven AVID students per IB class. 
Jesus: I think that a really good way of doing that is maybe put all the AVID students in the same IB classes so they have the same teachers and they have each other in their classes. I always thought that that was a good one because it really helped us when we built a relationship with our AVID teacher. But if we all also build the same relationship with an IB teacher, it also is beneficial thing...And also being able to see your average peers in your IB classes, it encourages you to try harder because... you don't have to feel scared or you don't have to be intimidated by the other students

The presence of a small cohort of AVID students per IB class sends an affirming message to the AVID students that there are others like them in the program, and that perhaps the programs are not as separate as they seem. Additionally, it means that the students can collaborate more effectively for studying and AVID tutorial by sharing the same teacher and materials.

One potential barrier to cohort scheduling is the size of a school's master schedule, specifically how many offerings they have of each particular course, and the financial constraints that may prevent schools from adding sections of courses. For example, if a school only has one section of IB History of the Americas and only one section of AVID 11, each one essentially becomes its own miniature tracking system. The more sections that are offered of a particular course, the easier it is to complete cohort scheduling. Thus, it is in the best interest of schools sites to promote IB courses and AVID courses in an effort to create more sections and thus reduce the tracking that can emerge from singleton courses. 


\section{Am: Creating community and confidence.}

\section{Recommendation 5: Train teachers to use ethnic studies pedagogy.}

Coordinators and teachers need to make efforts to capitalize on the role of language, culture, aspirational wealth, and resistance capital of the underrepresented students in the IB classes. The missions of IB and AVID both call for educating global citizens, and students from bilingual or bicultural households are coming to those programs with a multitude of experiences that already prepare them for engaging the international community. However, as the findings demonstrated, most students did not perceive that the value of those familial or linguistic strengths existed outside of the Spanish class. As discussed in the literature on IB and demonstrated by the findings in this study, underrepresented students already struggle with confidence in the IB programs, and desire tools to help them manage their experience.

Nick: I would have liked more kind of workshops or tutorials on how to -like going back to the idea of being vocal and speaking up for yourself and speaking up when you know something is wrong, speaking up when you have an idea. I don't know how that could have worked but I think that would have been like something that could have benefited me in my IB classes.

In a recent study examining the experience of Latino and African American students in AP classes, the authors argued that schools should be urged to create a multicultural college going culture, ensuring that students have access to quality teachers who have been trained in, and have implemented ethnic studies pedagogy (Solarzano \& Ornelas, 2004). While the authors were primarily concerned with AP classes, the findings in this study of students' initial experiences in IB indicate that the recommendations are a fit for IB as well. In order to capitalize on the cultural, familial, and linguistic backgrounds of students, it is recommended that sites and 
programs, train teachers in ethnic studies pedagogy in order to help students develop their resistance capital and engage in transformational resistance (Solorzano \& Delgado Bernal, 2001).

Transformational resistance is best described as "proving wrong," and occurs on both internal and external levels. It is a key component of the success of students in this study. On the internal level, it may appear as if a student is conforming to cultural or instructional norms, yet still be motivated by a sense of social justice and critique of the system (Solorzano \& Delgado Bernal, 2001). Such students seek to change the system from the inside out. External resistance, on the other hand, involves "more conspicuous and overt type[s] of behavior" which may not conform to institutional or cultural norms and expectations (Solorzano \& Delgado Bernal, 2001, p. 325). Students in this category might engage in community action and outreach, or even express openly their desire to act against stereotypes. There are examples of transformational resistance throughout this study. Julio for example grew up in a primarily Spanish-speaking household. His parents did not graduate from high school and he had two brothers who dropped out of school. He was initially placed in remedial courses, and took it upon himself to speak to his counselors in order to get enrolled in IB prep courses and AVID. Julio exhibited external resistance by becoming a full IB diploma student but struggled, like Nick, to find the language to express his internal struggle. These sentiments were echoed in various degrees by all of the interview participants and one additional survey respondent. As stated by Sierra, "Teachers (IB) need to understand ...diversity and the students; not everyone comes from the same background"

Ethnic studies pedagogy weaves together the social context, methods, and content taught in the classroom with the goal of helping students interact with their world through the use of deep content knowledge and academic tools (Tintiangco-Cubales, et al., 2014). Additionally, 
teachers who critically analyze their pedagogy and identity, along with a culturally inclusive and empowering curriculum, have higher levels of engagement, as well as higher student outcomes (Tintiangco-Cubales, et al., 2014). Ethnic studies pedagogy has the capacity to empower students to acknowledge their culture language and stories of resistance (Tintiangco-Cubales, et al., 2014)

The AVID program, at its core, seeks to increase the aspirational, social, and navigational capital of historically underrepresented students through explicit instruction in hidden curriculum and increasing access to college knowledge. At the same time, the IB program has the capacity to increase social and linguistic capital. And, if taught using ethnic studies pedagogy, teachers can also bolster resistant capital, which is key to engaging in transformational resistance (Solorzano \& Delgado Bernal, 2001).

\section{Recommendations for further study}

There are many additional topics related to this study that, if explored, could yield a better understanding of the values, relationships, and achievement of students enrolled in IB and AVID. This study was a small sample, focused, primarily, on the experiences of students in the AVID and IB programs. Therefore, the findings have generated several new questions. Among these new potential areas of research are: 1) What are promising practices for AVID and IB public schools with highly integrated programs? How well are various policies and practices meeting the needs of the students and the schools? 2) What impact does the IB Middle Years Program (MYP) have on AVID students who enroll as IB Diploma students? 3) What is the impact of AVID on the performance of historically underrepresented IB diploma students? 4) Does the IB with its focus on internationalism and skills-based curriculum fit with the AVID 
model better than the Advanced Placement (AP) program with its curricular emphasis on content and a wide breadth of knowledge?

\section{Promising practices.}

As schools start to incorporate tighter relationships between the two programs, schools will experiment with scheduling, professional development, teacher practices, and other site based policies and practices. Tate's (2014) blog series is an informal example of the types of studies that would benefit both AVID and the IB. From the blog series, the AVID and IB community has learned about facilitators and barriers to tightly integrated programs, but there is very little research on how those practices are affecting student performance. IB has made recent recommendations for socioeconomically disadvantaged students in the Caspary and Woodworth (2016) report, but the report also creates a series of follow-up questions. For example, one recommendation in the report is to rethink homework, indicating that students at the site studied felt similarly overwhelmed about the IB workload as students in this study. However, what are the existing practices at AVID and IB schools attempting to address this issue, and how have these policies affected performance?

\section{AVID and performance of IB Diploma candidates.}

Because there have been barriers to the recruitment and retention of AVID/IB Diploma candidates, there has not been any research comparing the performance of underrepresented student diploma candidates with those underrepresented diploma candidates enrolled in AVID. One potential study could be to compare underrepresented full IB diploma without AVID with those who opted into AVID. 


\section{AVID/Middle Years Program and the effect on Diploma candidates.}

Another potential study would be the connection and performance of students in the IB diploma who were in AVID and at schools with middle years programs (IB MYP). The IB MYP is another IB program that extends from the $7^{\text {th }}-10^{\text {th }}$ grades, and is designed to promote IB curriculum, assessments, and culture in the pre-diploma years. The schools in this study did not have the IB MYP, and it may be of interest to AVID and IB to see what relationships exist between underrepresented students who are in AVID and MYP and the IB Diploma program as compared to their counter parts without the MYP.

\section{AVID/IB compared to AVID/AP.}

AP is a far more popular program than IB, however, one potential area of study is the experience of IB/AVID students compared to AP/AVID students and the role of AVID as a support. For example, AVID and IB have a heavy focus on skill development whereas AP has a focus on content and breadth of knowledge. AP courses move at a much faster pace than IB, and the IB tends to draw on and emphasize a depth of knowledge. Because underrepresented students struggle with self-perception, social pressure, and the pace and amount of work in advanced courses, a study comparing the performance and experiences of the students in the programs in a variety of school settings may indicate whether one of the combinations of programs is a better fit for underrepresented students.

\section{Reflection on the Research Process}

When I began this process, I believed that these two programs would work in conjunction with one another, especially after interviewing the coordinators, and hearing about the integrated policies and practices that they had implemented at their various schools. I also believed that IB would be a source of skills related to writing, research, and cultural diversity and awareness, 
whereas I thought AVID would include more structural academic supports. While analyzing the data the first time, I was surprised by many of what I identified as limits of the IB program, namely the racialized descriptions of the IB, and the perceived lack of support or value for bilingualism. I had initially hoped to have 30-50 respondents from two schools, and while the data from the survey was more mixed, the interviews were mainly from one site. I was concerned initially that by using two sites, this study could become a comparative study of AVID programs. While I would have liked to have more interviews from the second site, the survey data, which included ten responses from one site, twelve responses from the site with the most interviews, and three responses where the site could not be identified, supported the interview findings.

While the findings in this study demonstrate clear patterns of experience, especially given the convergent nature of the design, the small samples are a limitation. I would like to see this study replicated in schools across California with the same demographics. However, the sites used for this study have demographics similar to my own school in terms of percentages of Latino and socioeconomically disadvantaged students. Thus, the recommendations of this study are relevant to my current school site, and those with similar demographics, but may not be generalizable to high schools with markedly different demographics.

\section{Conclusions}

The IB and AVID programs both contain features that address barriers to student success and have the potential to create meaningful reform if they are operating in cooperation and not in isolation. For many students coming from socioeconomically disadvantaged backgrounds, the IB program can have a huge financial benefit to students who complete the IB Diploma. If a student earns an IB Diploma, meaning, they pass the internal and external exams for seven core courses, 
write a 4000 word extended essay, and fulfill the community service requirements, that student graduates from high school with 30 semester units for the UC / CSU system, essentially allowing them to start college as a sophomore. Not only will the student have already written a 10-15 page research paper, they will have written academic papers, and conducted experiments in every core discipline, and more importantly, the IB diploma saves students a year on tuition, thus increasing their ability to graduate within four to six years.

The findings of this study demonstrate that many of the barriers of college readiness are addressed through enrollment in AVID and IB. AVID constructs strong peer and adult mentor support structures, teaches explicit academic behaviors such as time management, study skills, and socialization, and incorporates targeted instruction to build college knowledge. IB, on the other hand, provides a rigorous education with a heavy focus on accuracy, precision, research, writing, and critical thinking, thus incorporating the necessary academic skills to succeed in higher education. More importantly, AVID played a significant role in the student success in the IB program for most of the students in this study, specifically AVID's emphasis on social acceptance, cultural celebration and support, and academic behaviors. As both IB and AVID continue to expand, the potential symbiotic relationship is demonstrated by the students in this study. The job of educators is to hasten the journey to "I am" and create smooth transitions between AVID and IB and high school and college. Rather than focusing on the opportunity gap, AVID and IB schools can focus on helping the Sierras, Nicks, Julios, and others to level-up and not only make the most of high school, but to enroll, transition and successfully complete their university education. 


\section{References}

American Association of Community Colleges. (2012). Reclaiming the American Dream. Washington DC: 2 lst-Century Commission on Future of Community Colleges.

Anyon, J. (1980). Social class and the hidden curriculum of work. Journal of Educational Research, 162(1), 67-92.

AVID Center. (2014). What is AVID secondary. Retrieved from AVID.org: http://www.avid.org/what-is-avid-secondary.ashx

Bailey, T., \& Mechur Karp, M. (2003). Promoting college access and success. U.S. Department of Education.

Bergeron, L. (2015). Diploma Programme students' enrollment and outcomes at US postsecondary institutions 2008-2014. Universty of Wisconsin, La Crosse, Department of Education, La Crosse, WI.

Bernhardt, P. E. (2013). The Advancement Via Individual Determination (AVID) program: Providing cultural captial and college access to low-income students. School Community Journal, 23(1), 203-222.

Bourdieu, P. (1986). The forms of capital. In Cultural theory: An anthology (pp. 81-93).

Bowles, S., \& Gintis, H. (1976). Schooling in capitalist America educational reform and the contradictions of economic life. New York: Basic Books, Inc.,Publishers.

Burris, C. C., Welner, K. G., Wiley, E. W., \& Murphy, J. (2007, April). A world-class curriculum for all. Educational Leadership, 53-56.

Burris, C. C., Wiley, E., Welner, K., \& Murphy, J. (2008). Accountibility, rigor, and detracking: Achievement effects of embracing a challenging curriculum as a universal good for all students. Teachers College Record, 110(3), 571-608. 
Cammarota, J. (2004). The gendered and racialized pathways of Latina and Latino youth: Different struggles, different resistances in an urban context. Anthropology \& Education Quarterly, 35(1), 53-74.

Caspary, K., Woodworth, K., Keating, K., \& Sands, J. (2016). International baccalaureate national trends for low-income students 2008-2014. Menlo Park: SRI International.

Coca, V., Johnson, D., Kelley-Kemple, T., \& et al. (2013). Working to my potential: The postsecondary experiences of CPS students in the International Baccalaureate Diploma Program. $19(1)$.

Conchas, G. Q. (2001). Structuring failure and success: Understanding the variability in Latino school engagement. Harvard Educational Review, 3, 475-503.

Conley, D. (2007). Redefining college readiness. Eugene, OR: Educational Policy Improvement Center.

Conley, D. T., McGaughy, C. L., \& Kirtner, J. (2010). College readiness practices at 38 high schools and the development of the college career ready school diagnostic tool. American Educational Research Association. Denver.

Conley, D., McGaughy, C., \& Davis-Molin, W. (2014). International Baccalaureate: Examining college readiness. Education Policy Improvement Center.

Corcoran, T. B., \& Gerry, G. B. (2010). Expanding access, participation, and success in International Baccalaureate programs: Year 1 documentation report. Consortium for Policy Research in Education. Teachers College.

Creswell, J. W., \& Plano Clark, V. L. (2011). Designing and conducting mixed methods research. Thousand Oaks: Sage Publications. 
Darling-Hammond, L. (2010). The Flat World and Education: How America's Committment to Equity Will Determine our Future. New York: Teachers College Press.

Duarte, G. (2012 ). International baccalaureate diploma program's impacting high school culture and climate. Ann Arbor: ProQuest.

Espinosa, S. R. (2012). Impact of cultural capital on Advance via Individual Determination students in two southern California high schools. Ann Arbor: ProQuest.

Federal Census Bureau. (2010). Federal Census. Census Bureau.

Finn, P. (1999). Literacy with an attitude: Educating working class children in their own self interest. New York: SUNY.

Geiser, S., \& Atkinson, R. C. (2010). Beyond the Master Plan: The Case for Restructuring Baccalaureate Education in California. Center for Studies in Higher Education, 1-38.

Gira, R., \& Poole, R. (2013, November 22). AVID and IB: Complementary, not competitors. Retrieved from AVID.org: http://avidcollegeready.org/college-careerreadiness/2013/11/22/avid-and-ib-complementary-not-competitors.html

Gonzales, J. (2013). The role of social capital and school structure on Latino academic success. LUX: A Journal of Transdisciplinary Writing and Research from Claremont graduate University.

Halic, O. (2013). Post-secondary educational attainment of IB diploma candidates from US high schools. International Baccalaureate Research.

Huerta, J., Watt, K. M., \& Reyes, P. (2013). An examination of AVID graduates college preparatory and post-secondary progress: Community college versus four year university students. Journal of Hispanic Education, 12(1), 86-101.

IBO. (2014). The IB Diploma Programme. Cardiff: IBO. 
Koch, B., Slate, J., \& Moore, G. W. (2013). Hispanic student performance on Advanced Placement exams: A multiyear comparison. Journal of Education Research, 135-152.

Kohn, A. (2011, April 27). Poor teaching for poor children...in the name of reform. Education Week, 30(29), 32 .

Kouba, R. (2011). Impact of the advancement via individual determination program on students' perceptions of college readiness. University of Houston-Clear Lake.

Kyburg Dickenson, R. (2007). Minority student voices: Advanced Placement and International Baccalaureate students speak out. American Educational Research Association. Chicago.

Ladson-Billings, G. (2006). From the achievement gap to the education debt: Understanding achievement in U.S. schools. Educational Researcher, 35(7), 3-12.

Mattern, K. D., Shaw, E. J., \& Xiong, X. (2009). The relationship between AP exams and college performance outcomes. College Board.

May, H., \& Perna, L. (2011). A longitudinal study of student and school diversity in the Interantional Baccalaureate (IB) program in the US. Annual Meeting of the American Eductional Research Association. New Orleans.

Mayer, A. (2006). Interrupting social reproduction: The implementation of an international baccalaureate program at an urban high school. Ann Arbor: ProQuest.

Mayer, A. (2010). Factors influencing the implementation of an International Baccalaureate program in a diverse urban high school. Journal of Advanced Academics, 22(1), 78-105.

McCready, B. (2014). Leaving the college track? The causes and effects of high school student exit from Advancement via Individual Determination (AVID).

McKinsey and Company. (2009). The Economic Impact of the Achievement Gap in America's Schools. McKinsey and Company. 
Misra, A. (2016, Jan 18). E2: Excellence and Equity. Retrieved from International Baccalaureate Organization: http://blogs.ibo.org/blog/category/programme-related-news-and-topics/e2excellence-and-equity/

Moore, C., Offstein, J., \& Shulock, N. (2011). Consequences of neglect: Performance trends in California higher education. Cal State Sacramento. Sacramento: Institute for Higher Education Leadership Policy.

National Center for Public Policy and Higher Education and Southern Regional Education Board. (2010). Beyond Rhetoric: Improving College Readiness through Coherent State Policy.

O'Conner, R. (2011). Raising all boats? An examination of the claims that the International Baccalaureate is good for all. Iowa: University of Iowa. Retrieved from http://ir.uiowa.edu/etd/1166

Perna, L. W., May, H., Yee, A., \& al., e. (2013). Unequal access to rigorous high school curricula: an exploration of the opportunity to benefit from the International Baccalaureate Diploma Programme (IBDP). Educational Policy.

Solarzano, D. G., \& Ornelas, A. (2004). A critical race analysis of Latina/o and African American Advanced Placement enrollment in public high schools. The High School Journal, 15-26.

Solorzano, D. G., \& Delgado Bernal, D. (2001). Examining transformational resistance through a critical race and Latcrit theory framework:Chicana and Chicano students in an urban context. Urban Education, 308-342.

Steinberg, A., \& Almeida, C. A. (2008). Raising Graduation Rates in an Era of High Standards: Five Commitments for State Action. New York: Carnegie Corporation. 
Swanson, M. C. (1989, February). Advancement via individual determineation: Project AVID. Educational Leadership, 63-64.

Tate, A. (2014, April 25). AVID and IB: Success with a schoolwide approach. Retrieved November 8, 2014, from AVID.org: http://avidcollegeready.org/college-careerreadiness/2014/4/25/avid-and-ib-success-with-a-schoolwide-approach.html

Tintiangco-Cubales, A., Kohli, R., Sacramento, J., Henning, N., Agarwal-Rangnath, R., \& Sleeter, C. (2014). Toward an ethnic studies pedagogy: Implications for K-12 schools from the research. The Urban Review.

Valenzuela, A. (1999). Subtractive schooling: caring relations and social capital in the education of Mexican American youth. In Subtractive Schooling (pp. 81-94).

Walter, C. P., Jane Lo, A., \& Jude Yeo, S. (2013). Beyond Breadth-speed-test: Toward deeper knowing and engagement in an advanced placement course. American Education Research Journal, 50(6), 1424-1459.

Watt, K. M., Johnston, D., Huerta, J., \& al., e. (2008). Retention of first-generation collegegoing seniors in the college prepatory program AVID. American Secondary Education, $37(1), 17-39$.

Welch, E. W. (2010). Integrating AVID with IB at J.E.B. Stuart high school and Glasgow middle school in Fairfax county, Virginia. Access, 16(Spring), pp. 8-9.

Yonezawa, S., \& Jones, M. (2006). Students perspectives on detracking. Theory into Practice, $45(1), 15-23$.

Yonezawa, S., Wells, A. S., \& Serna, I. (2002). Choosing tracks: "Freedom of choice" in detracking schools. American Educational Research Journal, 39(1), 37-67. 
Yosso, T. (2005). Whose culture has capital? A critical race theory discussion of community cultural wealth. Race Ethnicity and Education, 8(1), 69-91. 
Appendices 


\section{Appendix A - Recruitment Email}

Good morning,

I received your information from the AVID coordinator at your high school, and hoped you would be interested in taking a short survey with an option to be interviewed. My name is Holly Royaltey, and I am an AVID Coordinator, AVID teacher, and history teacher as well as a graduate student in the education doctorate program at San Francisco State.

I am conducting a study on how well AVID and IB worked for college readiness and transitions, and I am mostly interested in the student perspective. I have attached the link to the survey, and I want to thank you in advance for your time.

You should open the link below as completing the survey in the email does not always mean the survey will submit.

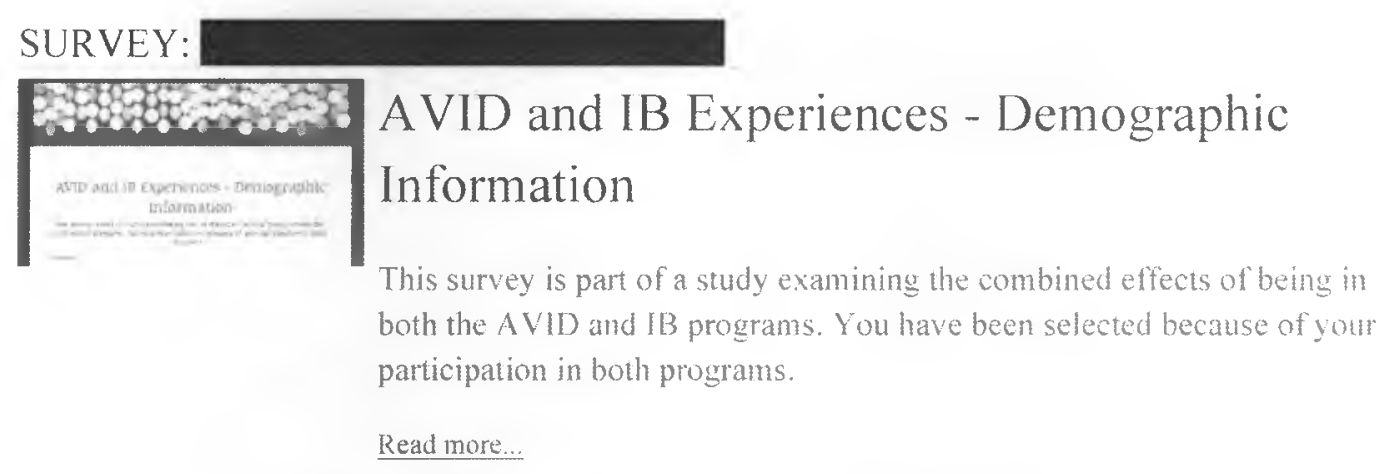

If you have any questions about the survey, please feel free to email me at:

(a) mail.sfsu.edu

Thanks, and please feel free to forward this email and survey to any other A VID students from who graduated between 2011 and 2014 .

$\mathrm{xxx}-\mathrm{xxx}-\mathrm{xxxx}$

AVID Coordinator - High School 


\section{Appendix B - Survey Questionnaire}

\section{AVID and IB Experiences - Demographic Information}

Thank you for your interest and participation in this survey. Please respond to the following questions.

* Required

1. What year did you graduate from high school *

Mark only one oval.

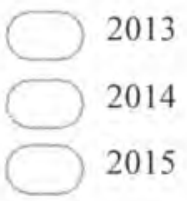

2. Highest level of education of your parents: *

Mark only one oval.

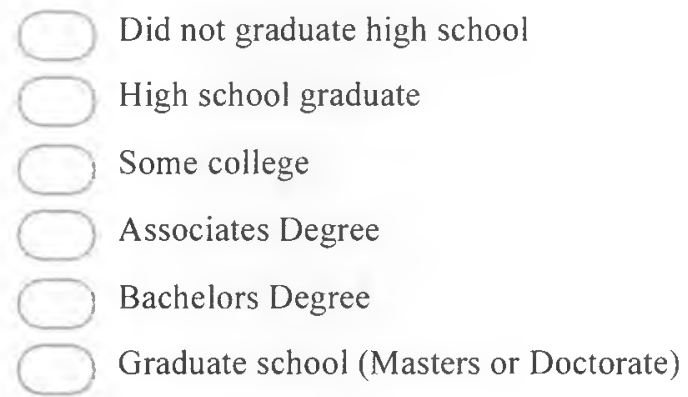

3. Yearly income of family when you were in high school * Mark only one oval.

Less than $\$ 20,000$

$\$ 20,000-\$ 40,000$

$\$ 40,000-\$ 60,000$

$\$ 60,000-\$ 80,000$

More than $\$ 80,000$ 
4. Ethnicity?*

Mark only one oval.

African-American/Black/Afro-Caribbean Heritage

Hispanic/Latino Heritage

Asian-American/Asian Heritage

American-Indian, Pacific Islander Heritage

Middle Eastern Heritage

White/European heritage

Multiethnic Heritage

Decline to state

Other:

5. Gender *

Mark only one oval.

Female

Male

Intersex

Transgendered

Other:

\section{High School and College Information}

The following questions will be about your participation in the AVID and IB programs at your high school, as well as your college choices and progress

6. What was your high school grade point average? *

Mark only one oval.

$2.0-2.49$

2.5-2.99

$3.0-3.49$

$3.5-4.0$

Above a 4.0 
7. Grades you were enrolled in the AVID program in your middle school or high school * Please check all that apply

Check all that apply.

Grade 7

Grade 8

T) Grade 9

- Grade 10

Grade 11

Grade 12

AVID Post-Secondary

8. What type of college do you currently attend? *

Mark only one oval.

California Community College

California State University

Private college

University of California

9. What was your current college grade point average?

Mark only one oval.

Below a 2.0

2.0-2.49

2.5-2.99

$3.0-3.49$

$3.5-4.0$

Above a 4.0

10. How many units have you completed? *

Mark only one oval.

Fewer than 6 units 7

to 12 units

13 to 18 units

18 to 24 units More

than 24 units Other: 
11. What is your intended major? *

Just pick the overall category that best fits your choice

Mark only one oval.

Undeclared

Sciences

Engineering

Visual or performing arts

Humanities - history, political science

Literature or creative writing

Communications

Human Sciences - Sociology, psychology

Other:

\section{Here is the next step - College Academic Skills}

These next few questions relate to your self identified level of preparation in college academic skills, and the role of AVID and IB in your preparation

12. Academic skills (college reading and writing tasks) *

Mark only one oval.

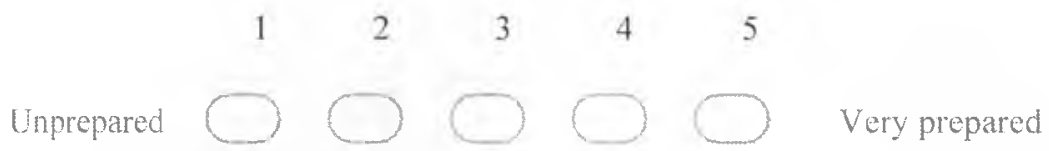

13. Where did you learn and practice these skills * Mark only one oval.

1. My preparation came more from my IB classes

2. My preparation came more from my AVID classes

3. My preparation came from both programs

Other:

14. I know what questions to ask when I need help *

Mark only one oval.

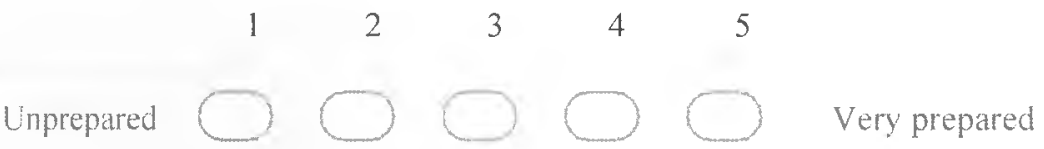


15. Where did you learn and practice these skills * Mark only one oval.

1. My preparation came more from my IB classes

2. My preparation came more from my AVID classes

3. My preparation came from both programs

Other:

16. Are there any comments you would like to add about your academic preparation for college? Is there any thing you would like to add about the role of AVID or IB in your academic preparation?

\section{Learning styles and Techniques}

These questions relate to your self identified level of preparation in different kinds of learning skills and techniques, and the role of AVID and IB in your preparation.

17. Note taking strategies *

Mark only one oval.

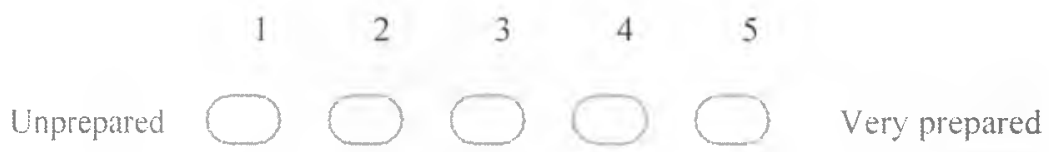

18. Where did you learn and practice these skills * Mark only one oval.

1. My preparation came more from my IB classes

2. My preparation came more from my AVID classes

3. My preparation came from both programs

O Other:

19. Organization Strategies * Mark only one oval.

$\begin{array}{lllll}1 & 2 & 3 & 4 & 5\end{array}$


Unprepared

$\square \square \square$ Very prepared 
20. Where did you learn and practice these skills * Mark only one oval.

1. My preparation came more from my IB classes

2. My preparation came more from my AVID classes

3. My preparation came from both programs

Other:

21. I understand how I learn (my strengths and weaknesses) *

Mark only one oval.

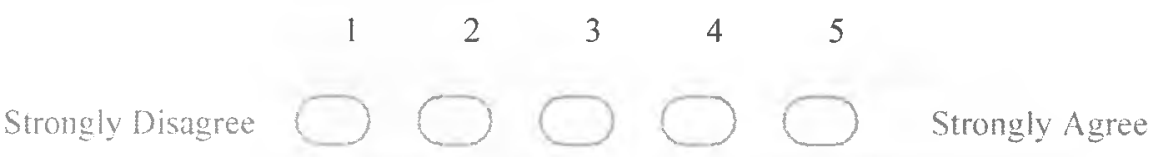

22. Where did you learn and practice these skills *

Mark only one oval.

1. My preparation came more from my IB classes

2. My preparation came more from my AVID classes

3. My preparation came from both programs

Other:

23. I am prepared when I encounter academic frustrations (challenging courses, content, etc) * Mark only one oval.

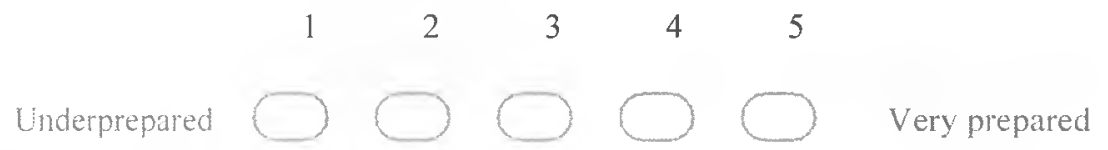

24. Where did you learn and practice these skills *

Mark only one oval.

1. My preparation came more from my IB classes

2. My preparation came more from my AVID classes

3. My preparation came from both programs

Other: 
25. (Optional) Are there any comments you would like to add about your knowledge of learning skills and techniques

Is there any thing you would like to add about the role of AVID or IB in your knowledge of learning styles and techniques?

\section{Key Content Knowledge:}

These questions relate to your self identified level of preparation in the knowledge and skills in the different academic disciplines, as well as the role of AVID and IB in your preparation.

26. Key content knowledge (background and academic content for history, sciences, math, writing, arts, etc) *

This is asking about the actual content you learned in your classes

Mark only one oval.

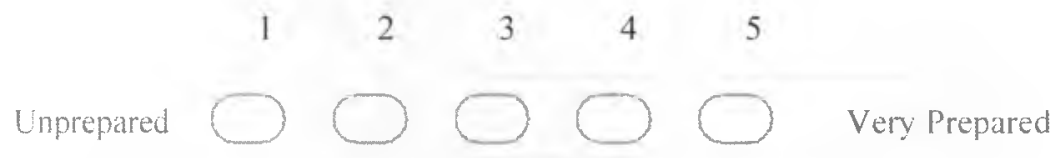

27. Where did you learn and practice these skills *

Mark only one oval.

\section{My preparation came more from my IB classes}

2. My preparation came more from my AVID classes

3. My preparation came from both programs

Other:

28. My cultural and ethnic backgrounds were valued in my high school classes * Mark only one oval.

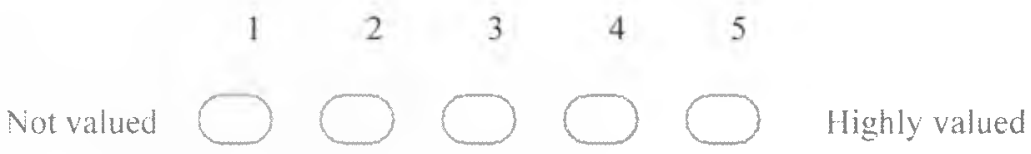

29. Where did this take place? *

Mark only one oval.

1. My ethnic or cultural values were more valued in my IB classes

2. My ethnic or cultural values were more valued my AVID classes

3. My ethnic or cultural values were valued from both programs 
Other: 
30. The experiences of my family were valued in my classes in high school * Mark only one oval.

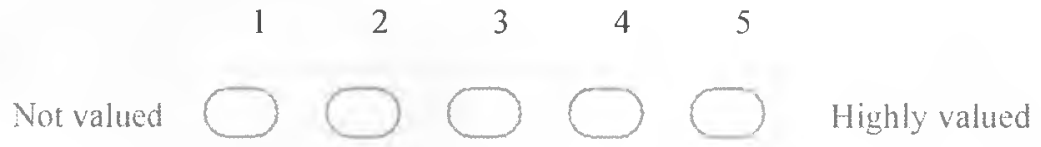

31. Where did this take place? *

Mark only one oval.

1. My families experiences were more valued in my IB classes

2. My families experiences were more valued in my AVID classes

3. My families experiences were valued in both programs

Other:

32. I understand different skills and procedures that are required by different disciplines (Math, Literature, History) *

Mark only one oval.

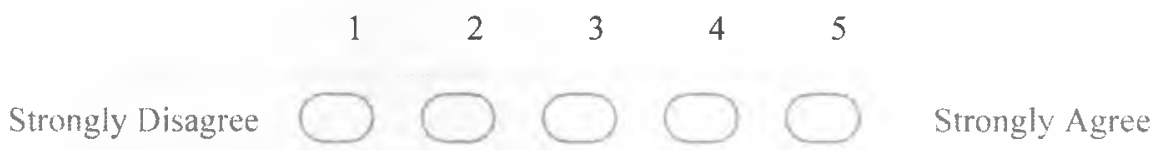

33. Where was this addressed in your high school? *

Mark only one oval.

1. This was addressed more in my IB classes

2. This was addressed more in my AVID classes

3. This was addressed in both programs

Other:

34. (Optional) Are there any comments you would like to add about your knowledge of different academic disciplines

Is there any thing you would like to add about the role of AVID or IB in your understanding of different academic disciplines 
Key Transition Knowledge and Skills:

Almost done - I really appreciate this...your feedback is highly valuable 
35. How prepared were you in college knowledge (navigating college portals, selecting classes) * Mark only one oval.

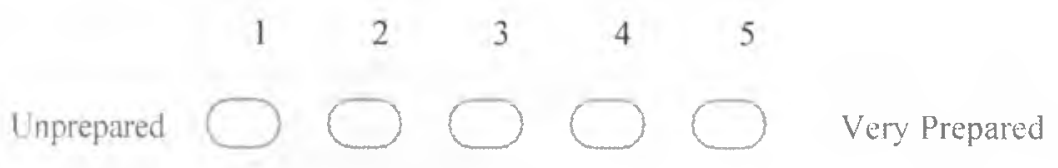

36. Where was this addressed in your high school? *

Mark only one oval.

1. This was addressed more in my IB classes

2. This was addressed more in my AVID classes

3. This was addressed in both programs

Other:

37. My preparation level for financial aid, and navigating the financial aid system. * Mark only one oval.

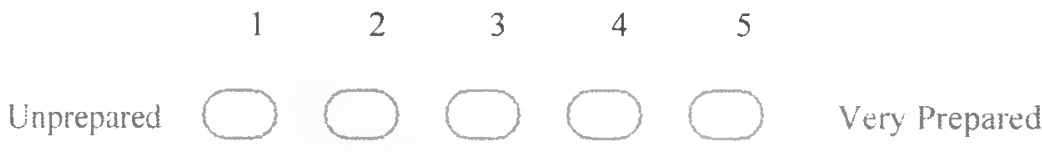

38. Where was this addressed in your high school? * Mark only one oval.

1. This was addressed more in my IB classes

2. This was addressed more in my AVID classes

3. This was addressed in both programs

Other:

39. There was encouragement for students like me to go to university * Mark only one oval.

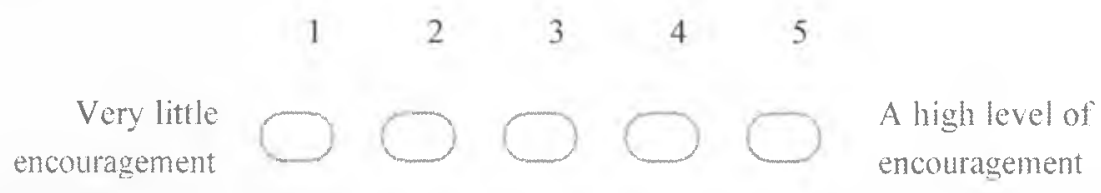

40. Where was this addressed in your high school? * Mark only one oval.

1. This was addressed more in my IB classes

2. This was addressed more in my AVID classes

3. This was addressed in both programs

Other: 
41. There was support for my questions about college *

Mark only one oval.

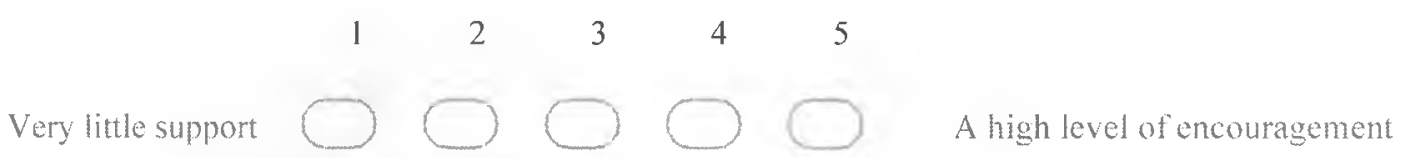

42. Where was this addressed in your high school? *

Mark only one oval.

1. This was addressed more in my IB classes

2. This was addressed more in my AVID classes

3. This was addressed in both programs

Other:

43. (Optional) Are there any comments you would like to add about your encouragement and knowledge about college transitions or support?

Is there any thing you would like to add about the role of AVID or IB in your encouragement and knowledge about college transitions or support

\section{Well done - these are the last questions. Again, I cannot thank you enough}

44. Would you be willing to be interviewed? *

Interviews will be 30-40 minutes with one or two possible phone calls for follow up questions

Mark only one oval.

Yes

No Stop filling out this form.

\section{Thanks for volunteering to be interviewed.}

45. Please provide a permanent email address where you can be reached throughout the summer and fall semester. * 


\section{Appendix C - Interview Protocol}

I. How would you describe the relationship between the AVID and IB programs at your school? Did the programs seem very separate or more connected?

2. Why did you take IB courses? Were you a full diploma student? Why or why not?

3. Going back... Why did you enroll in AVID?

4. Do you consider yourself bi/multi lingual?

5. Was this valued in your AVID or IB experiences? Do you have an example from one or both programs?

6. Did you consider bilingualism a strength, or a weakness, in your AVID or IB classes?

7. If you could have done anything differently in your high school AVID experience, what would it be?

8. If you could have done anything different in your IB experience in high school what would it be?

9. What do you identify as beneficial about IB coursework? Why? In other words, what benefits do you see as a college student?

10. How did AVID or IB emphasize the role of effort?

11. How would you characterize your effort in the AVID / IB programs? Why?

12. Do you consider one program or the other as an influence on your hopes and dreams?

13. Did you feel overwhelmed in one or both programs? How did you address this?

14. What was challenging about being a part of the AVID program in high school? Why?

15. What would you have wanted more of from your AVID program? 
16. What was challenging about being a part of the IB coursework in high school? Why?

17. What would you have wanted more of from your IB courses?

18. How did the IB and/or AVID programs affect your personal confidence?

19. Where did you get information about college?

20. Do you consider yourself a successful IB student? Did AVID play a role in your definition or experience? If so, how?

21. Did the IB or AVID program increase or decrease the importance of your cultural, ethnic, generational, or socioeconomic identity?

22. If you could give one piece of advice to current AVID/IB students, what would it be?

23. How did you learn about college?

24. Has your college experience brought you closer with your family or created distance? Why?

25. How would you characterize the role of AVID in your decision to attend university? What role did IB play in your decision to attend university?

26. What would you say to AVID or IB students who are struggling to believe they can make it college?

27. If you could give one piece of advice to AVID/IB coordinators and teachers, what would it be? 